Aus der Abteilung Virologie

(Prof. Dr. med. F. T. Hufert)

im Zentrum Hygiene und Humangenetik

der Medizinischen Fakultät der Universität Göttingen

\title{
Inhibition des Interferon-Beta-Systems durch Tribec-Virus
}

\author{
INAUGURAL-DISSERTATION \\ zur Erlangung des Doktorgrades \\ der Medizinischen Fakultät der Georg-August-Universität zu Göttingen
}

vorgelegt von

Nora Elena Brandt

aus

Hannover

Göttingen 2012 
Dekan: Prof. Dr. med. M. P. Schön

I. Berichterstatter: Prof. Dr. med. F. T. Hufert

II. Berichterstatter/in:

III. Berichterstatter/in:

Tag der mündlichen Prüfung: 


\section{Inhaltsverzeichnis}

Abkürzungsverzeichnis ................................................................................................... 7

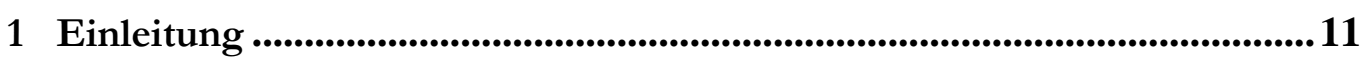

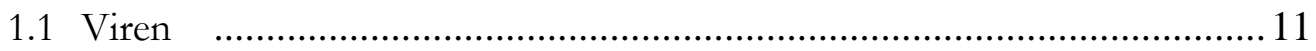

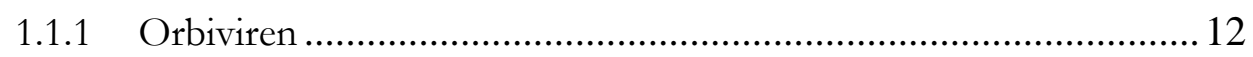

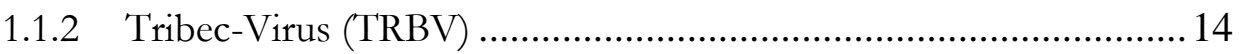

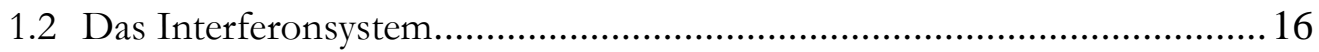

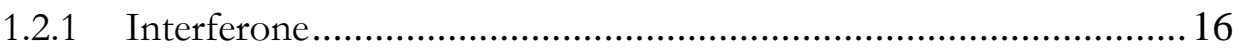

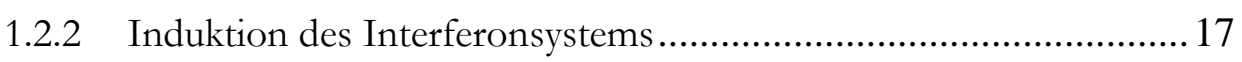

1.2.2.1 Interferon- $\beta$-Gen-Induktion................................................. 18

1.2.3 Wirkungsweise der Interferone ............................................... 20

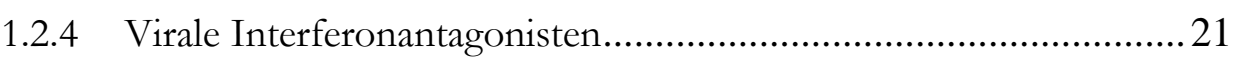

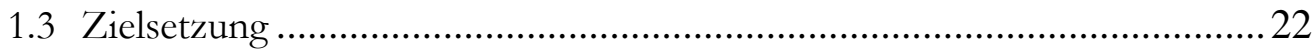

2 Material und Methoden ...............................................................................23

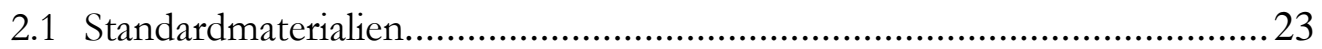

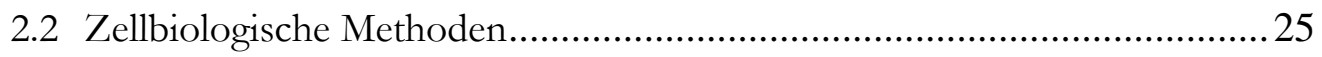

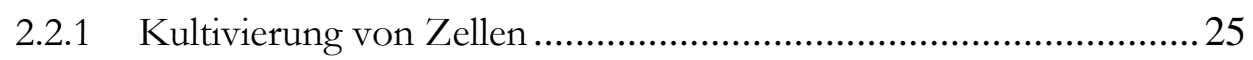

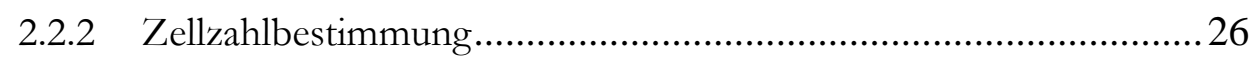

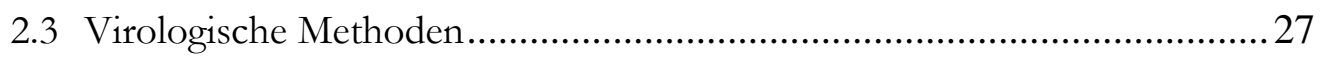

2.3.1 Anzucht von Tribec-Viren (TRBV) ..........................................27

2.3.2 Anzucht von RVFV-Clone-13 ................................................ 28

2.3.3 Bestimmung von Virustitern mittels Kulturinfektionsdosis-Tests

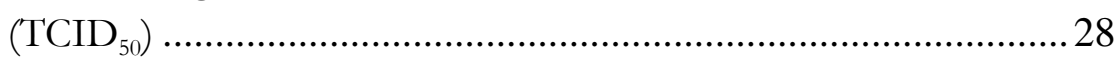

2.3.4 Virusinfektion der Zellen in Gewebekulturflaschen.......................29

2.3.5 Virusinfektion der Zellen in 96-Well-Platten ................................ 31

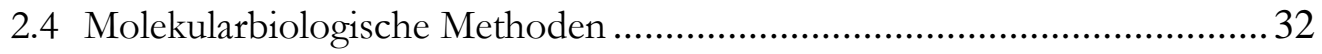

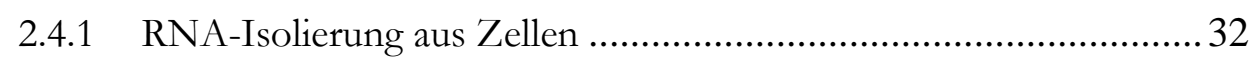

2.4.2 Spektrometrische Konzentrationsbestimmung von RNA..............33

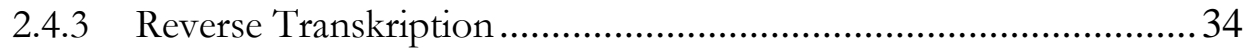

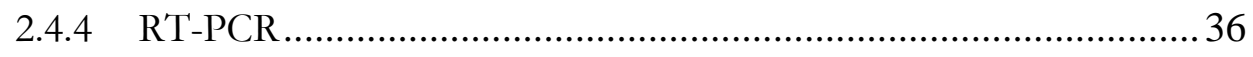

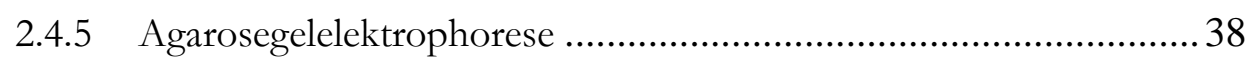

2.4.6 Dual-Luciferase-Reporter-Assay mit HEK-293-Zellen................... 40

2.4.6.1 Messung der IFN- $\beta$-Promotoraktivität nach Infektion mit TRBV bzw. RVFV-Clone-13........................................................... 43 
2.4.6.2 Messung der IFN- $\beta$-Promotoraktivität nach Transfektion von Expressionsplasmiden für virale Gene

2.4.6.3 Messung der Aktivität eines AP-1-responsiven Promotors nach Transfektion von Expressionsplasmiden für virale Gene

2.4.6.4 Messung der Aktivität eines NF-xB-responsiven Promotors nach Transfektion von Expressionsplasmiden für virale Gene .46

2.4.6.5 Messung der Aktivität eines NF- $x$ B-responsiven Promotors nach Transfektion und Stimulation mit TNF- $\alpha$. 46

2.4.6.6 Messung der Aktivität eines IRF-3-responsiven Promotors nach Transfektion von Expressionsplasmiden für virale Gene.....

2.4.6.7 Messung der Aktivität eines IRF-3-responsiven Promotors nach Transfektion und Stimulation mit IRF-3(5D)

2.4.7 Statistik

2.4.8 Impedanzmessung virusinfizierter Zellen mittels xCELLigenceSystem

3 Ergebnisse.

3.1 Viabilitätsbestimmung TRBV-infizierter Zellen mittels

Impedanzmessung .50

3.1.1 Die murinen Zelllinien IFNAR-/- und PKR +/+ ......................50

3.1.2 Humane Nierenzellen HEK-293 ................................................. 55

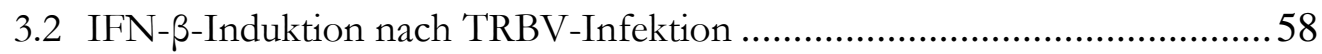

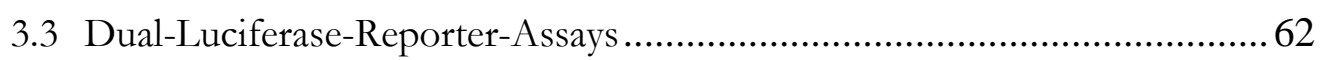

3.3.1 IFN- $\beta$-Promotoraktivität nach Infektion und Stimulation mit RNA VSV-infizierter Vero-E6-Zellen

3.3.2 IFN-ß-Promotoraktivität nach Infektion und Stimulation mit $\operatorname{poly}(\mathrm{I}: \mathrm{C})$......

3.3.3 Einfluss von TRBV-Genprodukten auf die Aktivität des humanen IFN- $\beta$-Promotors

3.3.3.1 Messung der IFN- $\beta$-Promotoraktivität nach Transfektion von Expressionsplasmiden für TRBV-Gene und Stimulation mit RNA VSV-infizierter Vero-E6-Zellen.

3.3.3.2 Messung der IFN- $\beta$-Promotoraktivität nach Transfektion von Expressionsplasmiden für TRBV-Gene und Stimulation mit poly(I:C)

3.3.3.3 Messung der Aktivität eines AP-1-responsiven Promotors nach Transfektion von Expressionsplasmiden für TRBV-Gene und Stimulation mit MEKK 
3.3.3.4 Messung der Aktivität eines NF- $x$ B-responsiven Promotors nach Transfektion von Expressionsplasmiden für TRBV-Gene und Stimulation mit poly(I:C) .75

3.3.3.5 Messung der Aktivität eines NF- $x$ B-responsiven Promotors nach Transfektion von Expressionsplasmiden für TRBV-Gene mit RNA VSV-infizierter Vero-E6-Zellen

3.3.3.6 Messung der Aktivität eines NF- $x$ B-responsiven Promotors nach Transfektion von Expressionsplasmiden für TRBV-Gene und Stimulation mit TNF- $\alpha$

3.3.3.7 Messung der Aktivität eines IRF-3-responsiven Promotors nach Transfektion von Expressionsplasmiden für TRBV-Gene und Stimulation mit RNA VSV-infizierter Vero-E6-Zellen .....

3.3.3.8 Messung der Aktivität eines IRF-3-responsiven Promotors nach Transfektion von Expressionsplasmiden für TRBV-Gene und Stimulation mit poly(I:C)

3.3.3.9 Messung der Aktivität eines IRF-3-responsiven Promotors nach Transfektion von Expressionsplasmiden für TRBV-Gene und Stimulation mit IRF-3(5D)

4 Diskussion

4.1 Interferonkompetente Zellen sind nicht vor einer Infektion durch das TRBV geschützt.

4.2 Das TRBV hemmt die Induktion des Typ-I-Interferons IFN- $\beta$ .92

4.2.1 Der Einfluss von TRBV-Infektionen auf die Aktivierung des IFN- $\beta$ Promotors

4.2.2 Einfluss verschiedener TRBV-Proteine auf die Aktivierung des IFN$\beta$-Promotors

4.2.2.1 TRBV-Segment 9 codiert für ein oder mehrere Proteine, die die IFN- $\beta$-Synthese hemmen 96

4.2.2.2 TRBV-Helikase/ORF-Xa haben keinen Einfluss auf die AP-1abhängige Promotoraktivität

4.2.2.3 TRBV-Helikase/ORF-Xa induzieren eine NF- $x$ B-abhängige Promotoraktivität nach Transfektion verschiedener RNA-Spezies

4.2.2.4 TRBV-Helikase/ORF-Xa hemmen die TNF- $\alpha$-induzierte Aktivierung eines NF- $\varkappa$ B-responsiven Promotors

4.2.2.5 TRBV-Helikase/ORF-Xa hemmen die Aktivierung eines IRF-3responsiven Promotors 102

4.3 Fazit 105 
5 Zusammenfassung ................................................................................................ 106

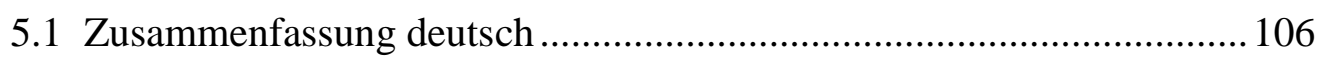

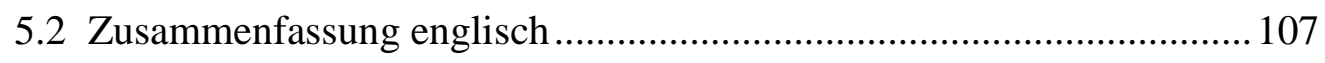

6 Abbildungsverzeichnis ....................................................................................... 108

7 Literaturverzeichnis ............................................................................................ 112 


\section{Abkürzungsverzeichnis}

Es werden die nach dem internationalen Einheitssystem vereinbarten Basiseinheiten verwendet (SI-Einheiten). Geläufige Zeichen und Abkürzungen sind in der Liste nicht aufgeführt.

abs.

Absolut

AK Antikörper

AP-1 Aktivierendes Protein-1 (engl. ,activator protein 1")

$=\mathrm{ATF}-2 / \mathrm{c}-\mathrm{Jun}$ dimer

AS Aminosäure

ATP Adenosin-Triphosphat

bp Basenpaare (engl. „,base pairs“')

BTV Bluetonguevirus

cAMP Zyklisches Adenosinmonophosphat

CARD Kaspase rekrutierende Domäne

CARDIF Mitochondrien-assoziierter Interferon- $\beta$-induzierender Adaptor

CBP CREB bindendes Protein

cDNA Komplementäre (engl. „complementary“) DNA

CPE Zytopathischer Effekt

CREB cAMP-responsives-Element-Bindeprotein

dd $\mathbf{H}_{2} \mathbf{O} \quad$ Ultrafiltriertes deionisiertes Wasser

DEPC Diethylpyrocarbonat

DEPC- $\quad$ Mit DEPC behandeltes und daher RNasefreies Wasser

$\mathrm{H}_{2} \mathrm{O}$

DMEM Dulbecco's modified Eagle-medium

DNA Desoxyribonukleinsäure (engl. „desoxyribonucleic acid“)

Dnase Desoxyribonuklease 
dNTP Desoxynukleotidtriphosphat

ds Doppelstrang (engl. ,double-stranded“)

DTT Dithiothreitol

EDTA Ethylendiamintetraacetat

elF-2a eukaryontischer Initiationsfaktor 2a

FF Firefly (amerikanischer Leuchtkäfer, Photinus pyralis)

FKS Fetales Kälberserum

g Erdbeschleunigung

hCMV Humanes Zytomegalie-Virus

IFN Interferon

IFNAR Interferon- $\alpha / \beta$-Rezeptor

I $x \mathbf{B}$ Inhibitorprotein von NF- $x \mathrm{~B}$

IKK I $\quad$ I B-Kinase

IL Interleukin

IPS-1 IFN- $\beta$-Promotor stimulierendes Protein-1 (CARDIF)

IRF Interferon regulierender Faktor (engl. ,interferon regulatory factor")

ISG Interferon-stimulierbares Gen

ISGF IFN-stimulierender Genfaktor

ISRE (engl. ,interferon-stimulated regulatory element“)

JAK Januskinasen

$\mathbf{K b} \quad$ Kilobasen

KEMV Kemerovo-Viren

Lsg. Lösung

Luc Luciferase

MAVS (engl. ,mitochondriated antiviral signaling protein“) 
MCS (engl. ,multiple cloning side“)

MDA-5 RNA-Helikase (engl. ,melanoma differentiation associated gene 5“)

MEM Minimum Essential Medium

MOI Infektiöse Viruspartikel pro Zelle (engl. „multiplicity of infection“)

mRNA (engl. ,messenger“ RNA)

MW $\quad$ Mittelwert

Mx Orthomyxovirus-Resistenz

NF- $x \mathbf{B}$ Kernfaktor (engl. „nuclear factor") $x \mathrm{~B}$ („kappa-light-chain-enhancer“ of activated B-cells)

NK Natürliche Killerzellen

NS Nichtstruktur-Protein

OAS 26-5'-Oligoadenylatsynthetase

ORF Engl. „open reading frame“

p300 Protein-300, Co-Faktor

PAMPs Pathogenassoziiertes molekulares Muster (engl. „pathogenassociated molecular pattern")

PBS Dulbecco's PBS (Phosphat-gepufferte Salzlösung, engl. „phosphate buffered saline")

PCR Polymerase-Kettenreaktion (engl. „polymerase chain reaction“)

pDC plasmazytoide dendritische Zellen

PKR Proteinkinase R

poly(I:C) Polyinositolcytidinsäure, hier: lw_ (low weight) poly(I:C)

PRDs „positive regulatory domains“

PRR pattern recognition receptor

REN Renilla reniformis

RIG-I RNA-Helikase (engl. „,retinoic acid inducible gene I“)

RNA Ribonukleinsäure (engl. ,ribonucleic acid“) 


\begin{tabular}{|c|c|}
\hline RNase & Ribonuklease \\
\hline rpm & Umdrehungen pro Minute (engl. „,rounds per minute“) \\
\hline RT & Raumtemperatur \\
\hline RT & Reverse Transkriptase \\
\hline RVFV & Rift-Valley-Fever-Virus \\
\hline ss & Einzelstrang (engl. „,single-stranded“) \\
\hline STAT & $\begin{array}{l}\text { Signal-Transduktoren und Aktivatoren der Transduktion (engl ,signal } \\
\text { transducer and activator of transcription“) }\end{array}$ \\
\hline TAK & (engl. ,TGF- $\beta$-activated kinase“) \\
\hline TANK & Aktivator des nukleären Faktors aus der TRAF-Familie \\
\hline Taq & „Thermus aquaticus“ \\
\hline TBE & Tick-Borne-Enzephalitis-Virus \\
\hline TBK-1 & TANK-bindende Kinase-1 (engl. „TANK-binding Kinase 1“) \\
\hline TBP & „tatabox binding protein“ \\
\hline TCID $_{50}$ & Kulturinfektionsdosis 50\% (engl. „tissue culture infectious dose“) \\
\hline TGF- $\beta$ & Engl. „Transforming Growth Factor- $\beta^{\prime \prime}$ \\
\hline TLRs & Toll-like Rezeptoren \\
\hline TNF & Tumornekrosefaktor \\
\hline TRAF & TNF-Rezeptor-assoziierter Faktor \\
\hline TRBV & Tribec-Virus \\
\hline Tyk-2 & Tyrosinkinase-2 \\
\hline $\mathbf{U}$ & Einheit (engl. „unit“") \\
\hline VISA & Virusinduzierter signaling Adaptor (CARDIF) \\
\hline VP & Virales Protein \\
\hline VSV & Virus „Vesicular stomatitis virus“ \\
\hline wt & Wildtyp \\
\hline
\end{tabular}




\subsection{Viren}

Als Viren (lat.: „virus“, Gift, Saft, Schleim) werden parasitäre Krankheitserreger bezeichnet, welche aufgrund eines fehlenden eigenen Stoffwechsels biologisch nicht zu den Lebewesen gerechnet werden. Es handelt sich um inerte Gebilde, die im Wesentlichen aus der die Erbinformation enthaltenden Nukleinsäure, einigen Proteinen und wenigen weiteren Bestandteilen bestehen. Da Viren keinen eigenen Stoffwechsel besitzen, sind sie obligat intrazellulär und bei ihrer Vermehrung auf die Wirtszelle angewiesen. Außerhalb der Wirtszelle werden die in der Regel infektiösen Viruspartikel Virionen genannt. Aufgrund ihrer geringen Größe (die meisten Viren sind kleiner als 0,1 Mikrometer) sind Viren ultrafiltrierbar (die Poren der Bakterienfilter haben einen Durchmesser von etwa 0,2 Mikrometer) und konnten so lange Zeit nicht nachgewiesen werden, weshalb sie als ein in lebenden Zellen vermehrungsfähiges „Gift“ bezeichnet wurden. Auch die Anzüchtung auf künstlichen Nährböden, wie sie für Bakterien verwendet wurden, war mit Virusagenzien nicht möglich. Die Virusanzucht in Tierversuchen war zeitaufwändig und schwierig. Erst 1928 führten H.B. und M.C. Maitland die Methode der Gewebekultur ein. Zunächst wurde die erfolgreiche Virusreplikation im Tierversuch oder durch das Vorhandensein von Einschlusskörperchen in den infizierten Zellen nachgewiesen. Im Jahr 1949 entdeckten John F. Enders, T. H. Weller und F.C: Robbins bei der Erforschung des Poliovirus den Zytopathischen Effekt (CPE). Es handelt sich hierbei um leicht erkennbare Zellveränderungen in mit dem Virus infizierten embryonalen humanen Nierenzellen (Modrow et al. 2003).

Die Einteilung der Viren in Familien erfolgt aufgrund des Aufbaus des Virusgenoms aus RNA oder DNA, der Orientierung des Genoms (Positiv- oder Negativstrangorientierung), der eventuellen Segmentierung des Genoms und der Anordnung der Gene im Genom. Weiter werden die Capsidform sowie das Vorhandensein oder nicht Vorhandensein einer Membranhülle berücksichtigt. Die weitere Unterteilung in Genera (Unterfamilien) und Typen erfolgt überwiegend nach 
serologischen Kriterien und der Ähnlichkeit der Viren in ihrer Genomsequenz (Modrow et al. 2003).

Die Infektion der Zelle durch ein Virus beginnt mit der Adsorption, der Anheftung des infektiösen Partikels an die äußere Zellmembran. Die Viren besitzen dafür spezielle Strukturen an ihrer Oberfläche, mit denen sie mehr oder weniger spezifisch an ihre Wirtszelle binden können. Als Penetration bezeichnet man die Aufnahme des Virus in die Zelle entweder durch rezeptorvermittelte Endozytose oder durch Fusion der Virenhülle mit der Zellmembran (nur bei behüllten Viren). Das Freisetzen des Virusgenoms und dessen Transport an den Ort seiner Replikation nennt man Uncoating, bei der Replikation wird das Genom durch Strukturen der Wirtszelle abgelesen und vermehrt. Hierfür müssen die Viren teilweise spezifische Proteine mit in die Zelle einbringen, wie z.B. die RNA-abhängige RNA-Polymerase, welche Negativstrang-RNA-Genomfragmente in translatierbare mRNA-Moleküle umschreibt. Während der Virusmorphogenese werden die durch die Wirtszelle neu synthetisierten Virusbestandteile zusammengesetzt. Anschließend erfolgt durch Budding (Exozytose), Zelllyse oder Apoptose die Freisetæung der infektiösen neuen Viruspartikel (Modrow et al. 2003).

\subsubsection{Orbiviren}

Die Orbiviren (lat. „orbis“, Ring, Kreis) gehören zur Familie der Reoviridae (,,respiratory enteric orphan virus“) und erscheinen im Elektronenmikroskop mit ringförmigen Capsomeren um den inneren Kern. Der Genus Orbivirus umfasst 22 Spezies mit insgesamt 160 verschiedenen Serotypen (Dilcher et al. 2010; Dilcher et al. 2012).

Die Reoviren besitzen neben den Birnaviren als einzige Viren ein segmentiertes, doppelsträngiges RNA- (dsRNA-) Genom (Modrow et al. 2003). Das Genom der Orbiviren besteht aus zehn unterschiedlich großen dsRNA-Segmenten. Orbiviren besitzen sieben Strukturproteine, jedoch keine Lipidhülle (Roy 1996). Der am besten untersuchte Vertreter der Orbiviren ist das Bluetonguevirus (BTV). Die sieben Strukturproteine (VP1-VP7) dieses Virus sind in zwei Schichten organisiert. Die äußere Hülle besteht aus den zwei großen Proteinen VP2 und VP5, der innere Kern 
aus den fünf anderen Proteinen sowie dem dsRNA-Genom (Roy 1996). In einigen Publikationen wird auch von einem intermediären Capsid aus VP7 und VP3 gesprochen (s. Abbildung 1).

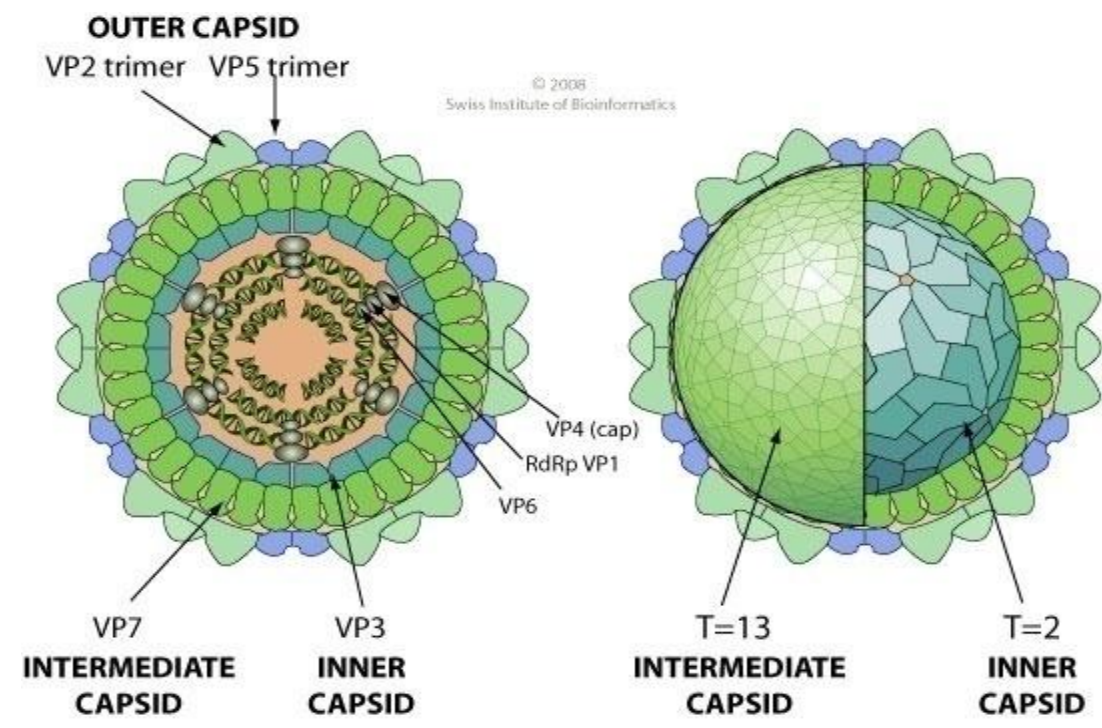

Abbildung 1: BTV als Vertreter der Orbiviren (Swiss Institute of Bioinformatics 2011).

Die Viruspartikel können aufgrund ihrer hohen Stabilität längere Zeit in Gewässern ihrer Umwelt außerhalb des Wirtsorganismus überdauern (Modrow et al. 2003).

Die Genomsegmente werden ihrer Länge nach angeordnet und benannt. Neben den sieben Strukturproteinen kodieren sie für vier Nicht-Strukturproteine (NS) 1-3 und NS3a (s. Abbildung 2).

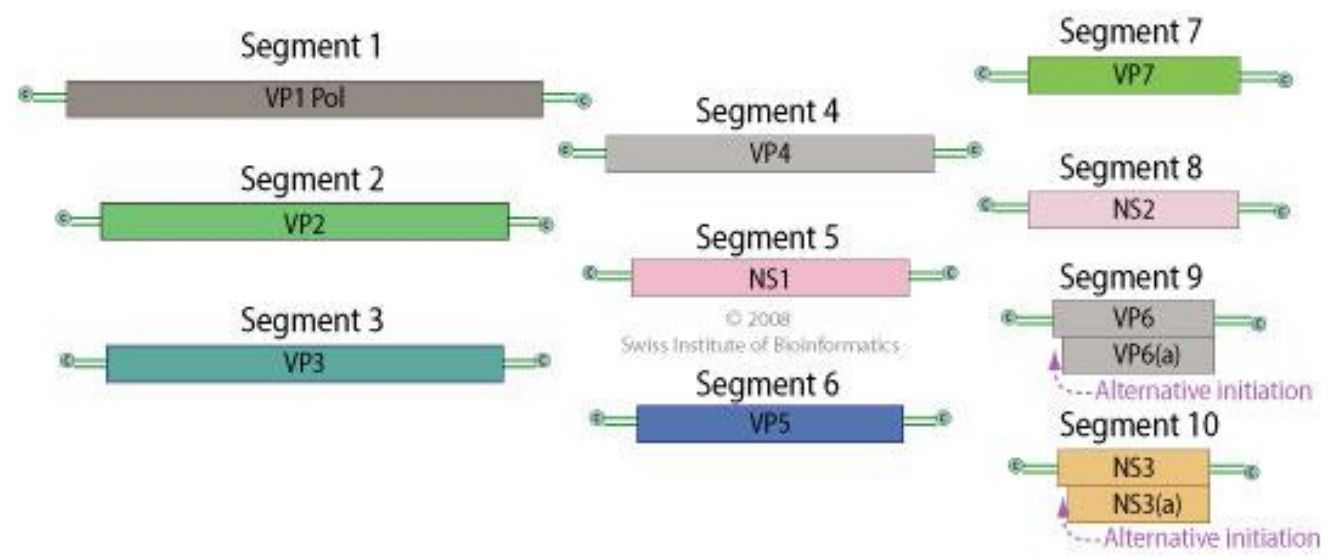

Abbildung 2: Genom der Orbiviren (hier BTV) (Swiss Institute of Bioinformatics 2011). 
Zu der Synthese von NS3 und NS3a kommt es durch einen alternativen Leserahmen auf Segment 10. Beide Proteine sind glykosyliert und spielen eine Rolle bei der Freisetzung der Viruspartikel aus der Wirtszelle (Dilcher et al. 2012).

\subsubsection{Tribec-Virus (TRBV)}

Das Tribec-Virus (TRBV) gehört zum Genus der Orbiviren und wird zur Gruppe der Kemerovo-Viren (KEMV) gerechnet (Libikova et al. 1964; Gresikova et al. 1965). Es handelt sich um ein Arbovirus, welches erstmalig 1963 in der Region Tribec, Slowakei, aus Zecken (Ixodes ricinus, gemeiner Holzbock) isoliert wurde (Gresikova et al. 1965). Wie bei allen Orbiviren besteht das Genom der Tribec-Viren aus zehn unterschiedlich großen dsRNA-Segmenten, welche für sieben Strukturproteine und vier NS-Proteine kodieren. Im Vergleich zu BTV sind einige virale Gene auf anderen Segmenten codiert (s. Abbildung 3).

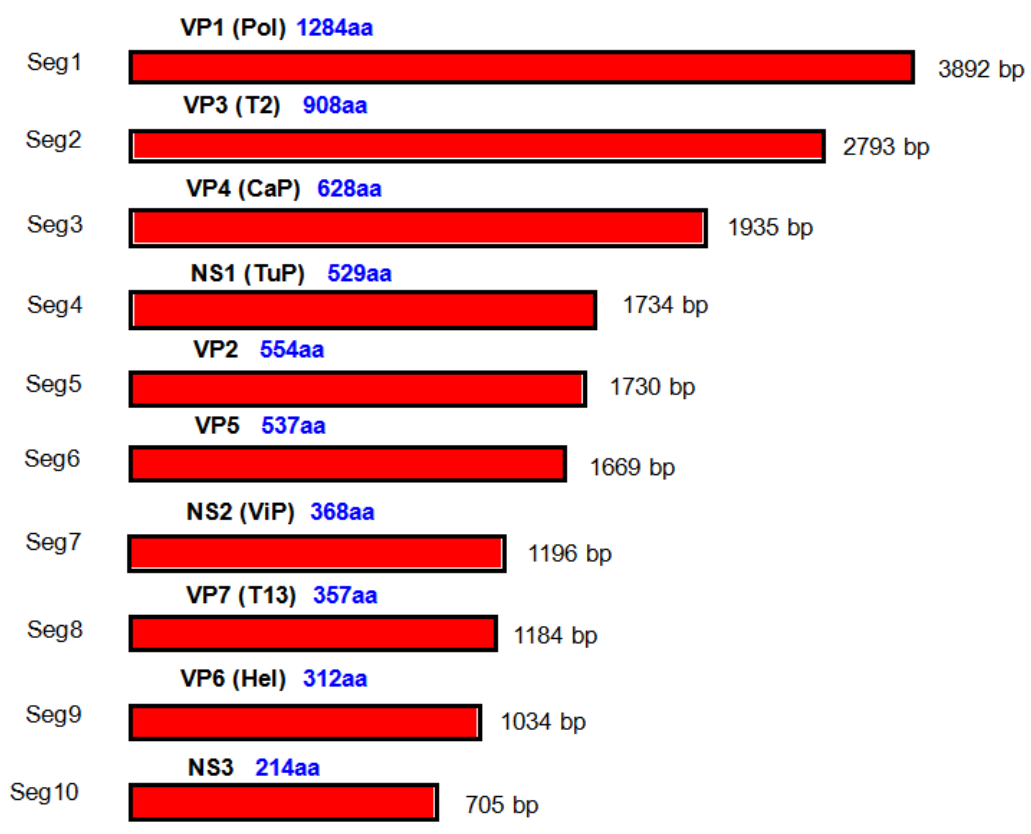

Abbildung 3: Genomsegmente des TRBV (Dilcher et al. 2010).

Auf dem Segment 9 des Tribec-Virus befinden sich drei ORFs („overlapping open reading frame“, ORF-Xa, -Xb, -Xc) im Leserahmen der VP6(Hel) Sequenz (Dilcher et al. 2012).

Bei Untersuchungen in der Slowakei wurden 1963 neun Viruslinien in Zecken und 
zwei Viruslinien in kleinen Säugetieren nachgewiesen, die nicht zum Tick-BorneEnzephalitis (TBE)-Serokomplex gehörten und deren serologische Eigenschaften eine Ähnlichkeit zum Kemerovo-Virus aufwiesen (Libikova et al. 1964; Gresikova et al. 1965). In Ziegen, die in der Region Tribec geweidet hatten, konnten 1965 Antikörper gegen das TRBV nachgewiesen werden (Ernek et al. 1966). Auch bei der Untersuchung menschlicher Serumproben in Kostolany, Slowakei, konnten in 3\% der Proben Antikörper gegen das Tribec-Virus nachgewiesen werden (Gresikova et al. 1965). Das Virus zeigt zwei Tage nach Infektion von embryonalen Hühnerzellkulturen einen zytopathischen Effekt, in neugeborenen Mäusen verläuft die Infektion nach vier bis sechs Tagen tödlich (Gresikova et al. 1965). Bei experimentellen Infektionen von Labormäusen und Rhesusaffen mit dem Tribec-Virus wurden Meningitiden und Enzephalitiden erzeugt, eine Virusvermehrung im Organismus konnte gezeigt werden (Gresikova et al. 1966). Bisher konnte das Tribec-Virus in Tschechien, Weißrussland, der Ukraine, Moldawien, Russland (Wolga), Rumänien, Italien und Deutschland nachgewiesen werden (Dobler 1996; Suss und Schrader 2004; Dobler et al. 2006). Das Virus wird durch Zecken (Ixodes ricinus, gemeiner Holzbock und Haemaphysalis punctata, Rote Schafzecke) übertragen. Als Reservoir gelten die Rötelmaus (Myodesglareolus) und die Kleinwühlmaus (Pitymys subterraneus) (Gresikova et al. 1965), zudem wurde das TRBV in Feldhasen (Lepus europaeus) nachgewiesen (Dobler et al. 2006). Möglicherweise verursacht das TRBV beim Menschen eine unspezifische, fieberhafte Erkrankung mit neurologischen Symptomen und spielt bei der Entstehung aseptischer Meningitiden, Meningoenzephalitiden und Enzephalitiden eine Rolle (Gresikova et al. 1966; Suss und Schrader 2004). Daher hat das Bundesamt für Verbraucherschutz und Lebensmittelsicherheit das TRBV als Spender- und Empfängerorganismus für gentechnische Arbeiten in die Risikogruppe 2 eingeordnet (Bundesamt für Verbraucherschutz und Lebensmittelsicherheit 2009). 


\subsection{Das Interferonsystem}

Das Interferonsystem wird als primäre Immunantwort bei Virusinfektionen aktiviert und zum angeborenen, unspezifischen Immunsystem gerechnet (Kayser et al. 2005). Das Interferon wurde 1957 von Alick Isaacs und Jean Lindenmann als ein neues Protein entdeckt, als sie mit Experimenten an bebrüteten Hühnereiern ein als Interferenz bezeichnetes Phänomen untersuchten. Nach Behandlung mit hitzeinaktiviertem Virus zeigte der Organismus Immunität gegen den Wildtyp-Virus. Alick Isaacs und Jean Lindenmann erkannten den Zusammenhang mit dem neuen Protein und benannten es nach dem untersuchten Phänomen „Interferon“ (Isaacs und Lindenmann 1957).

Auch im nicht infizierten Zustand gibt es eine physiologische Basiskonzentration des Interferons im Organismus (Taniguchi und Takaoka 2001). Diese ist unter anderem Voraussetzung für die schnelle Induktion der Interferon-Gene nach Infektion sowie auch für die Aktivierung der dendritischen Zellen als Teil des spezifischen Immunsystems (Zietara et al. 2009). In virusinfizierten Zellen wird eine Signalkaskade in Gang gesetzt, welche in der Synthese von Typ-I-Interferon mündet und benachbarte Zellen aktiviert. Daraufhin werden diese durch Expression vieler durch Interferon stimulierbarer Gene (ISGs) in einen sogenannten antiviralen Status versetzt und die Ausbreitung der Viren auf diese Weise begrenzt. Um diese erste Abwehr zu umgehen, haben Viren wirkungsvolle Gegenstrategien entwickelt, wie die Unterdrückung der Interferonsynthese, die Ausschaltung des IFN-Signalweges oder die Blockierung von antiviralen Effektorproteinen (Weber et al. 2004; Randall und Goodbourn 2008).

\subsubsection{Interferone}

Als Interferone (IFNs, engl. „to interfere“: eingreifen) wird eine Gruppe von Proteinen bezeichnet, welche als Zytokine vor allem von Leukozyten, Monozyten und Fibroblasten sezerniert werden und immunstimulierende, antivirale sowie antitumorale Wirkungen entfalten. Die Einteilung erfolgt nach der Aminosäuresequenz, der Induktionsart und der biologischen Aktivität in drei Klassen (Weber et al. 2004). Als Typ-I-Interferon (zuerst entdeckt von Isaacs und Lindenmann 1957) werden 13 
IFN- $\alpha$-Subtypen und IFN- $\beta$, sowie weniger gut untersuchte Subtypen wie IFN- $\omega,-\varepsilon$, $-\tau,-\delta$ und $-\varkappa$ zusammengefasst. Die IFN- $\alpha$-Subtypen und das IFN- $\beta$ sind direkt in die Immunantwort bei Virusinfektionen involviert, wobei in der vorliegenden Arbeit das IFN- $\beta$, auch als „Fibroblasten-Interferon“ bezeichnet, näher untersucht wurde. Das Typ-II-Interferon wird auch als „Immun-Interferon“ bezeichnet und ist identisch mit IFN- $\gamma$. Es wird von aktivierten T-Zellen und Natürlichen Killerzellen (NK-Zellen) gebildet (Kayser et al. 2005). In die Gruppe der Typ-III-Interferone werden IFN- $\lambda 1$, $-\lambda 2$, und $-\lambda 3$ gerechnet, auch bezeichnet als Interleukin (IL)-29, IL-28A und IL-28B (Uze und Monneron 2007).

\subsubsection{Induktion des Interferonsystems}

Obwohl von allen Zellen des Körpers Typ-I-Interferone gebildet werden, unterscheiden sich die einzelnen Zelltypen in dem Ausmaß ihrer Produktion einzelner Interferonsubtypen (Weber et al. 2004). So wird in plasmazytoiden dendritischen Zellen (pDC) vor allem Interferon- $\alpha$ gebildet, in Fibroblasten und vielen anderen Zelltypen initial Interferon- $\beta$ und erst in der Folge Interferon- $\alpha$ (Weber et al. 2004; Kayser et al. 2005). Eine Infektion der Zelle durch Viren oder andere mikrobielle Erreger kann durch besondere intra- und extrazelluläre Rezeptoren (pattern recognition receptors, PRRs) erkannt werden. $\mathrm{Zu}$ den verschiedenen detektierten Strukturen, sogenannten pathogen associated molecular patterns (PAMPs) zählen vor allem Zwischenprodukte des viralen Replikationszyklus wie Doppelstrang-RNA (dsRNA), Einzelstrang (single-stranded)-RNA (ssRNA) und 5'-Triphosphat-RNA. Auch synthetische Substanzen wie Polyinositolcytidinsäure (poly(I:C)) haben sich als effiziente Interferon-Induktoren erwiesen (De Clercq 2006). Die unterschiedlichen induzierenden Substanzen führen je nach Zelllinie, Infektionsstatus und anderen Faktoren über verschiedene Signalwege zur InterferonProduktion (Randall und Goodbourn 2008). 


\subsubsection{Interferon- $\beta$-Gen-Induktion}

Am besten erforscht ist die Induktion der Interferon- $\beta$-Gen-Expression (Schema s. Abbildung 4):

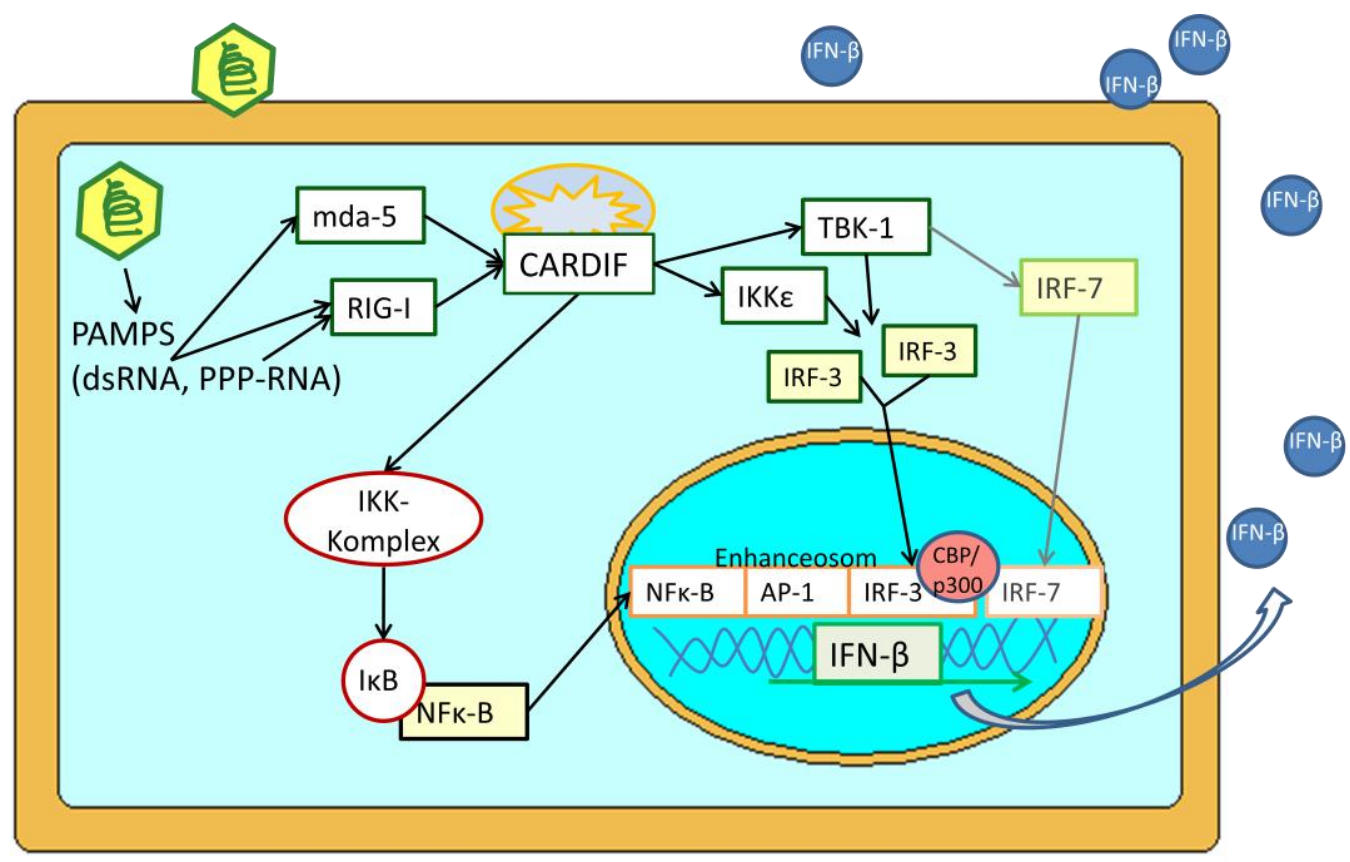

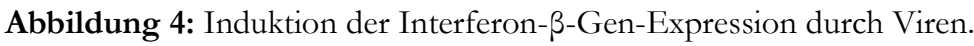

Die zytoplasmatischen RNA-Helikasen RIG-I (engl. ,,retinoic acid inducible gene $\mathbf{I}^{\text {“) }}$ und MDA-5 (engl. „melanoma differentiation associated gene 5“) werden durch bestimmte Virusstrukturen (PAMPs) wie 5'-Triphosphat-RNA und dsRNA aktiviert. Mit ihrer N-terminalen sogenannten Caspase rekrutierenden Domäne (CARD) (Hiscott 2007) binden sie an den Mitochondrien-assoziierten Interferon- $\beta$ induzierenden Adaptor CARDIF (auch virusinduzierter signaling Adaptor VISA oder Mitochondrien-assoziiertes antivirales Signal-Protein MAVS oder IFN- $\beta$ Promotor stimulierendes Protein IPS-1) (Randall und Goodbourn 2008). Dieser seinerseits agiert als Gerüst für weitere Enzyme, so dass zur Familie der IxBInhibitorproteine (IKK) gehörende Kinasen aktiviert werden können. Diese spielen eine wichtige Rolle in der Koordination der Aktivierung des Interferon regulierenden Faktors 3 (IRF-3) und des Kernfaktors $x \mathrm{~B}$ (engl. „nuclear factor“, NFx-B) (Fitzgerald et al. 2003). Die Kinasen IKKe und TANK-bindende Kinase (TBK-1) 
phosphorylieren den IRF-3, welcher hierdurch homo-dimerisiert und vom zytoplasmatischen Raum in den Zellkern wandert. Gemeinsam mit den stressaktivierten Co-Aktivatoren p300 und dem CREB-bindenden Protein (CBP) steigert

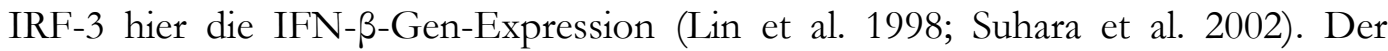
allgemeine Transkriptionsfaktor NFx-B liegt normalerweise an sein Inhibitor-Protein $\mathrm{I} x \mathrm{~B}$ gebunden im zytoplasmatischen Raum vor und kann erst im aktivierten Zustand in den Zellkern wandern. Die Aktivierung geschieht durch Abbau des InhibitorProteins I $x$ B durch einen IKK-Komplex (Hoffmann et al. 2006; Randall und Goodbourn 2008). Im Zellkern bildet NFx-B gemeinsam mit den Transkriptionsfaktoren IRF-3 und dem stressaktivierten Aktivierenden Protein (AP)-1 nach der Bindung an den IFN- $\beta$-Promotor das sogenannte Enhanceosom, welches die IFN- $\beta$ Expression stimuliert (Weber et al. 2004; Panne et al. 2007). Die Interferone werden von der infizierten Zelle sezerniert und binden parakrin und autokrin an Typ-I-Interferonrezeptoren (IFNAR), welche sich nahezu auf allen Zelltypen befinden (Schema s. Abbildung 5).

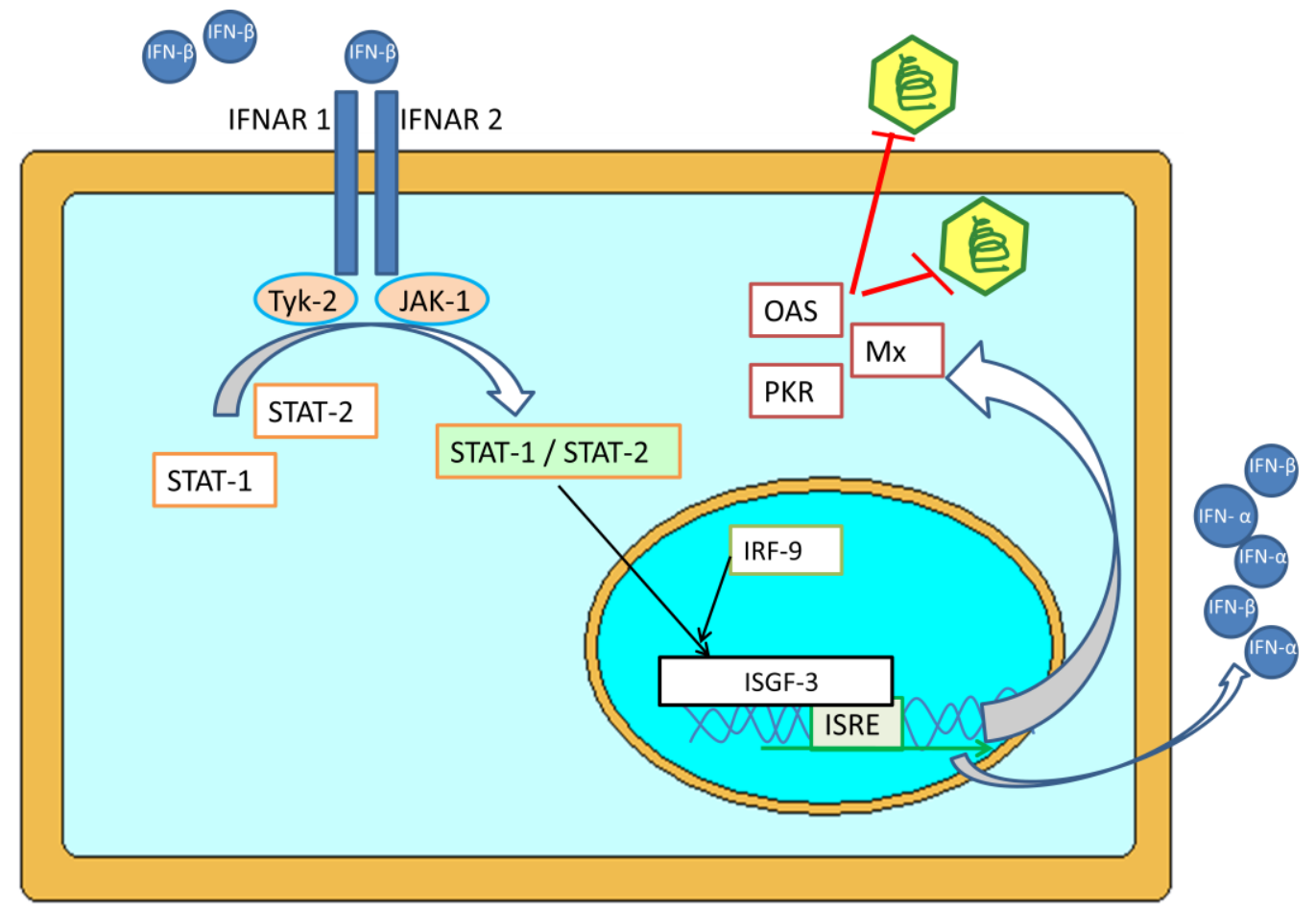

Abbildung 5: Interferon- $\beta$-Signalkaskade. 
Dieser Rezeptor besteht aus den beiden Untereinheiten IFNAR-1 und IFNAR-2. Durch die Bindung von Interferon bilden die beiden Monomere ein Dimer, wodurch die mit dem Rezeptor assoziierten Tyrosinkinasen JAK-1 (JAK steht für JanusKinasen oder ,just-another-kinase“) und Tyk-2 (Tyrosinkinase-2) aktiviert werden. Am aktivierten Rezeptor sind nun Bindungsstellen für die zwei Transkriptionsfaktoren STAT-1 und STAT-2 (Signal-Transduktoren und Aktivatoren der Transduktion) frei. Werden diese phosphoryliert, schließen sie sich zu einem Heterodimer zusammen und können in den Zellkern transportiert werden, wo sie mit IRF-9 den Transkriptionskomplex IFN-stimulierender Genfaktor (ISGF)-3 bilden, der an bestimmte DNA-Sequenzen im Promotorbereich der ISGs (Interferon stimulierbare Gene) bindet und gemeinsam mit Co-Aktivatoren die Expression dieser Gene bewirkt. Der sogenannte JAK-STAT-Signalweg ist auch an der Signalübermittlung von verschiedenen anderen Zytokinen und Wachstumsfaktoren beteiligt. Es sind vier JAKs und 7 STATs bekannt (Stark et al. 1998).

\subsubsection{Wirkungsweise der Interferone}

Heute sind über 300 durch Interferon stimulierbare Gene (ISG) bekannt (de Veer et al. 2001). Die Expression dieser durch Interferon stimulierbaren Gene bewirkt neben der Produktion von weiterem Interferon- $\beta$ auch die Ausschüttung der Interferon- $\alpha$ Subtypen in großen Mengen, so dass es vorübergehend zu einer starken Interferonantwort kommt, welche bei Infektion auch systemisch den gesamten Organismus einbeziehen kann (Kayser et al. 2005). Zusätzlich werden Interferoninduzierte Proteine mit antiviraler Wirkung synthetisiert, welche im Zusammenspiel den antiviralen Status der Zelle bewirken. Sowohl die Genexpression als auch die Aktivität der ISGs unterliegen einer strengen intrazellulären Kontrolle. Beispielsweise wird die Protein-Kinase $\mathbf{R}$ (PKR) durch Interferon induziert, muss jedoch zusätzlich durch dsRNA aktiviert werden, so dass sie nur in einer virusinfizierten Zellen aktiv ist (Stark et al. 1998; Weber et al. 2004; Kayser et al. 2005). Vor allem die frühen Schritte der Virusreplikation werden durch die antiviralen Proteine gestört, wie die Transkription bzw. Replikation des viralen Genoms. Die Protein-Kinase R (PKR) bewirkt im aktiven Zustand durch Phosphorylierung die Inaktivierung des Initiationsfaktors elF-2a. Dadurch ist die zelluläre Proteinsynthese gestoppt. Das 
IFN-induzierte MxA-Protein kann die Nukleokapside einiger RNA-Viren inaktivieren und so z.B. Orthomyxoviren (Mx steht für Orthomyxovirus-Resistenz), Influenzaviren und Bunyaviren hemmen. Die IFN-induzierte 2'-5'-Oligoadenylatsynthetase (OAS) katalysiert die Veresterung von bis zu fünf AdenosinTriphosphaten (ATPs) zu 2‘-5‘-Oligoadenylaten. Diese binden eine latent, d.h. inaktiv im Zytoplasma vorkommende Ribonuklease (RNase L), welche virale und zelluläre RNA abbaut. Die IFN-induzierte OAS muss wie die PKR zusätzlich durch dsRNA aktiviert werden, so dass ihre Wirkung auf virusinfizierte Zellen begrenzt ist (Kayser et al. 2005).

\subsubsection{Virale Interferonantagonisten}

Viren haben effektive Strategien entwickelt, um diese erste Abwehr durch das Interferonsystem zu umgehen. Neben der Unterdrückung der Interferonsynthese spielen auch die Hemmung der Signaltransduktion und die Blockierung von antiviralen Effektorproteinen eine Rolle (Weber et al. 2003; Weber et al. 2004; Randall und Goodbourn 2008).

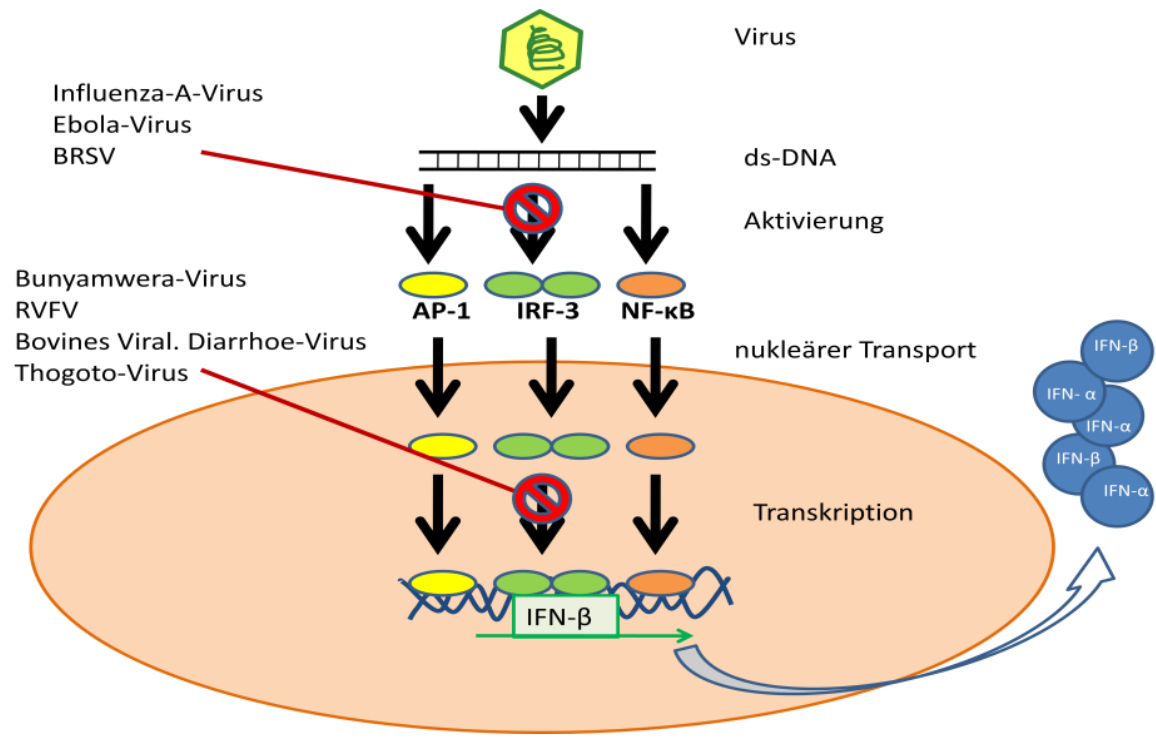

Abbildung 6: Inhibition des Interferonsystems durch verschiedene Viren, Abbildung modifiziert nach Weber et al. (2003, S. 210).

So kann das Nichtstruktur-Protein (NS)-1 vom Influenza-A-Virus die Phosphorylierung von IRF-3 und damit seinen Transport in den Nukleus blockieren. Das Virale Protein VP35 einiger Ebola-Virusstämme (Ebola-Zaire- und Ebola- 
Reston) greifen an der gleichen Stelle der Interferonsynthese an. Die Transkription wird vom Nichtstruktur-Protein NSs des Rift-Valley-Fieber-Virus (RVFV) und des Bunyamwera-Virus gehemmt. Der Transkriptionsfaktor IRF-3 wandert hier zwar in den Nukleus, kann jedoch nicht den IFN- $\beta$-Promotor aktivieren (s. Abbildung 6), da die RNA-Polymerase-II-vermittelte Transkription durch die NSs-Proteine gehemmt wird (Weber et al. 2003).

\subsection{Zielsetzung}

Das Ziel der vorliegenden Arbeit ist die Untersuchung der Pathogenitätsfaktoren des TRBV, speziell die Wirkung auf das Interferonsystem in infizierten eukaryontischen Zellen. Für Reoviren ist bisher nur eine Interferenz mit der IFN-vermittelten IFNSignaltransduktion, nicht aber mit der IFN-Induktion beschrieben. Daher soll die Induktion des Interferonsystems beziehungsweise dessen Hemmung durch TRBV in verschiedenen Zelllinien untersucht werden. Weiterhin sollen die viralen Genprodukte identifiziert werden, welche als Antagonisten des Interferonsystems wirken. 


\section{$2 \quad$ Material und Methoden}

\subsection{Standardmaterialien}

Regelmäßig in den meisten Versuchen verwendete Materialien, im Folgenden als Standardmaterialien bezeichnet:

\section{Geräte}

$\mathrm{CO}_{2}$-Inkubator

Gefrierschrank $\left(-20^{\circ} \mathrm{C}\right)$

Heraeus Sepatech GmbH, Osterode, Deutschland

Gefrierschrank $\left(-80^{\circ} \mathrm{C}\right)$

Liebherr GmbH, Ochsenhausen, Deutschland

Gefriertruhe $\left(-140^{\circ} \mathrm{C}\right)$

Thermo Scientific, Rockford, USA

Inkubator

Inverses Mikroskop

Kühlschrank $\left(5^{\circ} \mathrm{C}\right)$

Mehrkanalpipette 50-200 $\mu$ l

Mikroskop

Thermo Scientific, Rockford, USA

Heraeus Sepatech GmbH, Osterode, Deutschland

Nikon Instruments Europe B.V, Amstelveen, Niederlande

Liebherr GmbH, Ochsenhausen, Deutschland

Eppendorf AG, Hamburg, Deutschland

Nikon Instruments Europe B.V, Amstelveen, Niederlande

Multipette

Sterilbank

Varifuge RI

Vortex

Waage

Wärmebad

Zentrifuge

Zentrifuge (Megafuge 1.0R)

Eppendorf AG, Hamburg, Deutschland

Heraeus Sepatech GmbH, Osterode, Deutschland

Heraeus Instruments GmbH, Hannover, Deutschland

Bender \& Hobein AG, Zürich, Schweiz

Sartorius AG, Göttingen, Deutschland

Köttermann GmbH \& Co KG, Uetze/Hänigsen, Deutschland

Eppendorf AG, Hamburg, Deutschland

Thermo Scientific, Rockford, USA

\section{Verbrauchsartikel}

Gewebekulturflaschen mit Filter $\left(25 \mathrm{~cm}^{2}\right)$

Greiner Bio-One GmbH, Frickenhausen, Deutschland

Gewebekulturflaschen mit Filter $\left(75 \mathrm{~cm}^{2}\right)$

Greiner Bio-One GmbH, Frickenhausen, Deutschland

Handschuhe - Latex

Mikroflex Corporation, Wien, Österreich

Mehrkanalpipette

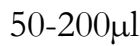

Eppendorf AG, Hamburg, Deutschland 
Mikroschraubgefäße (2,0ml)

Parafilm

Pipette

Pipetten mit Spitzen

$(2 \mathrm{ml}, 5 \mathrm{ml}, 10 \mathrm{ml}, 25 \mathrm{ml})$

Pipettenspitzen mit Filter

$(0,1-10 \mu \mathrm{l}, 1,0-100 \mu \mathrm{l}, 101-1000 \mu \mathrm{l})$

Pipettus

Röhrchen (15ml, 50ml)

Safe- Lock-Tubes

$(0,5 \mathrm{ml}, 1,5 \mathrm{ml}, 2 \mathrm{ml})$

Vernichtungsbeutel

$(300 \mathrm{~mm} \times 200 \mathrm{~mm})$

Zellkulturplatten96 well

Zellkulturplatten, 6 well, 12 well

\section{Medien und Puffer}

DMEM

DMEM (gebrauchsfertig)

MEM

MEM (gebrauchsfertig)

PBS
Sarstedt AG \& Co, Nümbrecht, Deutschland

American National Can, Chicago, USA

Eppendorf AG, Hamburg, Deutschland

Hirschmann Laborgeräte GmbH \& Co. KG, Eberstadt, Deutschland

Starlab GmbH, Ahrensberg, Deutschland

Hirschmann Laborgeräte GmbH \& Co. KG, Eberstadt, Deutschland

Sarstedt AG \& Co, Nümbrecht, Deutschland

Eppendorf AG, Hamburg, Deutschland

Lab Logistic Group GmbH, Meckenheim, Deutschland

Greiner Bio-One GmbH, Frickenhausen, Deutschland

Greiner Bio-One GmbH, Frickenhausen, Deutschland

c.c.pro GmbH, Oberdorla, Deutschland

500ml DMEM, 50ml FKS, 100U/ml Penicillin, $100 \mu \mathrm{g} / \mathrm{ml}$ Streptomycin, 526,6 mg/l Glutamin

c.c.pro GmbH, Oberdorla, Deutschland

$500 \mathrm{ml}$ MEM, 50ml FKS, 100U/ml Penicillin, $100 \mu \mathrm{g} / \mathrm{ml}$ Streptomycin, 526,6 mg/l Glutamin

c.c.pro GmbH, Oberdorla, Deutschland 


\subsection{Zellbiologische Methoden}

\subsubsection{Kultivierung von Zellen}

\section{Material:}

Materialien aus der Liste der Standardmaterialien s. Abschnitt 2.1 23, zusätzlich:

\section{Enzyme}

Trypsin

Biochrom AG, Berlin, Deutschland

\section{Zelllinien}

HEK 293

Humane embryonale Nierenzellen mit funktionellem IFN-System, Zellen mit besonders niedriger Passagenanzahl. Microbix Biosystems Inc., Toronto, Kanada

IFNAR-/-

Murine Zellen ohne Interferon-I-Rezeptor. Freundlicherweise zur Verfügung gestellt von Jovan Pavlovic, Institute of Medical Virology, University of Zürich, Zürich, Schweiz

$\mathrm{PKR}+/+$

Murine wt-Zellen. Freundlicherweise zur Verfügung gestellt von Jovan Pavlovic, Institute of Medical Virology, University of Zürich, Zürich, Schweiz

Vero B4

DSMZ GmbH, Braunschweig, Deutschland

Vero E6

Zellen ohne funktionelles IFN-System. ATCC, Manassas, USA

\section{Methode:}

Den Medien DMEM und MEM wird vor Gebrauch 10\% FKS sowie 100U/ml Penicillin, $100 \mu \mathrm{g} / \mathrm{ml}$ Streptomycin und 526,6mg/l Glutamin zugesetzt. Alle Zellen werden unter $5 \% \mathrm{CO}_{2}$ bei $37^{\circ} \mathrm{C}$ in $75 \mathrm{~cm}^{2}$-Gewebekulturflaschen kultiviert. Mit Ausnahme der Trypsinlösung werden die Medien und Lösungen vor Gebrauch im Wasserbad auf $37^{\circ} \mathrm{C}$ erwärmt. Die Zelllinien Vero E6, HEK-293, IFNAR-/- und $\mathrm{PKR}+/+$ werden in DMEM kultiviert, die Zelllinie Vero B4 in MEM. Bei Erreichen der Konfluenz des Zellrasens (ca. zweimal pro Woche) werden die Zellen passagiert. Hierzu wird das Medium abgesaugt und die Zellen mit 5ml PBS gewaschen, um Medienreste zu entfernen. Danach werden die Zellen mit $1 \mathrm{ml}$ Trypsin vom Flaschenboden gelöst, die Vero-Zelllinien Vero B4 und Vero E6 werden hierzu für $5 \mathrm{~min}$. bei 
$37^{\circ} \mathrm{C}$ inkubiert, da Trypsin sein Wirkungsoptimum bei Wärme hat. Zum Lösen der Zellen werden die Kulturflaschen seitlich mit der Hand angeschlagen. Danach wird die Trypsinreaktion durch Zugabe von $4 \mathrm{ml}$ serumhaltigem Medium gestoppt und die Zellen durch mehrmaliges Aufziehen mit der Pipette vereinzelt. Je nach Wachstumsgeschwindigkeit der Zelllinie werden 0,5-0,25ml des Trypsinats in die Kulturflasche zurückpipettiert (entspricht 1/10-1/20), der Rest wird verworfen oder zur Zellaussaat für Versuche verwendet. Nach Zugabe von frischem Medium (Gesamtvolumen je $75 \mathrm{~cm}^{2}$ Flasche $12 \mathrm{ml}$ ) werden die Zellen für die nächste Wachstumsphase unter $5 \% \mathrm{CO}_{2}$ bei $37^{\circ} \mathrm{C}$ inkubiert.

\subsubsection{Zellzahlbestimmung}

\section{Material:}

Materialien aus der Liste der Standardmaterialien s. Abschnitt 2.1 S. 23, zusätzlich:

\section{Verbrauchsartikel}

Einmalzählkammer

Hycor Biomedical Inc:, Kalifornien, USA

Chemikalien

Trypanblau

Sigma-Aldrich Corporation, St. Louis, USA

\section{Methode:}

Die Zellzahlbestimmung erfolgt mittels einer Einmalzählkammer von Hycor Biomedical Inc. $\left(\mathrm{KOVA}^{\circledR}\right.$ GLASSTIC $^{\circledR}$ SLIDE 10). Dazu werden $10 \mu \mathrm{l}$ Trypsinat (s. 2.2.1) mit $90 \mu \mathrm{l}$ Trypanblau vermischt und hiervon $10 \mu \mathrm{l}$ in die Zählkammer gegeben. Unter dem Lichtmikroskop werden 4 bis 9 Großquadrate mit jeweils 9 Kleinstquadraten ausgezählt und der Mittelwert berechnet. Zellaggregate werden nicht mitgezählt, da verklumpte Zellen nicht so gut anwachsen. Zellen, die auf den die Quadrate begrenzenden Linien liegen, werden nicht doppelt gezählt. Die Bestimmung der Zellzahl erfolgt nach folgender Formel:

\section{Mittelwert $\times 10^{5 *}=$ Zellzahl $/ \mathrm{ml}$.}

*Faktor leitet sich ab aus dem Volumen eines Großquadrats $\left(0,1 \mu \mathrm{l}=10^{-4} \mathrm{ml}\right)$ sowie der Verdünnung der Zellsuspension in Trypanblau $\left(1: 10=10^{-1}\right)$ 


\subsection{Virologische Methoden}

\subsubsection{Anzucht von Tribec-Viren (TRBV)}

\section{Material:}

Materialien aus der Liste der Standardmaterialien s. Abschnitt 2.1 S. 23, zusätzlich:

\section{Viren}

Tribec-Virus (TRBV)

Freundlicherweise zur Verfügung gestellt von G. Dobler, Institut für Mikrobiologie der Bundeswehr

\section{Zelllinien}

Vero B4

$$
\text { DSMZ GmbH, Braunschweig, Deutschland }
$$

\section{Methode:}

Tribec-Virus (TRBV) wird in Vero-B4-Zellen in gebrauchsfertigem MEM (s.o.) in $75 \mathrm{~cm}^{2}$-Gewebekulturflaschen vermehrt. Dazu werden Vero-B4-Zellen bei Erreichen einer ca. 75\%igen Konfluenz mit einer MOI von 0,1 (infektiöse „Einheiten“ pro Zelle, engl. "multiplicity of infection") TCID $_{50}$-Einheiten infiziert. Bei Eintritt des zytopathischen Effekts wird der Überstand geerntet und durch Zentrifugation bei $3000 \times g$ von Zelltrümmern gereinigt. Nach Aliquotierung in je $1 \mathrm{ml}$ wird der Virenüberstand bei $-80^{\circ} \mathrm{C}--140^{\circ} \mathrm{C}$ in Mikroschraubgefäßen gelagert. Die TCID 50 der gewonnenen Virussuspension wird durch Titration auf Vero-B4-Zellen bestimmt (s. Abschnitt 2.3.3). 


\subsubsection{Anzucht von RVFV-Clone-13}

\section{Material:}

Materialien aus der Liste der Standardmaterialien s. Abschnitt 2.1 S. 23, zusätzlich:

Viren

RVFV-Clone-13

Rift Valley Fever Virus, apathogenes RVFV-Isolat mit Deletion im NSs-Gen (Muller R et al. 1995)

\section{Zelllinien}

Vero E6

Zellen ohne funktionelles IFN-System. ATCC, Manassas, USA

\section{Methode:}

RVFV-Clone-13 wird auf Vero-E6-Zellen in gebrauchsfertigem DMEM (s.o.) in $75 \mathrm{~cm}^{2}$ - Gewebekulturflaschen gezüchtet. Dazu werden Vero-E6-Zellen bei Erreichen einer ca. 75\% igen Konfluenz mit einer MOI von 0,1 TCID $_{50}$-Einheiten RVFVClone-13 infiziert. Drei Tage nach Infektion wird der Überstand geerntet und durch Zentrifugation bei $3000 \times g$ von Zelltrümmern gereinigt. Nach Aliquotierung in je $1 \mathrm{ml}$ wird der Virenüberstand bei $-80^{\circ} \mathrm{C}--140^{\circ} \mathrm{C}$ gelagert. Der $\mathrm{TCID}_{50}$ wird durch Titration auf Vero-E6-Zellen bestimmt (s. Abschnitt 2.3.3).

\subsubsection{Bestimmung von Virustitern mittels Kulturinfektionsdosis-Tests $\left(\mathrm{TCID}_{50}\right)$}

\section{Material:}

Materialien aus der Liste der Standardmaterialien s. Abschnitt 2.1 S. 23, zusätzlich:

\section{Zelllinien}

Vero B4

DSMZ GmbH, Braunschweig, Deutschland

Vero E6

Zellen ohne funktionelles IFN-System, ATCC, Manassas, USA 


\section{Viren}

RVFV-Clone-13

Tribec-Virus
Rift Valley Fever Virus, apathogenes RVFV-Isolat mit Deletion im NSs-Gen (Muller R et al. 1995)

Freundlicherweise zur Verfügung gestellt von G. Dobler, Institut für Mikrobiologie der Bundeswehr

\section{Methode:}

Die Zelllinie, in der der zu testende Virus vermehrt wird (Vero B4 für TRBV und Vero E6 für RVFV-Clone-13) wird mit $10^{3}$ Zellen je Kavität in einem Volumen von $200 \mu \mathrm{l}$ in eine 96-Well-Platte ausgesät und für 24 Stunden unter $5 \% \mathrm{CO}_{2}$ bei $37^{\circ} \mathrm{C}$

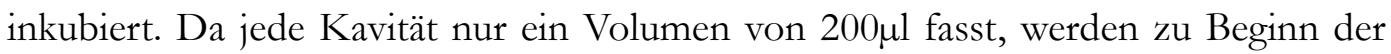

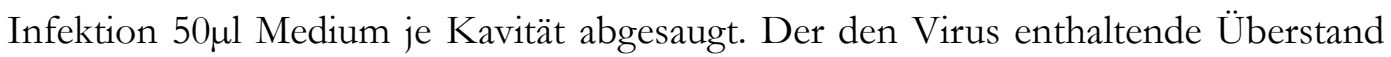
wird in seriellen 1:10 Schritten bis zu einer Verdünnungsstufe von 1:10 ${ }^{9}$ mit Medium

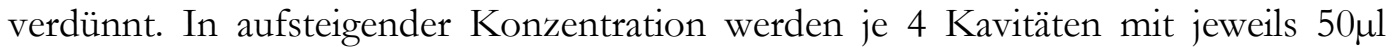
einer Verdünnungsstufe infiziert. Nach 6 Tagen wird unter dem Lichtmikroskop der zytopathische Effekt (CPE) bestimmt. Weisen 50\% der Kavitäten einer Verdünnungsstufe noch einen $\mathrm{CPE}$ auf, entspricht diese Verdünnungsstufe dem TCID $_{50}$. Erreicht der Virus z.B. in 50\% der Kavitäten mit einer Verdünnung von 1:10 $0^{7}$ noch einen CPE, so bedeutet dies einen TCID $_{50}$ von $1 \times 10^{7}$ in $50 \mu$, was einem TCID $_{50}$ von $2 \times 10^{8}$ in $1 \mathrm{ml}$ entspricht. Dieser Virustiter wird als Grundlage zur Bestimmung der MOI bei einer Virusinfektion benutzt.

\subsubsection{Virusinfektion der Zellen in Gewebekulturflaschen}

\section{Material:}

Materialien aus der Liste der Standardmaterialien s. Abschnitt 2.1 S. 23, zusätzlich:

\section{Zelllinien}

HEK 293

Humane embryonale Nierenzellen mit funktionellem IFN-System, Zellen mit besonders niedriger Passagenanzahl. Microbix Biosystems Inc., Toronto, Kanada 
IFNAR-/-

$\mathrm{PKR}+/+$

Vero B4

Vero E6

Viren

RVFV-Clone-13

Tribec-Virus
Murine Zellen ohne Interferon-I-Rezeptor. Freundlicherweise zur Verfügung gestellt von Jovan Pavlovic, Institute of Medical Virology, University of Zürich, Zürich, Schweiz

Murine wt-Zellen. Freundlicherweise zur Verfügung gestellt von Jovan Pavlovic, Institute of Medical Virology, University of Zürich, Zürich, Schweiz

DSMZ GmbH, Braunschweig, Deutschland

Zellen ohne funktionelles IFN-System. ATCC, Manassas, USA

Apathogenes RVFV-Isolat mit Deletion im NSs-Gen (Muller R et al. 1995)

Freundlicherweise zur Verfügung gestellt von G. Dobler, Institut für Mikrobiologie der Bundeswehr

\section{Methode:}

Die zu infizierenden Zellen werden mit einer zuvor festgelegten Zellzahl in $25 \mathrm{~cm}^{2}$ Gewebekulturflaschen in $5 \mathrm{ml}$ Medium ausgesät und bis zum Erreichen einer ca. $50 \%$ igen Konfluenz unter $5 \% \mathrm{CO}_{2}$ bei $37^{\circ} \mathrm{C}$ inkubiert. Für die Infektion wird das Medium aus den Gewebekulturflaschen entfernt und die Zellen mit $1 \mathrm{ml}$ Virussuspension (die den Zellrasen vollständig bedeckt) für 1 Stunde unter $5 \% \mathrm{CO}_{2}$ bei $37^{\circ} \mathrm{C}$ inkubiert. Die für die Infektion zu verwendende MOI wird auf Grundlage der ausgesäten Zellzahl berechnet. Nach der Inkubationszeit wird das Volumen mit 4ml Medium wieder auf das Gesamtvolumen der Gewebekulturflasche von 5ml aufgefüllt und die Zellen bis zum Erreichen eines zytopathischen Effekts (CPE) unter $5 \% \mathrm{CO}_{2}$ bei $37^{\circ} \mathrm{C}$ inkubiert. 


\subsubsection{Virusinfektion der Zellen in 96-Well-Platten}

\section{Material:}

Materialien aus der Liste der Standardmaterialien s. Abschnitt 2.1 S. 23, zusätzlich:

\section{Zelllinien}

HEK 293

Humane embryonale Nierenzellen mit funktionellem IFN-System, Zellen mit besonders niedriger Passagenanzahl. Microbix Biosystems Inc., Toronto, Kanada

IFNAR-/-

Murine Zellen ohne Interferon-I-Rezeptor. Freundlicherweise zur Verfügung gestellt von Jovan Pavlovic, Institute of Medical Virology, University of Zürich, Zürich, Schweiz

$\mathrm{PKR}+/+$

Vero B4

Vero E6

Viren

RVFV-Clone-13

Tribec-Virus
Murine wt-Zellen. Freundlicherweise zur Verfügung gestellt von Jovan Pavlovic, Institute of Medical Virology, University of Zürich, Zürich, Schweiz

DSMZ GmbH, Braunschweig, Deutschland

Zellen ohne funktionelles IFN-System. ATCC, Manassas, USA

Apathogenes RVFV-Isolat mit Deletion im NSs-Gen (Muller R et al. 1995)

Freundlicherweise zur Verfügung gestellt von G. Dobler, Institut für Mikrobiologie der Bundeswehr

\section{Methode:}

Die zu infizierenden Zellen werden in zuvor festgelegter Zellzahl in die Kavitäten der 96-Well-Platte ausgesät. Dazu wird eine Stammlösung der Zellsuspension mit entsprechender Zellkonzentration angesetzt und hiervon jeweils $200 \mu \mathrm{l}$ je Kavität mit einer Mehrkanalpipette auf die 96-Well-Platte gegeben. Die Zellen werden für 24 Stunden unter $5 \% \mathrm{CO}_{2}$ bei $37^{\circ} \mathrm{C}$ inkubiert. Da jede Kavität nur ein Volumen von

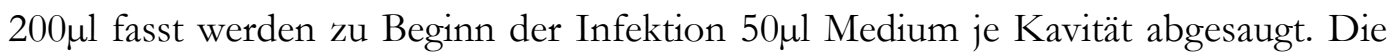
MOI wird auf Grundlage der je Kavität ausgesäten Zellzahl berechnet und eine entsprechende Virussuspension als Stammlösung angesetzt. Von dieser Virus- 
suspension werden $50 \mu \mathrm{l}$ je Kavität dazugegeben. Danach werden die Zellen bis zum Erreichen eines sichtbaren $\mathrm{CPE}$ unter $5 \% \mathrm{CO}_{2}$ bei $37^{\circ} \mathrm{C}$ inkubiert.

\subsection{Molekularbiologische Methoden}

\subsubsection{RNA-Isolierung aus Zellen}

\section{Material:}

Materialien aus der Liste der Standardmaterialien s. Abschnitt 2.1 S. 23, zusätzlich:

\section{Geräte}

Spektralphotometer (NanoDrop)

PEQLAB Biotechnologie GmbH, Erlangen,

\section{Chemikalien}

2-Propanol (Isopropanol) Deutschland

Chloroform

Merck KgaA, Darmstadt, Deutschland

DEPC-Wasser

Merck KGaA, Darmstadt, Deutschland

Ethanol abs.

Carl Roth GmbH \& CoKG, Karlsruhe, Deutschland

peqGOLD RNA-TriFast ${ }^{\mathrm{TM}}$

Carl Roth GmbH \& CoKG, Karlsruhe, Deutschland

PEQLAB Biotechnologie GmbH, Erlangen, Deutschland

\section{Methode:}

Es wird die peqGOLD RNA-TriFast ${ }^{\mathrm{TM}}$-Arbeitsanleitung von Peqlab befolgt. Die Methode basiert auf einer Einschritt-Flüssigphasen-Separation. Das gebrauchsfertige Reagenz enthält Phenol und Guanidinisothiocyanat. Nach Zugabe von Chloroform und anschließender Zentrifugation trennt sich das Homogenat in drei Phasen auf. Die kleinen DNA-Fragmente sind unpolar und lösen sich im sauren Phenol, die größeren DNA-Fragmente und Proteine finden sich in der Interphase. Die RNA ist in der oberen wässrigen Phase enthalten, da sie polarer ist und sich besser in Wasser löst.

Der Überstand wird durch Zentrifugation bei $3000 \times g$ von Zelltrümmern gereinigt und bei $-80^{\circ} \mathrm{C}$ für spätere Untersuchungen aufbewahrt. Die Zellen werden durch Zugabe von $2 \mathrm{ml}$ peqGOLD RNA-TriFast ${ }^{\mathrm{TM}}$ je $25 \mathrm{~cm}^{2}$-Gewebekulturflasche und mehrmaliges Aufziehen mit der Pipette lysiert. Um die Dissoziation der Nukleotidkomplexe zu gewährleisten, werden die Proben für 5 Minuten bei Raumtemperatur 
inkubiert. Anschließend werden die Proben auf je zwei Safe-Lock-Reaktionsgefäße à $1 \mathrm{ml}$ aufgeteilt. Je eingesetztem Milliliter peqGOLD RNA-TriFast ${ }^{\mathrm{TM}}$ werden der Probe $200 \mu$ Chloroform zugeben und die Proben für 15 Sekunden mittels Vortex geschüttelt. Nach 10 Minuten Inkubation bei Raumtemperatur werden die Proben 5 Minuten bei $12000 \times \mathrm{g}$ zentrifugiert $\left(4^{\circ} \mathrm{C}\right)$, um eine Phasenauftrennung zu erhalten. $500 \mu \mathrm{l}$ der die RNA enthaltenden wässrigen Phase werden in ein frisches Reaktionsgefäß überführt und mit gleichem Volumen Isopropanol versetzt. Nach 15 Minuten Inkubation bei $4^{\circ} \mathrm{C}$ und 15 minütiger Zentrifugation bei $12000 \times \mathrm{g}\left(4^{\circ} \mathrm{C}\right)$ wird das Isopropanol invertiert und das am Boden verbleibende Pellet mit $1 \mathrm{ml}$ 75\%igem Ethanol gewaschen und anschließend 10 Minuten bei $12000 \times g\left(4^{\circ} \mathrm{C}\right)$ zentrifugiert. Dieser Waschschritt wird einmal wiederholt und das Pellet anschließend 10 Minuten bei Raumtemperatur getrocknet. Die Resuspension des RNA-Pellets erfolgt mit $25 \mu \mathrm{l}$ DEPC-Wasser. Zum Schluss werden die Proben vereint und die RNAKonzentration spektrometrisch bestimmt (s. Abschnitt 2.4.2). Die fertigen RNAProben werden bei $-20^{\circ} \mathrm{C}$ aufbewahrt.

\subsubsection{Spektrometrische Konzentrationsbestimmung von RNA}

\section{Material:}

Materialien aus der Liste der Standardmaterialien s. Abschnitt 2.1 S. 23, zusätzlich:

\section{Geräte}

Spektralphotometer (NanoDrop)

PEQLAB Biotechnologie GmbH, Erlangen, Chemikalien

dd $\mathrm{H}_{2} \mathrm{O}$

Ultrafiltriertes, deionisiertes Wasser 


\section{Methode:}

Mit dem verwendeten Spektralphotometer können mittels Lichtabsorption DNAund RNA-Konzentrationen in sehr kleinen Volumina $(1 \mu \mathrm{l}-2 \mu \mathrm{l})$ direkt gemessen werden. Die Basen der Nukleinsäuren haben ihr Absorptionsmaximum bei $260 \mathrm{~nm}$ Messwellenlänge und werden in diesem Bereich von dem Photometer erfasst. Zur Reinheitskontrolle der DNA errechnet das Photometer während der Messung einen 260:280nm Quotienten, welcher vorzugsweise zwischen 1,8 und 2,0 liegen sollte, um Verunreinigungen durch Proteine auszuschließen. Jedoch kann das Gerät nicht zwischen DNA und RNA unterscheiden, so dass bei Verunreinigung der RNA mit DNA die Werte verfälscht würden. Zur Bestimmung der RNA-Konzentration wird der NanoDrop von Peqlab benutzt. Die Durchführung erfolgt nach den Angaben des Herstellers. Nach Initialisierung des Gerätes und Messung des Leerwertes werden $1,5 \mu l$ Probe in das Gerät pipettiert und gemessen. Die Daten dieser Messung dienen als Ausgangswert für die Einstellung aller Proben auf die gleiche RNAKonzentration (zwischen 300ng/ $\mu \mathrm{l}$ und 500ng/ $\mu \mathrm{l}$ ). Dabei erfolgt die Verdünnung der Proben mit dd $\mathrm{H}_{2} \mathrm{O}$.

\subsubsection{Reverse Transkription}

\section{Material:}

Materialien aus der Liste der Standardmaterialien s. Abschnitt 2.1 S. 23, zusätzlich:

\section{Geräte}

Thermocycler Biometra GmbH, Göttingen, Deutschland

\section{Verbrauchsartikel}

PCR- Reaktionsgefäße $(0,2 \mathrm{ml})$

Greiner Bio-One GmbH, Frickenhausen,

\section{Chemikalien}

DEPC-Wasser

Dithiothreitol (DTT)

Carl Roth GmbH \& CoKG, Karlsruhe, Deutschland

Enzyme, Nukleotide

Desoxyribonukleotidtriphosphat

Fermentas GmbH, St. Leon-Rot, Deutschland (dNTP) $100 \mathrm{mM}$ 
Random Hexamer Primer

Superscript ${ }^{\circledR}$ III

\section{Puffer}

$5 \times$ First-Strand Buffer
Amersham Biosciences Europe GmbH, Freiburg, Deutschland

Invitrogen Corporation, Kalifornien, USA

Invitrogen Corporation, Kalifornien, USA

\section{Methode:}

Die Transkription der RNA in cDNA erfolgt durch eine RNA-abhängige DNAPolymerase, der Reversen Transkiptase. Die Bezeichnung „revers“ beschreibt hierbei die spezielle Eigenschaft dieses Enzyms, den eigentlichen Transkriptionsprozess von der DNA zur RNA umzukehren. Durch die RNA-abhängige DNA-PolymeraseAktivität wird zunächst ein RNA-DNA-Hybridstrang synthetisiert. Danach wird der RNA-Anteil durch einen speziellen RNase-Anteil des Enzyms abgebaut. Da im mikrobiologischen Verfahren die RNA als Matrize dient und somit immer wieder erneut abgelesen werden muss, ist diese RNase Aktivität in den eingesetzten, rekombinant veränderten Enzymen nicht mehr vorhanden. Als Primer für die Reaktion werden randomisierte Primer verwendet, die aus sechs zufällig ausgewählten Nukleotiden bestehen. Da sich daraus eine Vielzahl an Kombinationsmöglichkeiten ergibt, kann gewährleistet werden, dass die im Reaktionsansatz enthaltene RNA komplett in cDNA umgeschrieben wird. Das verwendete Enzym Superscript III synthetisiert ss-cDNA und hat keine RNase-Aktivität. Die Durchführung erfolgt nach den Angaben des Herstellers.

Vor Beginn wird je nach Probenzahl eine Standardlösung hergestellt, die Reagenzien

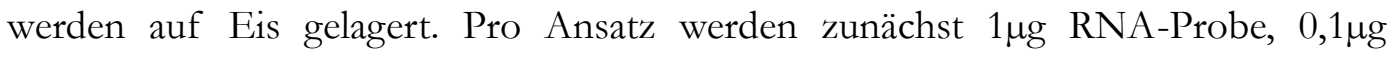
Random Hexamer Primer (RHP) und $1 \mu 110 \mathrm{mM}$ dNTPs mit $\mathrm{H}_{2} \mathrm{O}$ auf ein Gesamtvolumen von $14 \mu \mathrm{l}$ gebracht und 5 Minuten bei $65^{\circ} \mathrm{C}$ denaturiert, danach bei $4^{\circ} \mathrm{C}$ für 1 Minute inkubiert. Anschließend werden die Proben kurz zentrifugiert und je Ansatz $4 \mu \mathrm{l}$ 5xReaktionspuffer, $1 \mu \mathrm{l}$ Superskript III $(200 \mathrm{U} / \mu \mathrm{l})$ und $1 \mu \mathrm{l} 0,1 \mathrm{M}$ Dithiothreitol (DTT) hinzugefügt. Die Synthese der cDNA erfolgte bei $50^{\circ} \mathrm{C}$ für 60 min nach 5 minütiger Hybridisierung der Primer an die RNA bei $25^{\circ} \mathrm{C}$. Das Enzym wird bei $70^{\circ} \mathrm{C}$ für $15 \mathrm{~min}$ inaktiviert. Die fertige cDNA wird bei $-20^{\circ} \mathrm{C}$ gelagert. 


\subsubsection{RT-PCR}

\section{Material:}

Materialien aus der Liste der Standardmaterialien s. Abschnitt 2.1 S. 23, zusätzlich:

\section{Geräte}

PCR-Bank

G\&P Kunststofftechnik, Kassel, Deutschland

Thermocycler

Biometra GmbH, Göttingen, Deutschland

\section{Verbrauchsartikel}

PCR- Reaktionsgefäße $(0,2 \mathrm{ml}) \quad$ Greiner Bio-One GmbH, Frickenhausen, Deutschland

\section{Chemikalien}

Destilliertes Wasser für PCR Invitrogen Corporation, Kalifornien, USA

\section{Enzyme, Nukleotide}

Desoxyribonukleotidtriphosphat Fermentas GmbH, St. Leon-Rot, Deutschland (dNTP) $100 \mathrm{mM}$

Taq-DNA-Polymerase

„hu-ifn_beta_for”

„hu-ifn-beta_rev“"

„hu_gamma-actin_for”

„hu_gamma-actin_rev“"

„TRBV VP7 RTS FP“

„TRBV VP7 RTS RP“

„RVF FP“

„RVF RP“

\section{Puffer}

10×PCR-Puffer
5 PRIME GmbH, Hamburg, Deutschland

GACGCCGCATTGACCATCTA

CCTTAGGATTTCCACTCTGACT

GCCGGTCGCAATGGAAGAAGA

CATGGCCGGGGTGTTGAAGGTC

CACCGACCATGGACGCGTACACTGCACGAGC

GCTAACCCCGGGCTGACCCAGCCTGAAGGCAC TGCCACGAGTYAGAGCCA

GTGGGTCCGAGAGTYTGC

5 PRIME GmbH, Hamburg, Deutschland

\section{Methode:}

Die Polymerase-Kettenreaktion (engl. polymerase chain reaction) ermöglicht die selektive in-vitro-Amplifikation einer zuvor bestimmten Region der DNA, welche als Template (doppelsträngige DNA-Matrize) dient. Zunächst wird durch Erhitzen des PCR-Ansatzes eine Denaturierung (Trennung des Doppelstranges in zwei Einzelstränge) erreicht. Nach raschem Abkühlen auf ca. $50^{\circ} \mathrm{C}$ binden im Hybridisierungsschritt die im Reaktionsgemisch vorhandenen Oligonukleotide 
(Primer) an der Stelle der DNA, welche in ihrer Sequenz komplementär ist. Die Primer werden so gewählt, dass sie ein DNA-Fragment begrenzen, welches amplifiziert werden soll. Ein hoher Überschuss an Primern im Vergleich zur Template-DNA garantiert eine dauerhafte Bindung (Massenwirkungsgesetz). Während der Amplifikation bei ca. $70^{\circ} \mathrm{C}$ werden die an die DNA angelagerten Oligonukleotide von einer thermostabilen DNA-Polymerase (z.B. Taq-Polymerase, aus dem Bakterium Thermus aquaticus) durch den Anbau von einzelnen Desoxyribonukleotidtriphosphaten (dNTPs) verlängert. Die drei Schritte Denaturierung - Hybridisierung - Amplifikation werden vielfach wiederholt, was zu einer exponentiellen Zunahme der amplifizierten DNA führt. Bei der RT-PCR wird als Template cDNA benutzt, welche zuvor mittels reverser Transkription aus RNA hergestellt wurde.

Vor Beginn der Durchführung wird je nach Probenzahl eine Standardlösung hergestellt, die Reagenzien werden gekühlt gelagert. $1 \mu \mathrm{l}$ Template wird zu einem Reagenziengemisch aus 40,6 $\mu \mathrm{l} \mathrm{H}_{2} \mathrm{O}, 5 \mu \mathrm{l} 10 \times$ PCR-Puffer, $1 \mu \mathrm{l}$ dNTPs, $1 \mu \mathrm{l}$ Taq DNAPolymerase und je $1 \mu$ l Primer forward und Primer reverse gegeben. Die Primer werden als $10 \mu \mathrm{M}$ Lösungen in Wasser verwendet: Für die Interferon- $\beta$-spezifische PCR bei Vero-Zelllinien und HEK-293 werden die Primer „hu-ifn_beta_for“ bzw. „_rev“ verwendet. Für die Virus-spezifischen PCRs werden die Primer „TRBV VP7 RTS fp“ bzw. „-rp“ und „RVF fp“ und „-rp“ verwendet. Für die interne Kontrolle werden $\gamma$-actin-spezifische PCRs durchgeführt mit ,hu-gamma_actin_for“ bzw. „_rev“. Die PCR wird im Thermocycler bei folgenden Bedingungen durchgeführt:

\begin{tabular}{|c|c|c|}
\hline Deckelheizung & $95^{\circ} \mathrm{C}$ & \\
\hline 2 Minuten & $95^{\circ} \mathrm{C}$ & \\
\hline 30 Sekunden & $95^{\circ} \mathrm{C}$ & Wiederholung: 34X, \\
\hline 30 Sekunden & $56^{\circ} \mathrm{C}$ & entspricht 35 Zyklen \\
\hline 1 Minute & $72^{\circ} \mathrm{C}$ & \\
\hline 5 Minuten & $72^{\circ} \mathrm{C}$ & \\
\hline PAUSE & $8^{\circ} \mathrm{C}$ & \\
\hline
\end{tabular}

Die Amplifikate werden bei $-20^{\circ} \mathrm{C}$ gelagert. 


\subsubsection{Agarosegelelektrophorese}

\section{Material:}

Materialien aus der Liste der Standardmaterialien s. Abschnitt 2.1 S. 23, zusätzlich:

\section{Geräte}

ChemiDoc XRS System

Bio Rad Laboratories GmbH, München, Deutschland

Gel-Elektrophoresekammer (groß) Invitrogen Corporation, Kalifornien, USA

Gel-Elektrophoresekammer (klein) Invitrogen Corporation, Kalifornien, USA

Mikrowellengerät AFK ${ }^{\circledR}$ Deutschland GmbH, Hamburg, Deutschland

\section{Verbrauchsartikel}

Handschuhe - Nitril

GE Healthcare Europe NV, Brüssel, Belgien

\section{Chemikalien}

Agarose

Biozym, Scientific GmbH, Oldendorf, Deutschland

Ethidiumbromid-Lösung $(10 \mathrm{mg} / \mathrm{ml})$

Carl Roth GmbH \& CoKG, Karlsruhe, Deutschland

\section{Nukleotide, Standards}

6×Orange Loading Dye

Fermentas GmbH, St. Leon-Rot, Deutschland

DNA-Längenstandard

(100bp, Ultra Low Range)

Fermentas GmbH, St. Leon-Rot, Deutschland

\section{Puffer, Lösungen, Medien}

Agarosegel (1\%ig)

100ml TAE[1×], $1 \mathrm{~g}$ Agarose, $5 \mu \mathrm{l}$ EthidiumbromidLösung

Agarosegel (3\%ig)

100ml TAE[1×], 3g Agarose, 5 $\mu$ l EthidiumbromidLösung

TAE $[1 \times]$

40ml TAE [50×] add. $1969 \mathrm{ml} \mathrm{H}_{2} \mathrm{O}$

TAE $[50 \times]$

242g Tris: 57,1 $\mathrm{ml}$ Essigsäure, 100ml 0,5M EDTA $(\mathrm{pH}=8,0)$

\section{Methode:}

Die Agarosegelelektrophorese wird als analytisches Verfahren benutzt, um DNAFragmente (z.B. PCR-Produkte) ihrer Größe nach aufzutrennen. Durch Gleichstrom wird bei der Gelelektrophorese ein elektrisches Feld erzeugt, in dem DNA-Moleküle und Proteine als elektrisch geladene Teilchen wandern und wegen ihrer unter- 
schiedlichen Ionenladung und molekularen Größe unterschiedlich schnell durch die Gelmatrix gelangen. Agarose als Polysaccharid bildet ein Maschenwerk aus parallelen Bündeln und wird zur Auftrennung von DNA-Fragmenten benutzt. Zum Anfärben der DNA wird Ethidiumbromid verwendet. Es handelt sich hierbei um einen zwischen die Basen der DNA interkalierenden Farbstoff. Durch die DNAInterkalation wird die Fluoreszenz der Substanz bei Anregung durch UV-Licht stark erhöht. Auf diese Weise leuchten die DNA-Banden im Agarosegel unter UV-Licht hell auf, während Stellen ohne DNA dunkel erscheinen. Die Lichtintensität ist dabei proportional zur vorhandenen DNA-Menge.

Für ein 1\%iges Gel wird 1g Agarose in 100ml TAE[1X] durch Erhitzen in der Mikrowelle gelöst. Für sehr kleine Fragmente, wie sie bei der RVFV-Clone-13spezifischen PCR entstehen, werden 3\%ige Gele mit 3g Agarose in 100ml TAE[1 $\times$ ] verwendet. Um die Banden im UV-Licht sichtbar zu machen, werden dem Gel nach Abkühlung auf ca. $60^{\circ} \mathrm{C}$ 0,5 $\mu$ l Ethidiumbromidlösung $(10 \mathrm{mg} / \mathrm{ml}$ Ethidiumbromid in $\left.\mathrm{H}_{2} \mathrm{O}\right)$ beigemischt. Das flüssige Gel wird in eine Gelschale (125 x 80 x 7,5mm für ein großes Gel) gegossen und ein Taschenkamm für 14 Geltaschen gesetzt. Nach dem Erstarren des Gels wird der Taschenkamm entfernt und das Gel in eine mit TAEPuffer $($ TAE $[1 \times])$ gefüllte Elektrophoresekammer gegeben. Es wird Puffer hinzugefügt, bis das Gel komplett bedeckt ist. Alternativ werden Mini-Gelkammern (100 x 70 x 0,5mm für kleine Gele, 1/3 des Ansatzes für ein großes Gel) verwendet. Je $5 \mu$ l DNA-Probe werden mit $1 \mu \mathrm{l}$, „6×Orange Loading Dye“ (Fermentas) versetzt und in eine Geltasche gefüllt. Zur Bestimmung der Fragmentgröße wurden 2,5 $\mu$ l DNA-Fragmentlängenstandard (100bp Leiter bzw. „Ultra Low Range“) verwendet. Die Elektrophorese wird bei einer konstanten Spannung von 100 bis $120 \mathrm{~V}$ für ca. 60min. durchgeführt. Die Gele werden unter UV-Licht im ChemiDoc XRS System fotografiert und zur besseren Darstellung zum Teil nachträglich am PC bearbeitet (invertiert). 


\subsubsection{Dual-Luciferase-Reporter-Assay mit HEK-293-Zellen}

\section{Material:}

Materialien aus der Liste der Standardmaterialien s. Abschnitt 2.1 S. 23, zusätzlich:

\section{Geräte}

Fluorometer

BMG LABTECH GmbH, Offenburg, Deutschland

\section{Verbrauchsmaterialien}

Lumitrac-Platten 96 well, weiß

Greiner Bio-One GmbH, Frickenhausen,

Chemikalien

DEPC-Wasser

Carl Roth GmbH \& CoKG, Karlsruhe, Deutschland

Dual-Luciferase-Reporter-Assay

Promega Corporation, Madison, USA

\section{Enzyme, Nukleotide, Standards}

und Vektoren

pI.18

Leerer eukaryontischer Expressionsvektor. Enthält eine Expressionskassette bestehend aus dem humanen CMV-IE-Promotor, dem CMV-Intron A, einer MCS zur Insertion von cDNA und einem hCMV polyA-Signal. Freundlicherweise zur Verfügung gestellt von Jim Robertson, National Institute for Biological Standards and Control, Herfordshire, Großbritannien.

pI.18-FLAG-deltaMx

Plasmid zur Expression eines trunkierten humanen Mx-Proteins, welches zusätzlich am N-Terminus mit einem FLAG-Tag versehen ist. Freundlicherweise zur Verfügung gestellt von Prof. Dr. Friedemann Weber, Abt. Virologie, Universität Marburg.

pUC19

pUC19 ist ein bakterielles high-copy-Plasmid für die Blau-Weiß-Selektion. Abt. Virologie, Universitätsmedizin Göttingen (UMG), Deutschland.

pcRII-TRBV-S7

pcRII-TRBV-S9

Plasmid zur Expression von TRBV-NS-2. Freundlicherweise zur Verfügung gestellt von Meik Dilcher, Abt. Virologie, Universitätsmedizin Göttingen (UMG), Deutschland.

Das Plasmid enthält neben der Sequenz zur Expression von TRBV-VP6(Hel) den alternativen Leserahmen ORF-Xa. Freundlicherweise zur Verfügung gestellt von Meik Dilcher, Abt. Virologie, Universitätsmedizin Göttingen (UMG), Deutschland. 
IRF-3(5D)

pFC-MEKK

lw_poly(I:C)

p125-Luc

p55A2-Luc

p55C1B-Luc

pAP1-Luc
Plasmid zur Expression eines künstlichen IRF-3Proteins, das durch Ersatz aller bei der Aktivierung phosphorylierten Serinreste durch Aspartat konstitutiv aktiv ist (Lin et al. 1998). Freundlicherweise zur Verfügung gestellt von John Hiscott, McGill University, Montreal, Kanada

Plasmid zur Expression von MEK-Kinase unter der Kontrolle des humanen CMV-Promotors. Agilent Technologies, Waldbronn, Deutschland.

Invivogen Corporation, Kalifornien, USA

Der Vektor beinhaltet die Firefly-LuciferaseReporter-cDNA unter der Kontrolle eines IFN- $\beta$ -

Promotor-Fragments (Nucleotide -125 bis +19 bezogen auf die TATA-Box) (Yoneyama et al. 1996). Der Vektor kodiert außerdem für eine Ampicillinresistenz zur selektiven Vermehrung von transformierten E. coli. Freundlicherweise zur Verfügung gestellt von Takashi Fujita, Tokyo Metropolitan Institute of Medical Science, Tokyo, Japan

Ein NF- $x \mathrm{~B}$ responsiver Promotor, der drei Kopien der PRD II (NF- $x$ B Bindungsstelle) des IFN- $\beta$ Promotors enthält (Fujita et al. 1989). Der Vektor kodiert außerdem für eine Ampicillinresistenz zur selektiven Vermehrung von transformierten E. coli. Freundlicherweise zur Verfügung gestellt von Takashi Fujita, Tokyo Metropolitan Institute of Medical Science, Tokyo, Japan

Ein IRF-3-responsiver Promotor mit acht Kopien der IRF-3 Bindungssequenz AAGTGA (Yoneyama et al. 1998)). Der Vektor kodiert außerdem für eine Ampicillinresistenz zur selektiven Vermehrung von transformierten E. coli. Freundlicherweise zur Verfügung gestellt von Takashi Fujita, Tokyo Metropolitan Institute of Medical Science, Tokyo, Japan

Ein AP-1 responsiver Promotor, der mehrere Kopien des AP-1 Enhancer Elements enthält, welches der PRD IV des IFN- $\beta$-Promotors entspricht. Der Vektor kodiert außerdem für eine Ampicillinresistenz zur selektiven Vermehrung von transformierten E. coli. Agilent Technologies, Waldbronn, Deutschland 
pRLSV40

TNF- $\alpha$

RNA aus nicht infizierten Vero- Laboreigene Herstellung. Es handelt sich um Zellen

RNA VSV-infizierter Verozellen

\section{Puffer, Lösungen, Medien}

FuGeneHD

Lipofectamine

OptiMEM

\section{Zelllinien}

HEK 293

\section{RVFV-Clone-13}

Tribec-Virus
Der Vektor beinhaltet die Renilla-Luciferase-cDNA unter der Kontrolle des konstitutiv aktiven SV40 early-Promotors. Der Vektor kodiert außerdem für eine Ampicillinresistenz zur selektiven Vermehrung von transformierten E. coli. Promega, Mannheim, Deutschland

Sigma-Aldrich, Deisenhofen, Deutschland
Gesamt-RNA aus Vero-E6-Zellen.

Laboreigene Herstellung. Es handelt sich um Gesamt-RNA aus Vero-E6-Zellen, welche 12 Stunden zuvor mit VSV infiziert wurden. Diese RNA wurde als 5'-Triphosphat-RNA benutzt (Pichlmair et al. 2006).

Roche, Mannheim, Deutschland

Invitrogen Corporation, Kalifornien, USA

Invitrogen Corporation, Kalifornien, USA

Humane embryonale Nierenzellen mit funktionellem IFN-System, Zellen mit besonders niedriger Passagenanzahl. Microbix Biosystems Inc., Toronto, Kanada

Apathogenes RVFV-Isolat mit Deletion im NSs-Gen (Muller R et al. 1995)

Freundlicherweise zur Verfügung gestellt von G. Dobler, Institut für Mikrobiologie der Bundeswehr

\section{Methode:}

Der Luciferase-Reporter-Assay basiert auf der Biolumineszenz einiger Naturstoffe (Luciferine) wie sie z.B. in dem amerikanischen Leuchtkäfer Photinus pyralis (engl. firefly) vorkommen. In Gegenwart des entsprechenden Enzyms (Luciferase) reagieren sie mit Sauerstoff zu Oxyluciferin und geben die freiwerdende Energie in Form von Licht ab (Lumineszenz). Bei der in-vitro-Messung wird zunächst der Promoter eines Gens, dessen Expression untersucht wird, mit dem Luciferase-Gen gekoppelt und in die Zelle transfiziert. Da die Expression der Luciferasen nun der 
Kontrolle der vorangeschalteten Promotoren unterliegt, ist die Aktivität der Luciferasen proportional zum Aktivitätsgrad der Promotoren. Diese Aktivität kann nun durch Zugabe von Luciferin zum Testsystem anhand der bei der Reaktion entstehenden Lumineszenz gemessen werden (de Wet et al. 1987; Sherf et al. 1996). Im vorliegenden Fall wird die Promotoraktivität vom Interferon- $\beta$-Gen einerseits nach Virusinfektion und andererseits nach Transfektion von Expressionsplasmiden für virale Gene vergleichend mit bzw. ohne anschließende Stimulation gemessen. In weiteren Versuchen wird die Aktivität artifizieller Promotoren, die selektiv durch die Transkriptionsfaktoren NF- $x$ B, AP-1 und IRF-3 aktiviert werden, nach Transfektion von Expressionsplasmiden für TRBV-Gene untersucht. Um den Einfluss von Schwankungen in Transfektionseffizienz und Zellzahl, sowie von Pipettierfehlern auf das Ergebnis zu vermindern, erfolgt stets eine Co-Transfektion mit einem Kontrollplasmid, hier pRLSV40, welches das Luciferase-Gen von Renilla reniformis (einer Weichkoralle) enthält und mit Hilfe des konstitutiv aktiven SV40 Promotors in eukaryontischen Zellen exprimiert wird.

Für die Durchführung wird der Dual-Luciferase-Reporter-Assay von Promega benutzt.

\subsubsection{Messung der IFN- $\beta$-Promotoraktivität nach Infektion mit TRBV bzw. RVFV-Clone-13}

Zunächst werden $5 \times 10^{5}$ Zellen in $2 \mathrm{ml}$ gebrauchsfertigem DMEM je Kavität in 6-Well-Platten ausgesät und für 24 Stunden unter $5 \% \mathrm{CO}_{2}$ bei $37^{\circ} \mathrm{C}$ inkubiert. Für die Infektion wird das Medium entfernt und die Zellen für 1 Stunde mit 250 $\mu$ l Virussuspension entsprechend einer MOI von 1 unter $5 \% \mathrm{CO}_{2}$ bei $37^{\circ} \mathrm{C}$ inkubiert. Anschließend wird das Medium mit je 1,75ml gebrauchsfertigem DMEM auf $2 \mathrm{ml}$ je Kavität aufgefüllt und die Zellen für 8 Stunden unter $5 \% \mathrm{CO}_{2}$ bei $37^{\circ} \mathrm{C}$ inkubiert. Als Transfektionsmethode dient die Lipofektion. Hierzu werden je Ansatz $4 \mu \mathrm{l}$ Lipofectamine und 100 $\mu$ OptiMEM nach 5Minuten Inkubationszeit bei RT mit

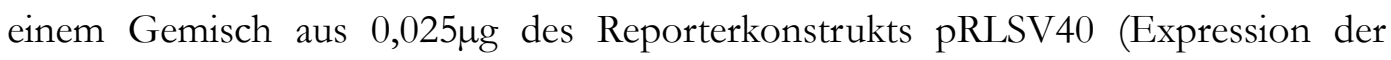
Renilla Luciferase mittels SV40 Promotor) und 1 $1 \mu \mathrm{g}$ des Reporterkonstrukts p125Luc (Expression der Firefly Luciferase mittels humanem IFN- $\beta$-Promotor) 
zusammengeführt und für 20 Minuten bei RT inkubiert. Je nach Probengröße wird eine Stammlösung hergestellt. Von dieser werden $200 \mu$ l je Kavität zu den Zellen gegeben und 18 Stunden unter $5 \% \mathrm{CO}_{2}$ bei $37^{\circ} \mathrm{C}$ inkubiert. Die Stimulation erfolgt je

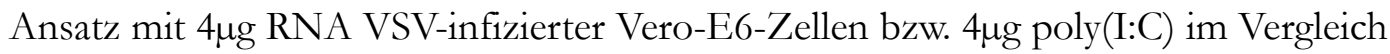
zur Stimulation mit RNA aus nicht infizierten Vero-E6-Zellen als Kontrolle, und wird wie schon die Transfektion der Reporterkonstrukte mit Lipofectamine durchgeführt. Die Lyse der Zellen erfolgt nach weiteren 20 Stunden Inkubation unter $5 \% \mathrm{CO}_{2}$ bei $37^{\circ} \mathrm{C}$. Hierzu wird das Medium verworfen und die Zellen zunächst mit PBS gewaschen, um Medienreste zu entfernen. Anschließend werden die Zellen mit

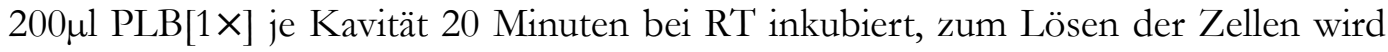
die Platte gelegentlich seitlich angeschlagen. Am FluostarOptima erfolgt zunächst die Messung der Firefly-Luciferase-Aktivität. Hierzu werden je 20 $\mu$ l Probe in eine weiße

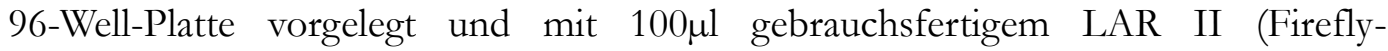
Luciferase-Substrat) vermischt. Nach erfolgter Messung wird je Probe ein Gemisch aus $2 \mu$ l Renilla-Luciferase-Substrat und 100 $\mu$ l Stop\&Glo-Puffer dazugegeben und die Renilla-Luciferase-Aktivität gemessen. Die Messwerte der Firefly-Luciferase-Aktivität werden in Microsoft Office Excel rechnerisch mit den Messwerten der RenillaLuciferase-Aktivität normalisiert und die Aktivität des Interferon- $\beta$-Promotors grafisch dargestellt.

\subsubsection{Messung der IFN- $\beta$-Promotoraktivität nach Transfektion von Expressionsplasmiden für virale Gene}

Auch hier dient als Transfektionsmethode die Lipofektion. Es werden vergleichend die Expressionsplasmide für das Virusprotein NS-2 (TRBV-S7), die virale Helikase (TRBV-S9, mit ORF-Xa Region), TRBV-S7+-S9 bzw. pI18-FDMx (als Kontrolle) zusammen mit den Reporterkonstrukten co-transfiziert. Bei pI18-FDMx handelt es sich um ein trunkiertes (funktionsloses) Mx-Protein im eukaryontischen ExpressionsVektor pI18, welches keinen Einfluss auf das Interferonsystem hat.

Zunächst werden $1 \times 10^{5}$ Zellen in $1 \mathrm{ml}$ gebrauchsfertigem DMEM je Kavität in 12Well-Platten ausgesät und für 24 Stunden unter $5 \% \mathrm{CO}_{2}$ bei $37^{\circ} \mathrm{C}$ inkubiert. Für die

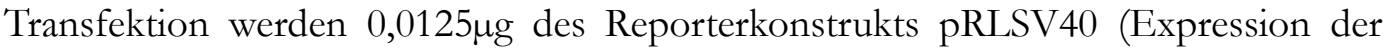
Renilla Luciferase mittels SV40 Promotor) und 0,5 $\mathrm{gg}$ des zu testenden Reporter- 
konstrukts p125-Luc (Expression der Firefly Luciferase mittels humanem IFN- $\beta$ -

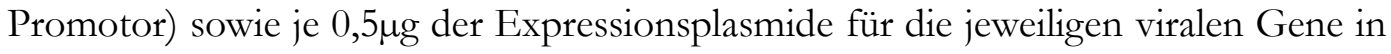
100 $\mu$ l OptiMEM verdünnt und anschließend mit $3 \mu$ FuGENE HD je Ansatz versetzt. Je nach Probengröße wird eine Standardlösung hergestellt. Von dieser werden nach 15 Minuten Inkubationszeit bei Raumtemperatur $100 \mu$ l je Kavität zu den Zellen gegeben und 24 Stunden unter $5 \% \mathrm{CO}_{2}$ bei $37^{\circ} \mathrm{C}$ inkubiert. Die Stimulation erfolgt je Ansatz mit $2 \mu \mathrm{g}$ RNA VSV-infizierter Zellen bzw. $4 \mu \mathrm{g}$ poly(I:C) im Vergleich zur Stimulation mit RNA aus nicht infizierten Vero-E6-Zellen als Kontrolle, und wird wie schon die Transfektion mit FuGENE HD durchgeführt. Die Lyse der Zellen erfolgt nach weiteren 16 Stunden Inkubation unter 5\% $\mathrm{CO}_{2}$ bei $37^{\circ} \mathrm{C}$. Hierzu wird das Medium verworfen und die Zellen zunächst mit PBS gewaschen, um Medienreste zu entfernen. Anschließend werden die Zellen mit 100 $\mu$ l PLB $[1 \times]$ je Kavität 20 Minuten bei RT inkubiert, zum Lösen der Zellen wird die Platte gelegentlich seitlich angeschlagen. Am FluostarOptima erfolgt zunächst die Messung der Firefly-Luciferase-Aktivität. Hierzu werden je $20 \mu l$ Probe in eine weiße

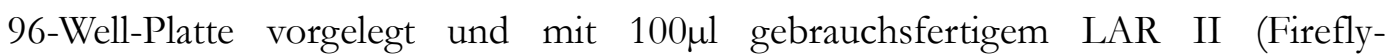
Luciferase-Substrat) vermischt. Nach erfolgter Messung werden je Probe ein Gemisch aus $2 \mu \mathrm{l}$ Renilla-Luciferase-Substrat und 100 $\mu$ l Stop\&Glo-Puffer dazugegeben und die Renilla-Luciferase-Aktivität gemessen. Die Messwerte der Firefly-Luciferase-Aktivität werden in Microsoft Office Excel rechnerisch mit den Messwerten der Renilla-Luciferase-Aktivität normalisiert und die Aktivität des IFN$\beta$-Promotors grafisch dargestellt.

\subsubsection{Messung der Aktivität eines AP-1-responsiven Promotors nach Transfektion von Expressionsplasmiden für virale Gene}

Auch hier werden zunächst $1 \times 10^{5}$ Zellen in $1 \mathrm{ml}$ gebrauchsfertigem DMEM je Kavität in 12-Well-Platten ausgesät und für 24 Stunden unter $5 \% \mathrm{CO}_{2}$ bei $37^{\circ} \mathrm{C}$ inkubiert. Je Ansatz werden $2 \mu$ l Lipofectamine mit 100 $\mu$ OptiMEM für fünf

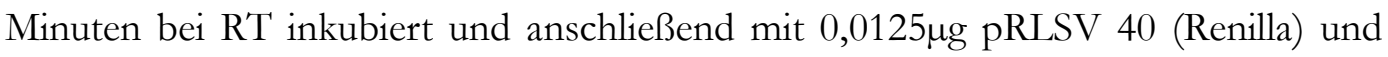

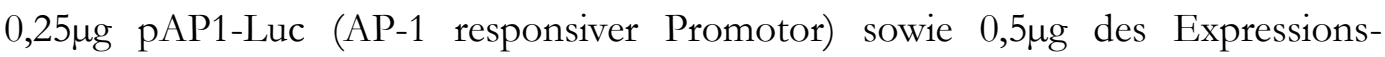

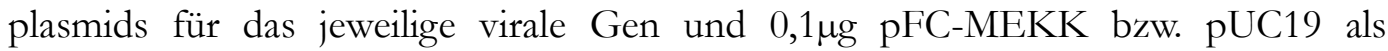

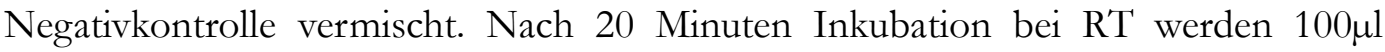


Gemisch auf die Zellen gegeben. Durch die Transfektion von pFC-MEKK kommt es zur Expression der MEK-Kinase, welche eine Signalkaskade aktiviert, welche wiederum zur Aktivierung von AP-1 führt.

Insgesamt 24 Stunden nach Transfektion erfolgen die Lyse der Zellen und die Messung der Luciferaseaktivität.

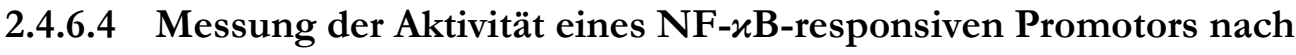 Transfektion von Expressionsplasmiden für virale Gene}

Wie unter 2.4.6.2 beschrieben werden Dual-Luciferase-Reporter-Assays nach Transfektion der Reporterkonstrukte und Expressionsplasmide für die viralen Gene mit FuGENE HD durchgeführt. Die Stimulation erfolgt auch hier mit RNA VSVinfizierter Verozellen bzw. poly(I:C) im Vergleich zur Stimulation mit RNA aus nicht infizierten Vero-E6-Zellen als Kontrolle. Als Reporterkonstrukt wird p55A2-Luc verwendet, welches einen NF- $x \mathrm{~B}$-responsiven Promotor enthält. Es handelt sich hierbei um einen synthetischen Minimalpromotor, dem drei NF- $x$ B-Bindungsstellen des humanen IFN- $\beta$-Promotors vorgeschaltet sind (Fujita et al. 1989).

\subsubsection{Messung der Aktivität eines NF- $\varkappa$ B-responsiven Promotors nach Transfektion und Stimulation mit TNF- $\alpha$}

Wie unter 2.4.6.3 beschrieben werden Dual-Luciferase-Reporter-Assays nach Transfektion der Reporterkonstrukte und Expressionsplasmide für die viralen Gene mit Lipofectamine durchgeführt. Als Reporterkonstrukt wird p55A2-Luc, das einen NF- $x$ B-responsiven Promotor enthält, verwendet. Die Stimulation mit $0,01 \mu \mathrm{g}$ TNF- $\alpha$ je Kavität erfolgt 12 Stunden nach Transfektion. Der Tumornekrosefaktor (TNF)- $\alpha$ aktiviert NF- $x$ B sehr effizient (Hoffmann et al. 2006), daher wird dieser als Stimulus benutzt. Nach weiteren 12 Stunden und damit 24 Stunden nach Transfektion erfolgen die Lyse der Zellen und die Messung der Luciferaseaktivität. 


\subsubsection{Messung der Aktivität eines IRF-3-responsiven Promotors nach Transfektion von Expressionsplasmiden für virale Gene}

Wie unter 2.4.6.2 beschrieben werden Dual-Luciferase-Reporter-Assays nach Transfektion der Reporterkonstrukte und Expressionsplasmide für die Virussegmente mit FuGENE HD durchgeführt. Die Stimulation erfolgt auch hier mit RNA VSV-infizierter Zellen bzw. poly(I:C) im Vergleich zur Stimulation mit RNA aus nicht infizierten Vero-E6-Zellen als Kontrolle. Als Reporterkonstrukt für das untersuchte IRF-3 wird p55C1B-Luc als IRF-3-responsiver Promotor verwendet. Es handelt sich hierbei um einen synthetischen Minimalpromotor, dem acht IRF-3Bindungsstellen des humanen IFN- $\beta$-Promotors vorgeschaltet sind (Yoneyama et al. 1998).

\subsubsection{Messung der Aktivität eines IRF-3-responsiven Promotors nach Transfektion und Stimulation mit IRF-3(5D)}

Wie unter 2.4.6.3 beschrieben werden Dual-Luciferase-Reporter-Assays nach Transfektion der Reporterkonstrukte und Expressionsplasmide für die viralen Gene mit Lipofectamine durchgeführt. Als Reporterkonstrukt für das untersuchte IRF-3 wird p55C1B-Luc als IRF-3-responsiver Promotor verwendet (s.o.). Die Stimulation erfolgt in diesem Versuch durch die Co-Transfektion von IRF-3(5D), als Negativkontrolle wird pUC19 co-transfiziert. Bei IRF-3(5D) handelt es sich um ein künstliches IRF-3-Protein, bei dem alle Serinreste, die bei der Aktivierung phosphoryliert werden, durch Aspartat ersetzt wurden. Dadurch ist diese IRF-3 Variante ohne Phosphorylierung konstitutiv aktiv (Lin et al. 1998).

\subsubsection{Statistik}

Für die Auswertung der Ergebnisse aus den Dual-Luciferase-Reporter-Assays werden innerhalb der jeweiligen Versuchsreihen die Einzelwerte für die Firefly-LuciferaseAktivität mit den Einzelwerten der normalisierten Renilla-Luciferase-Aktivität korrigiert und daraus der Mittelwert berechnet. Für die statistische Auswertung wird der Zweistichproben-t-Test unter der Annahme unterschiedlicher Varianzen angewandt. Als signifikant werden Unterschiede mit einem Signifikanzniveau von 
$\mathrm{p} \leq 0,5$ gewertet. Damit gilt bei Signifikanz der Ergebnisse eine mindestens 95\%ige Wahrscheinlichkeit, dass gemessene Unterschiede im Vergleich zur Kontrolle kein Zufall sind. Als sehr signifikant werden Unterschiede mit einem Signifikanzniveau von $\mathrm{p} \leq 0,01$, als hoch signifikant Unterschiede mit einem Signifikanzniveau von $\mathrm{p} \leq 0,001$ bezeichnet.

\subsubsection{Impedanzmessung virusinfizierter Zellen mittels xCELLigence- System}

\section{Material:}

Materialien aus der Liste der Standardmaterialien s. Abschnitt 2.1 S. 23, zusätzlich:

\section{Geräte}

xCELLigence Gerät

ACEA Bioscience/Roche, San Diego, USA

\section{Verbrauchsartikel}

96-Well-E-Plates

ACEA Bioscience/Roche, San Diego, USA

\section{Zelllinien}

HEK 293

Humane embryonale Nierenzellen mit funktionellem IFN-System, Zellen mit besonders niedriger Passagenanzahl, Microbix Biosystems Inc., Toronto, Kanada

IFNAR-/-

Murine Zellen ohne IFN-I-Rezeptor. Freundlicherweise zur Verfügung gestellt von Jovan Pavlovic, Institute of Medical Virology, University of Zürich, Zürich, Schweiz

$\mathrm{PKR}+/+$

Murine wt-Zellen. Freundlicherweise zur Verfügung gestellt von Jovan Pavlovic, Institute of Medical Virology, University of Zürich, Zürich, Schweiz

\section{Viren}

RVFV-Clone-13

Tribec-Virus (TRBV)
Apathogenes RVFV-Isolat mit Deletion im NSs-Gen (Muller R et al. 1995)

Freundlicherweise zur Verfügung gestellt von G. Dobler, Institut für Mikrobiologie der Bundeswehr 


\section{Methode:}

Durch das Auslesen der Impedanz können zelluläre Zustände nicht-invasiv und in Echtzeit quantitativ bestimmt werden. Der Zellanalysator xCELLigence von Roche Applied Science arbeitet mit sogenannten E-Plates im 96-Well-Format, welche am Boden jeder Kavität mit einem mikroelektronischen (Gold-)Sensorarray ausgestattet sind. Durch das Anlegen einer schwachen Wechselspannung $(20 \mathrm{mV})$ wird in der Kavität eine ionische Umgebung erzeugt. Wachsen am Boden der E-Plate adhärente Zellen, so führt ihre Interaktion mit den Mikroelektroden zu einer Zell-SubstratImpedanz-Antwort, welche proportional zur Anzahl der Zellen, ihrer Zellmorphologie und der Stärke ihrer Zelladhäsion ist (s. Abbildung 7) (Abassi 2008).

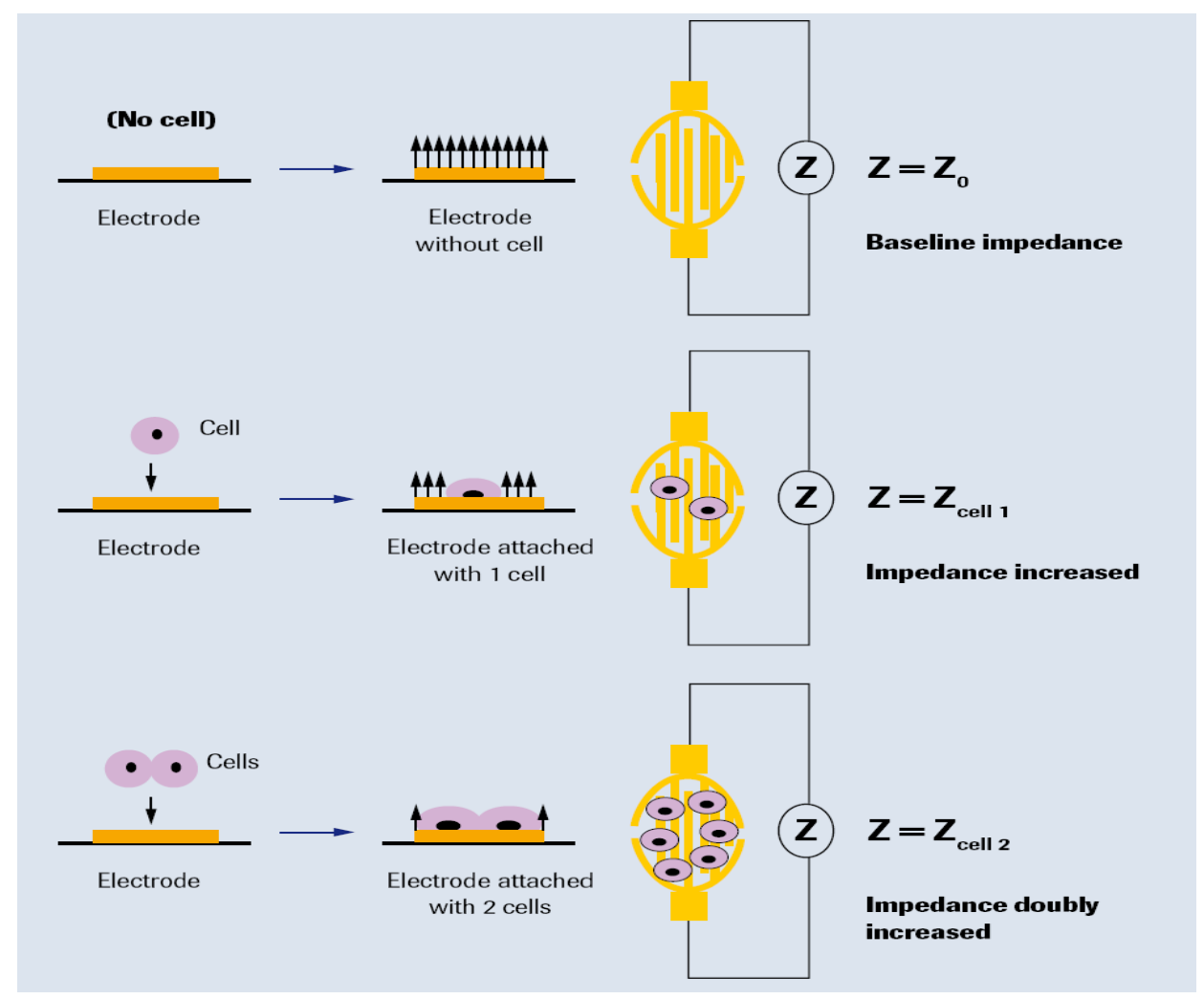

Abbildung 7: Schema der miteinander verbundenen Mikroelektroden, die in den Boden jeder Kavität der E-Plates eingearbeitet sind. Die Interaktion adhärenter Säugerzellen mit den Mikroelektroden führt zu einer Zell-Substrat-Impedanz-Antwort, die proportional zur Zahl der ausgesäten Zellen in den Wells, der Zellmorphologie und der Art der Zelladhäsion ist (Abassi 2008, S. 8).

Hier wird die Impedanzmessung dazu benutzt, das Wachstum der Zellen bzw. den zytopathischen Effekt (CPE) einer Virusinfektion im zeitlichen Verlauf zu verfolgen. 
Hierzu werden mehrere Zelllinien in unterschiedlichen Zelldichten in 96-Well-EPlates ausgesät und in verschiedenen Wachstumsphasen mit unterschiedlicher MOI infiziert. Das Gerät wird mit $100 \mu \mathrm{l}$ Medium je Kavität initialisiert (Hintergrundmessung). Dann werden $100 \mu \mathrm{l}$ je Kavität der zuvor vorbereiteten Zellsuspension mit einer Mehrkanalpipette dazugegeben und im Messgerät unter 5\% $\mathrm{CO}_{2}$ bei $37^{\circ} \mathrm{C}$ inkubiert. Die Wachstumsphase dauert zwischen 1 und 5 Tagen, abhängig von Zellinie und Zelldichte. Die Infektion erfolgt mit TRBV als zu untersuchendem Virus und RVFV-Clone-13 als Positivkontrolle (IFN- $\beta$-Induktor). Da die Kavitäten nur ein begrenztes Gesamtvolumen fassen, werden zu Beginn der Infektion 50 $\mu$ l Medium je Kavität abgesaugt. Die MOI wird auf Grundlage der je Kavität ausgesäten Zellzahl berechnet und eine entsprechende Virussuspension

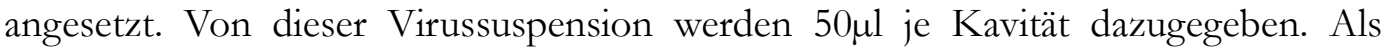

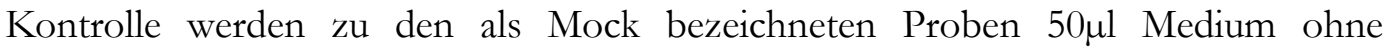
Viruspartikel gegeben. Danach werden die Zellen im Messgerät unter 5\% $\mathrm{CO}_{2}$ bei $37^{\circ} \mathrm{C}$ inkubiert, die Messung der Impedanz erfolgt über den gesamten Zeitraum des Experiments im Abstand von 15 bzw. 30 Minuten. Bei der Co-Infektion der Zellen mit beiden Virusstämmen werden die Proben zunächst mit TRBV infiziert, nach einer Inkubationszeit von 6 Stunden erfolgt dann die Infektion mit RVFV-Clone-13.

\section{$3 \quad$ Ergebnisse}

\subsection{Viabilitätsbestimmung TRBV-infizierter Zellen mittels Impedanzmessung}

\subsubsection{Die murinen Zelllinien IFNAR-/- und PKR+/+}

Die Fibroblasten-Zelllinie IFNAR-/- kommt aus genveränderten Mäusen und ist defizient für das Gen des Interferon-I-Rezeptors (Muller U et al. 1994). Daher findet bei diesen Zellen keine Aktivierung der Interferon-Signalkaskade statt. Somit kommt es zu keiner positiven Rückkopplung bzw. Weiterleitung des Interferonsignals. Die

Aktivierung der Interferon induzierbaren Gene und somit die Herstellung des antiviralen Zustandes der Zellen bleibt aus. Im Vergleich wurde die Wildtyp-Zelllinie $\mathrm{PKR}+/+$ mit beiden Viren infiziert. Da die Wachstumsgeschwindigkeit der beiden Zelllinien unterschiedlich, die Wachstumsphase jedoch für den Infektionszeitpunkt 
maßgeblich ist, wurden die IFNAR-/- Zellen einen Tag nach Aussaat, die PKR+/+ Zellen jedoch erst nach zwei Tagen infiziert.

Mittels Impedanzmessung (s. 2.4.8, S. 48) wurde die Wachstumskurve der Zelllinien nach Infektion mit dem zu untersuchenden Tribec-Virus (TRBV) im Vergleich zum Interferon stimulierenden RVFV-Clone-13 untersucht. Dazu wurden die Zellen in unterschiedlichen Zelldichten ausgesät und zu verschiedenen Zeitpunkten der Wachstumsphase mit unterschiedlichen MOIs infiziert. Die gemessene Impedanz ist proportional zur Anzahl der Zellen, ihrer Zellmorphologie und der Stärke ihrer Zelladhäsion und damit ein direktes Maß für die Vitalität der Zellen.

In der graphischen Darstellung der Messung ist die Zeit (in Stunden) auf der $\mathrm{x}$-Achse, der Zellindex (berechnet aus der gemessenen Impedanz) auf der $\mathrm{y}$-Achse aufgetragen. Die Wachstumskurve der nicht infizierten Zellen (Mock) ist jeweils blau dargestellt. Der Zellindex der mit RVFV-Clone-13 infizierten Zellen ist in Grün- und der mit TRBV infizierten Zellen in Rottönen (rot in der jeweils höheren MOI, magenta in der niedrigeren MOI) im zeitlichen Verlauf aufgetragen. Zu einem Artefakt in den Kurven zum Zeitpunkt der Infektion kommt es durch die kurzzeitige Unterbrechung der Messung und Entnahme der Kulturplatte aus dem Gerät. Im Platten-Schema ist die Auswahl der Kavitäten in den der jeweiligen Kurven entsprechenden Farben gezeigt. Die Kurve entspricht der Darstellung des Mittelwertes der Messung am Boden der jeweils gleich behandelten Kavitäten. 


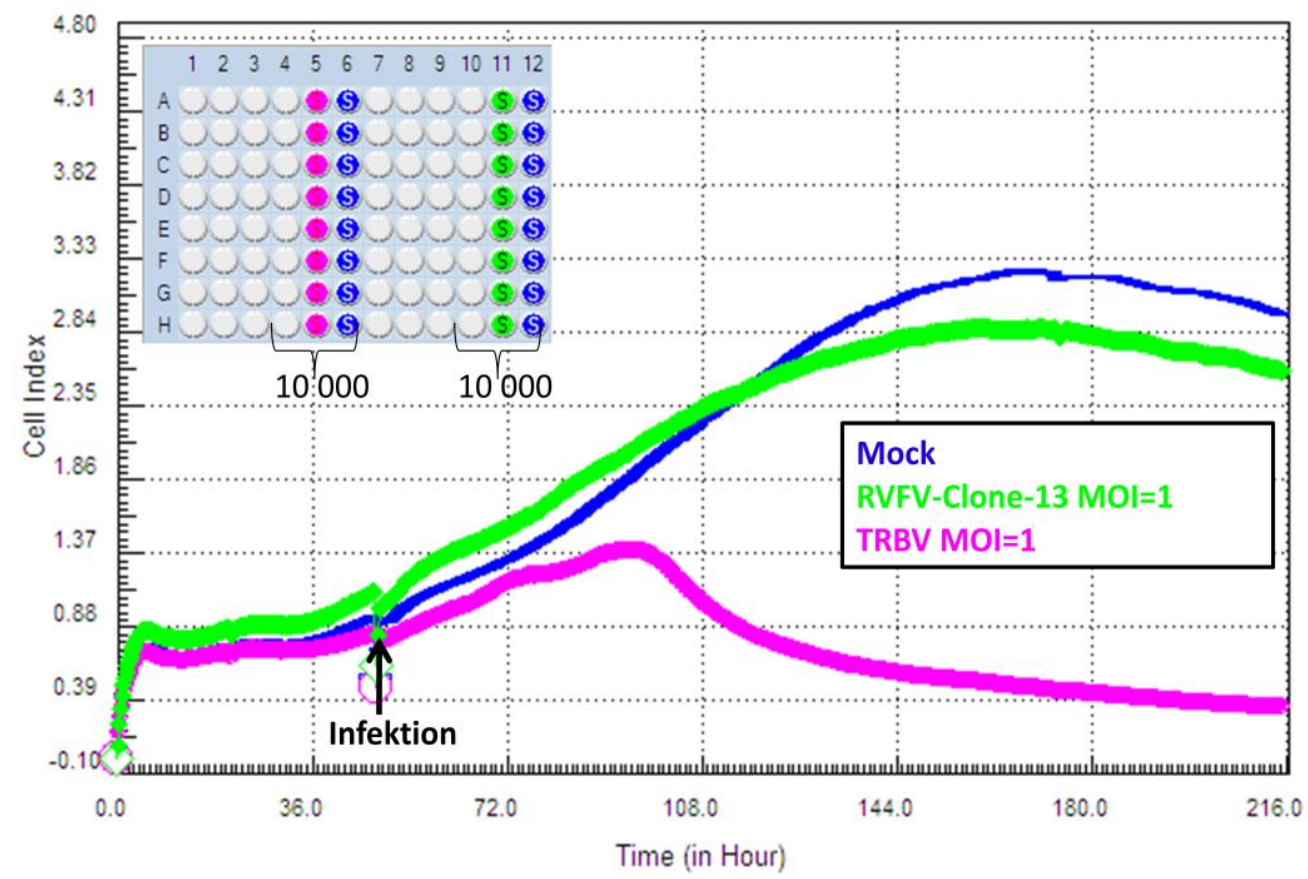

Abbildung 8: PKR+/+ (10 000 Zellen/Kavität), Infektion mit TRBV und RVFV-Clone-13, MOI=1 TCID $_{50}$-Einheiten.

Die Wildtyp-Zellen PKR+/+ wurden in einer Dichte von 10.000 Zellen je Kavität ausgesät und nach zwei Tagen mit TRBV und im Vergleich dazu mit RVFV-Clone-13 mit einer MOI von 1 TCID $_{50}$-Einheiten infiziert (s. Abbildung 8). Nach zwei weiteren Tagen ist bei den TRBV-infizierten Zellen ein deutliches Absinken des Zellindex zu sehen, während die Wachstumskurve der mit RVFV-Clone-13 infizierten Zellen der Kurve der Mock-behandelten Zellen folgt. Es ist also in den interferonkompetenten Wildtypzellen nach TRBV-Infektion mit einer MOI von $1 \mathrm{TCID}_{50}$-Einheiten ein zytopathischer Effekt (CPE) nachzuweisen, während die RVFV-Clone-13-infizierten Zellen sich weitgehend wie nicht infizierte Zellen verhalten. Allerdings bleibt anzumerken, dass bei höherer MOI (von $10 \mathrm{TCID}_{50^{-}}$ Einheiten) im gleichen Experiment auch in den RVFV-Clone-13-infizierten Zellen ein CPE nachgewiesen werden konnte (hier nicht gezeigt). 


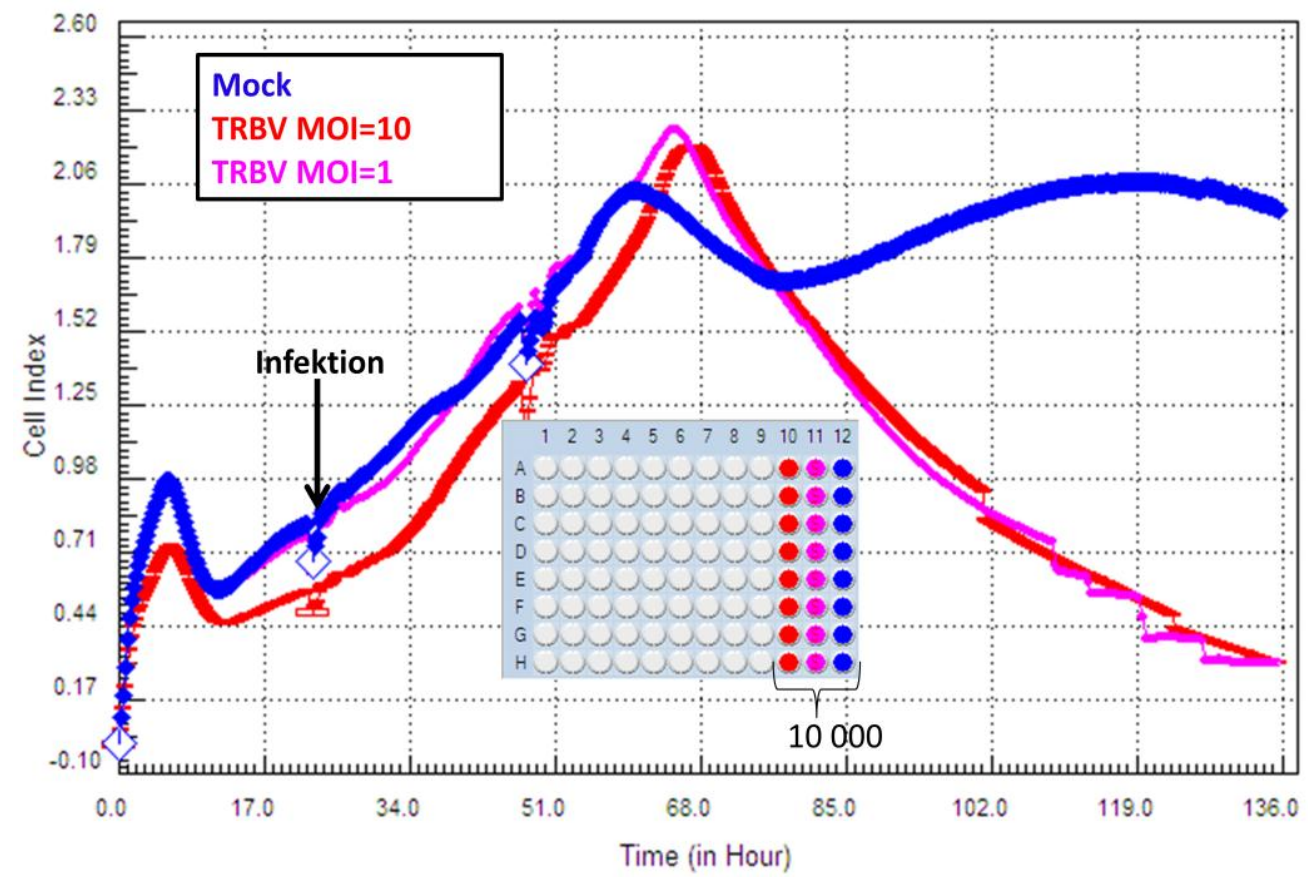

Abbildung 9: IFNAR-/- (10 000/Kavität) mit Tribec-Virus MOI 10 und 1 TCID 50 -Einheiten.

Mit identischen Versuchsbedingungen wurden IFNAR-/- Zellen infiziert. Da diese jedoch wesentlich schneller wachsen, erfolgte hier die Infektion bereits einen Tag nach der Zellaussaat. Im ersten Experiment wurden die Zellen mit TRBV infiziert. Sowohl bei den mit hoher MOI (rote Kurve in Abbildung 9) als auch bei den mit niedriger MOI (magenta in Abbildung 9 dargestellt) infizierten Zellen wird der CPE nach 42 bzw. 44 Stunden sichtbar, nach weiteren 8 Stunden fällt der Zellindex der infizierten Zellen deutlich unter den Zellindex der Mock-behandelten Zellen ab. 


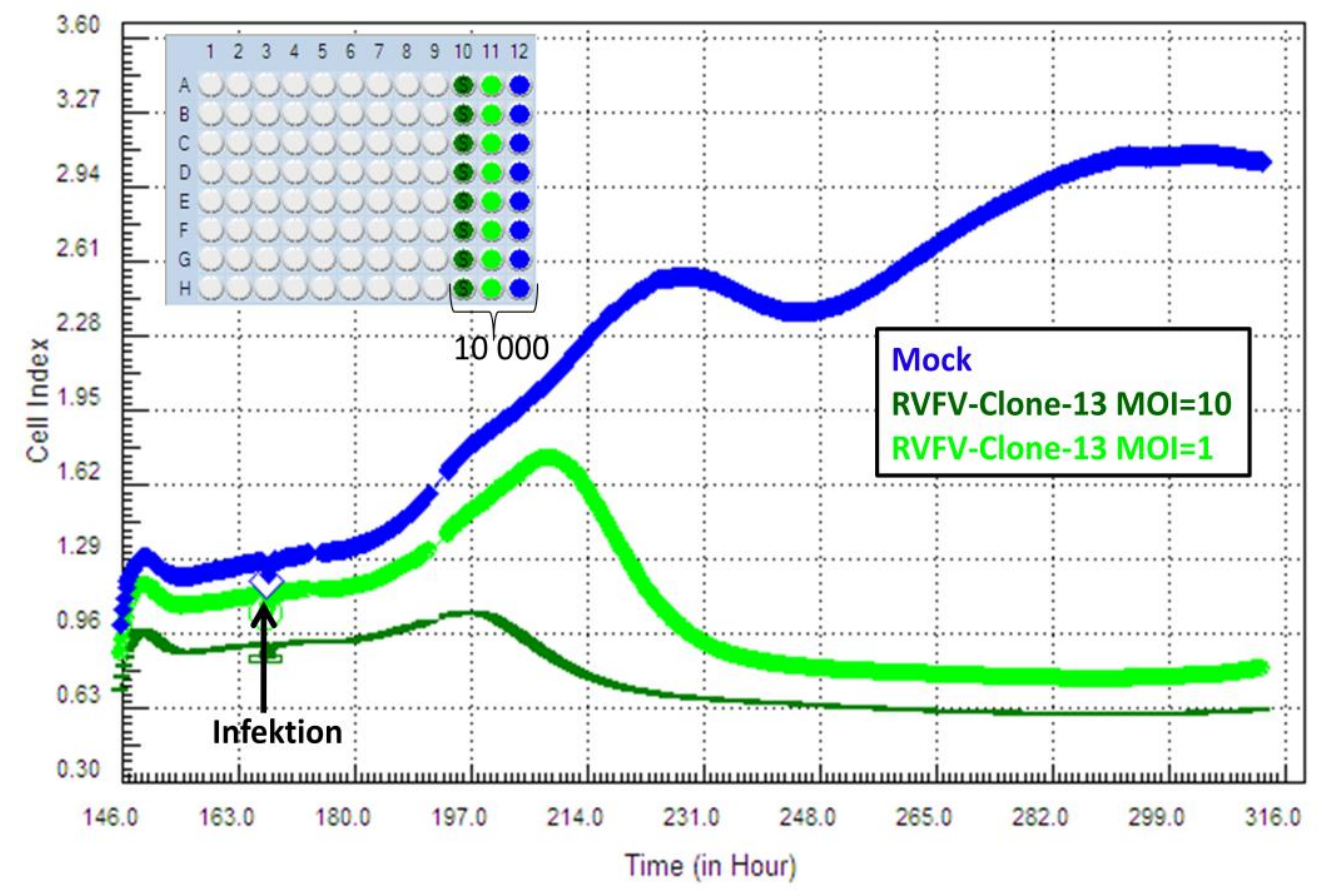

Abbildung 10: IFNAR-/- (10 000/Kavität) mit RVFV-Clone-13, MOI 10 und 1 TCID 50 -Einheiten.

In einem zweiten Experiment wurden die Zellen mit RVFV-Clone-13 infiziert. Da das Gerät nicht neu initialisiert wurde, entspricht die Zeiteinteilung der x-Achse einer Zeitfortführung des vorherigen Experiments, so dass 146 Stunden hier dem Zeitpunkt Null entsprechen (s. Abbildung 10). Die Infektion erfolgte 1 Tag nach Zellaussaat, ein CPE in den mit einer hohen MOI infizierten Zellen (dunkelgrüne Kurve in Abbildung 10) ist bereits nach 32 Stunden sichtbar. Der Zellindex der mit einer niedrigeren MOI infizierten Zellen (hellgrüne Kurve in Abbildung 10) fällt erst 42 Stunden nach Infektion ab.

In Zellen mit inkomplettem Interferonsystem kann demnach selbst bei niedriger Virenlast eine Infektion mit RVFV-Clone-13 nachgewiesen werden, während für eine Infektion der Wildtypzellen eine zehnfach höhere MOI des Interferon stimulierenden Virus notwendig ist. 


\subsubsection{Humane Nierenzellen HEK-293}

Die HEK-293-Zellen entstammen der embryonalen Niere des Menschen und besitzen ein intaktes Interferonsystem.

Wie unter Abschnitt 3.1.1 beschrieben, wurde mittels Impedanzmessung die Wachstumskurve der Zelllinie nach Infektion mit dem zu untersuchenden TRBV im Vergleich zum Interferon stimulierenden RVFV-Clone-13 untersucht. In einem weiteren Experiment wurden die Zellen im Vergleich zur Einzelinfektion mit RVFVClone-13 und TRBV co-infiziert. Hierzu wurden die Zellen in unterschiedlichen Zelldichten auf 96-Well-E-Plates ausgesät und zu verschiedenen Zeitpunkten der Wachstumsphase mit unterschiedlichen MOIs infiziert.

Wie oben ist in der graphischen Darstellung der Messung die Zeit auf der x-Achse, der Zellindex (berechnet aus der gemessenen Impedanz) auf der $\mathrm{y}$-Achse aufgetragen. Die Wachstumskurve der nicht infizierten Zellen (Mock) ist jeweils blau dargestellt. Der Zellindex der mit RVFV-Clone-13 infizierten Zellen ist in Grün- und der der mit TRBV infizierten Zellen in Rottönen (rot in der jeweils höheren MOI, magenta in der niedrigeren MOI) gegen die Zeit aufgetragen. Zu einem Artefakt in den Kurven zum Zeitpunkt der Infektion kommt es durch die kurzzeitige Unterbrechung der Messung und Entnahme der Kulturplatte aus dem Gerät. Im Platten-Schema ist die Auswahl der Kavitäten in den der jeweiligen Kurven entsprechenden Farben gezeigt. Die Kurve entspricht der Darstellung des Mittelwertes der Messung am Boden der jeweils gleich behandelten Kavitäten. 


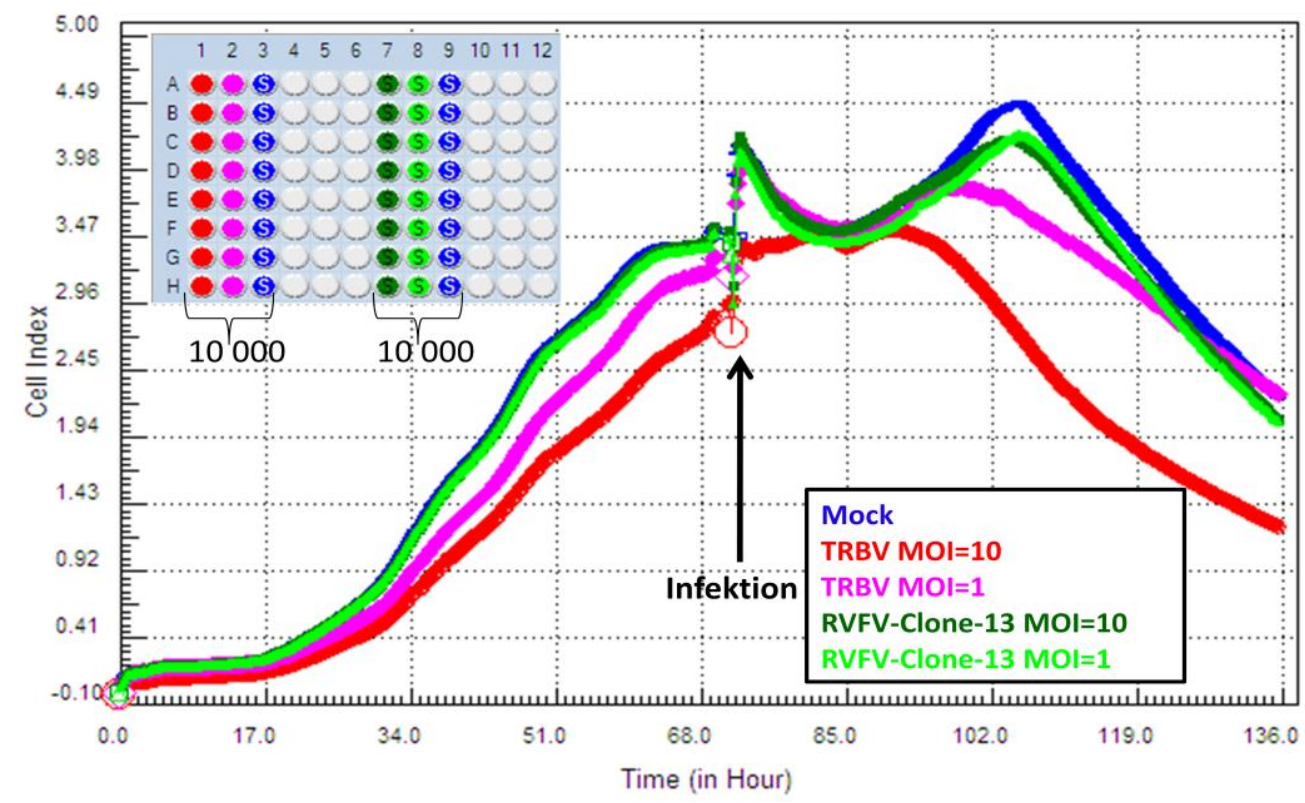

Abbildung 11: HEK-293-Zellen, 10000/Kavität, Infektion mit TRBV und RVFV-Clone-13, MOI=10 und MOI $=1 \mathrm{TCID}_{50}$-Einheiten.

Die HEK-293-Zellen wurden in einer Zelldichte von 10.000 Zellen je Kavität ausgesät und nach 3 Tagen mit einer MOI von 10 bzw. 1 TCID $_{50}$-Einheiten infiziert (s. Abbildung 11). Der Zellindex der RVFV-Clone-13-infizierten Zellen gleicht sowohl in den Kavitäten mit hoher Virenlast (dunkelgrün) als auch in den Kavitäten mit niedriger Virenlast (hellgrün) dem der Mock-behandelten Zellen (blau). In allen Kavitäten kommt es in den ersten 10 Stunden nach Infektion zum Abfall des Zellindex. Anders als die mit RVFV-Clone-13 bzw. Mock-behandelten Zellen erholen sich die mit TRBV infizierten Zellen jedoch nicht, sondern es kommt zu einem weiteren Abfallen des Zellindex, in den Kavitäten mit hoher MOI (rote Kurve) deutlicher zu sehen als in den Kavitäten mit niedriger MOI (Kurve in magenta). 


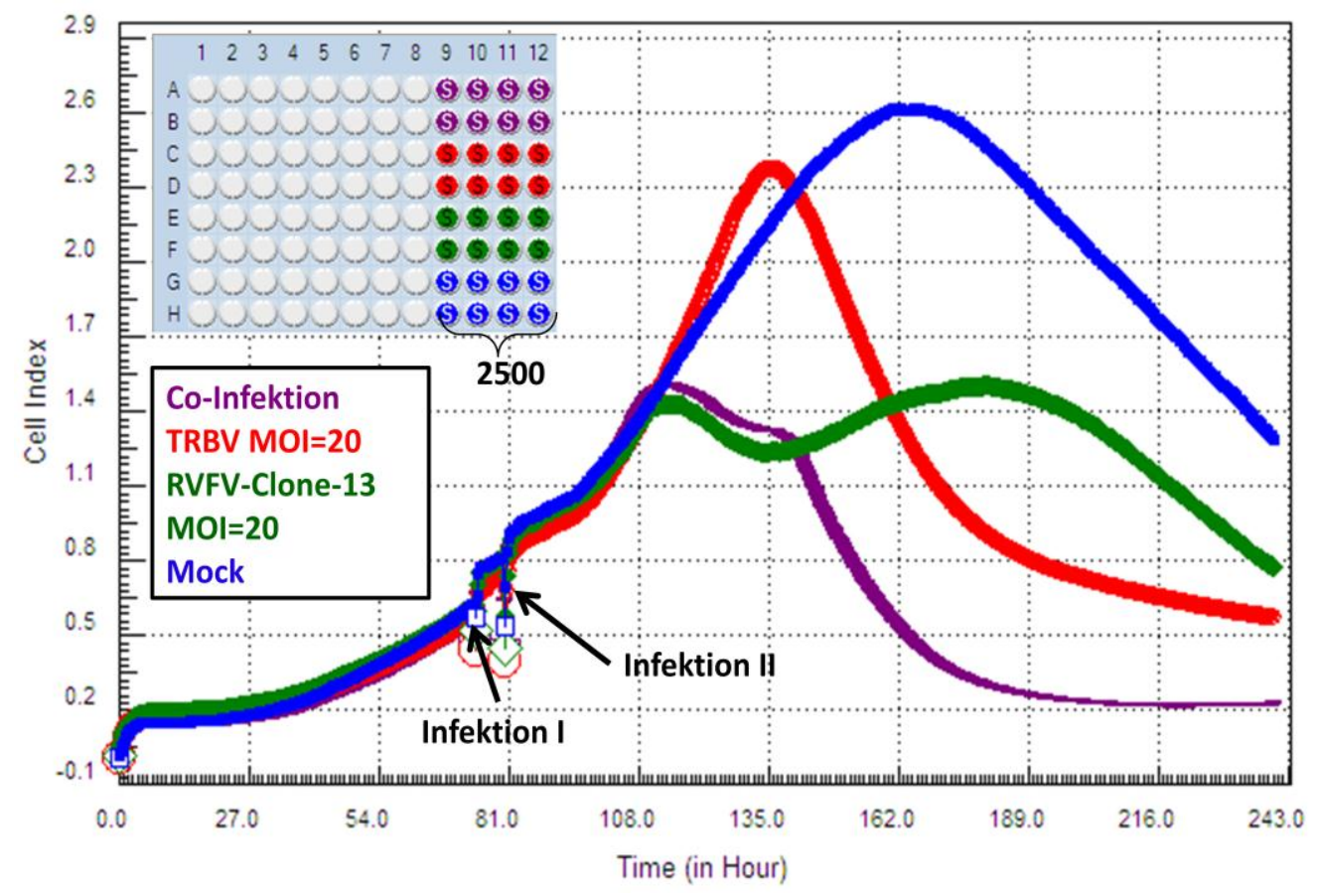

Abbildung 12: HEK-293-Zellen, 2.500/Kavität, Co-Infektion mit TRBV und RVFV-Clone-13, MOI=20 TCID 50 -Einheiten.

In einem weiterem Experiment wurden HEK-293-Zellen mit unterschiedlichen Zelldichten ausgesät und im Vergleich zur Einzelinfektion mit RVFV-Clone-13 und TRBV co-infiziert (s. Abbildung 12). Hierbei erfolgte in einem ersten Schritt die Infektion mit TRBV, 6 Stunden später dann die Infektion mit RVFV-Clone-13. Die jeweils nicht infizierten Zellen wurden wie Mock behandelt, so dass bei beiden Infektionen jeweils alle Kavitäten manipuliert wurden. Die Kavitäten mit einer Zelldichte von 2.500 Zellen je Kavität wurden 3 Tage nach Zellaussaat mit einer MOI von 20 TCID $_{50}$-Einheiten während einer recht frühen Phase des Zellwachstums infiziert. Sowohl die RVFV-Clone-13-infizierten Zellen (dunkelgrüne Kurve) als auch die co-infizierten Zellen (lila Kurve) zeigen 32 Stunden nach der zweiten Infektion (mit RVFV-Clone-13) ein Absinken des Zellindex. Während der Zellindex der RVFVClone-13-infizierten Zellen jedoch einen Tag später wieder leicht ansteigt und die Kurve den Wachstumsverlauf der Mock-behandelten Zellen (blaue Kurve) auf niedrigerem Niveau widerspiegelt, fällt der Zellindex der co-infizierten Zellen weiter ab. Damit spiegelt die Kurve der co-infizierten Zellen ab diesem Zeitpunkt den Kurvenverlauf der mit TRBV behandelten Kavitäten auf niedrigerem Niveau wider. 
Der Viabilitätsindex der TRBV-infizierten Zellen (rot dargestellt) erreicht 63 Stunden nach Infektion das Maximum und fällt daraufhin rapide ab. Zusammenfassend lässt sich sagen, dass die Infektion mit dem Typ-I induzierenden RVFV-Clone-13 die Viabilität der infizierten IFN-kompetenten HEK-293-Zellen weniger beeinträchtigt als eine Infektion mit TRBV. Eine Co-Infektion mit TRBV und RVFV-Clone-13 weist die stärkste Zytopathogenität auf. Die erhaltenen Ergebnisse erlauben die Hypothese, dass TRBV in der Lage ist, das antiviral wirksame Typ-I-IFN-System zu hemmen.

\subsection{IFN- $\beta$-Induktion nach TRBV-Infektion}

Um Aufschluss darüber zu erhalten, ob eine Infektion mit TRBV zur Induktion von Typ-I-IFNs führt, wurde mittels RT-PCR die IFN- $\beta$-Induktion als antivirale Reaktion in HEK-293-Zellen untersucht. Hierzu wurden die Zellen in $25 \mathrm{~cm}^{2}$ Gewebekulturflaschen in einer Dichte von $5 \times 10^{5}$ Zellen pro Flasche ausgesät. Nach einem Tag Wachstum wurden sie mit einer MOI von 0,5 TCID ${ }_{50}$-Einheiten mit dem das Interferonsystem induzierenden RVFV-Clone-13 und mit einer MOI von 1 TCID $_{50}$-Einheiten mit TRBV infiziert. Wie unter Abschnitt 2.4.4, S. 36 und 2.4.5, S. 38 beschrieben, wurden die Zellen mittels RT-PCR auf die Induktion des IFN- $\beta$ Gens untersucht. Die Abbildungen der Gele nach Elektrophorese sind so angeordnet, dass die Laufrichtung der Proben von oben nach unten verläuft und jeweils links der Proben ein DNA-Größenstandard aufgetragen ist. Die als Mock bezeichneten Zellen wurden mit Medium ohne Virus behandelt. In der PCR wurde eine Probe ohne DNA als Kontaminationskontrolle $\left(\mathrm{H}_{2} \mathrm{O}\right)$ eingesetzt. 


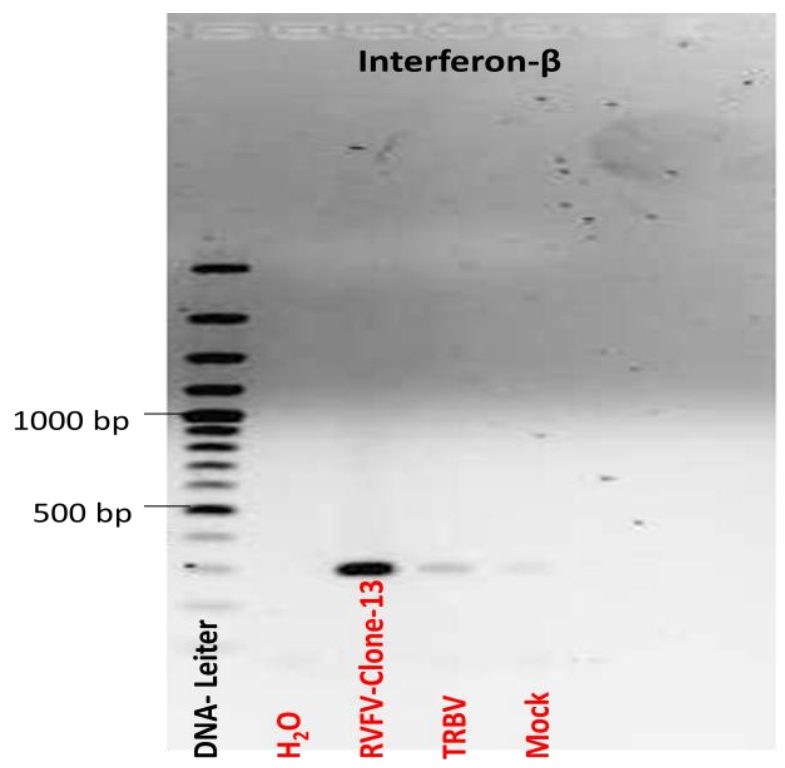

Abbildung 13: IFN- $\beta$-Induktion von RVFV-Clone-13 und TRBV in HEK-293-Zellen.

In der Gelelektrophorese (s. Abbildung 13) zeigt sich nach der IFN- $\beta$-spezifischen RT-PCR nur in dem mit RVFV-Clone-13 infizierten Ansatz ein deutliches Signal. Das Interferonsignal nach TRBV-Infektion ist wesentlich schwächer, obwohl die Viruslast hier doppelt so hoch war wie bei der RVFV-Clone-13-Infektion. Damit konnte gezeigt werden, dass eine TRBV-Infektion in der untersuchten Zelllinie offensichtlich eine nur sehr geringe IFN- $\beta$-Expression aktiviert.

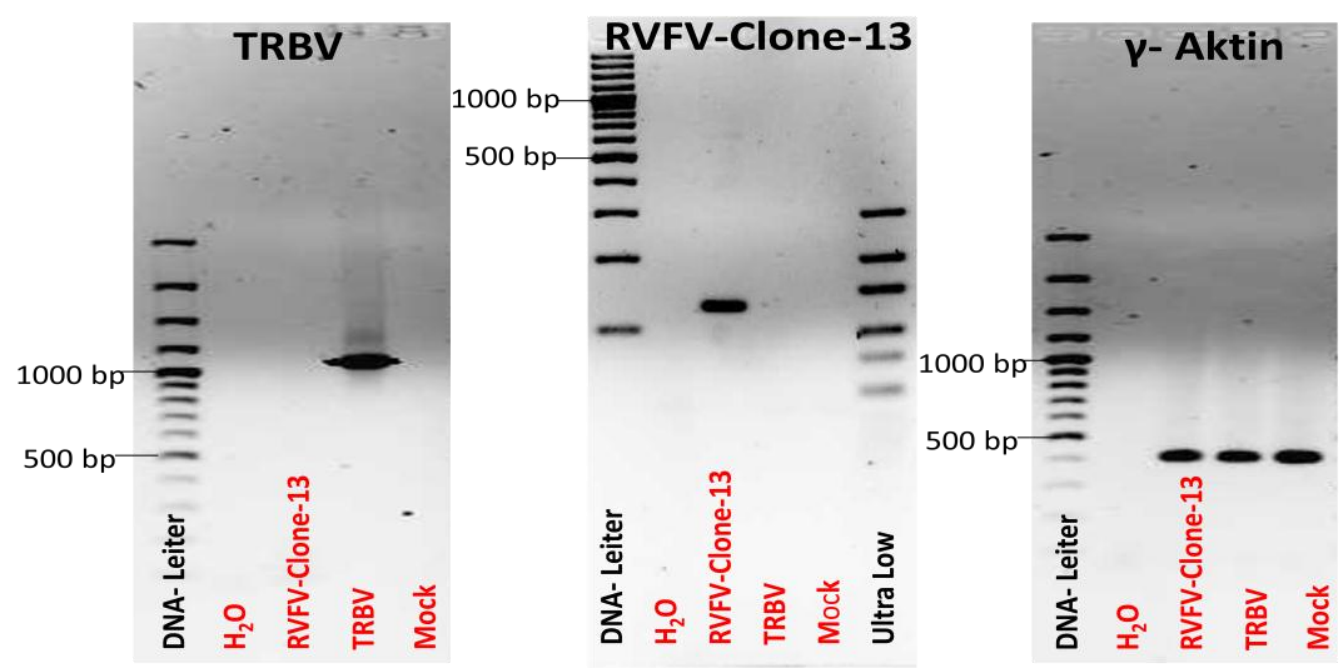

Abbildung 14: IFN- $\beta$-Induktion von RVFV-Clone-13 und TRBV in HEK-293-Zellen, Kontrolle der Virusinfektion mit TRBV und RVFV-Clone-13, interne Standardkontrolle mit $\gamma$-Aktin. 
Um auszuschließen, dass die beobachteten Unterschiede bezüglich der IFN- $\beta$ Expression auf eine fehlende Virusreplikation bzw. unterschiedliche Mengen an eingesetzter RNA zurückzuführen sind, wurden RT-PCRs zum Nachweis von TRBV- bzw. RVFV-Clone-13-spezifischen Transkripten sowie der Nachweis zellulärer $\gamma$-Aktin- Transkripte als Kontrollen durchgeführt. Die Kontrolle der Virusinfektion fiel sowohl bei der TRBV-spezifischen PCR (s. Abbildung 14 links) als auch bei der RVFV-Clone-13-spezifischen PCR (s. Abbildung 14 Mitte) positiv aus. Die $\gamma$-Aktin-spezifische PCR als interne Kontrolle (s. Abbildung 14 rechts) ergab in der Gelelektrophorese in allen Proben vergleichbar starke Banden. Die nur sehr geringe IFN- $\beta$-Transkription in dem mit TRBV infizierten Ansatz ist somit eine Folge der Virusinfektion und damit als eventueller Pathogenitätsfaktor von TRBV zu sehen.

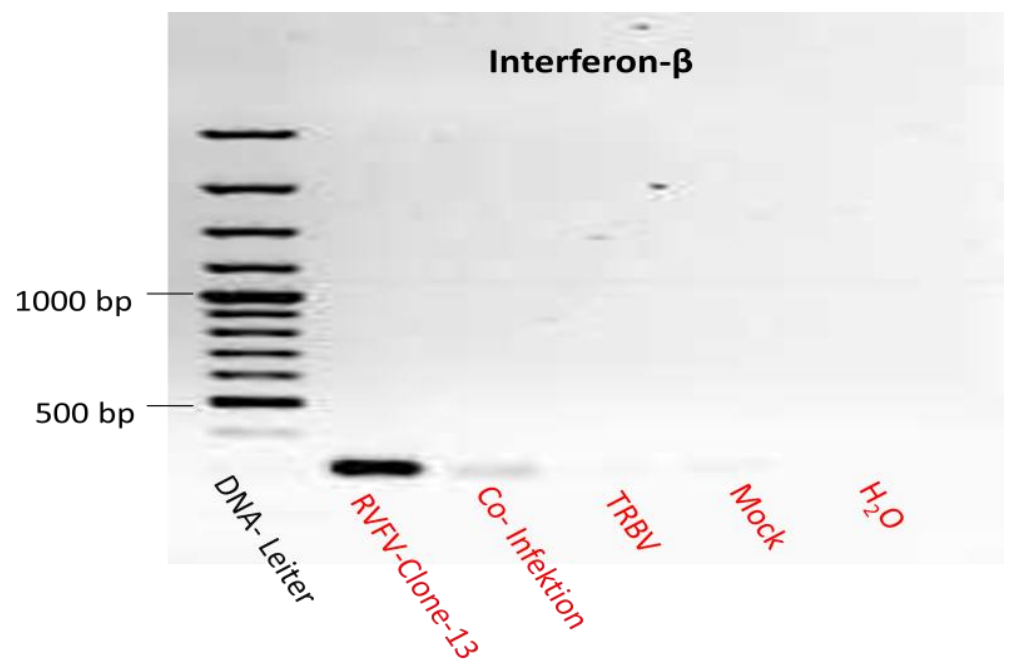

Abbildung 15: IFN-Induktion durch Co-Infektion mit RVFV-Clone-13 und TRBV in HEK-293Zellen.

Um zu untersuchen, ob die fehlende Aktivierung der IFN- $\beta$-Expression nach TRBVInfektion eine aktive Inhibition der IFN- $\beta$-Induktion darstellt, wurden CoInfektionsexperimente mit dem IFN- $\beta$ induzierenden RVFV-Clone-13 durchgeführt. Zu diesem Zweck wurden HEK-293-Zellen mit einer Zelldichte von $5 \times 10^{5}$ Zellen in $25 \mathrm{~cm}^{2}$-Gewebekulturflaschen ausgesät und nach einem Tag Zellwachstum mit 
RVFV-Clone-13 und TRBV co-infiziert. Hierbei erfolgte in einem ersten Schritt die Infektion mit TRBV, 6 Stunden später die Infektion mit RVFV-Clone-13. In der Gelelektrophorese nach RT-PCR zeigt sich wie erwartet eine deutliche Interferon- $\beta$ Bande nach RVFV-Clone-13-Infektion, jedoch eine wesentlich schwächere Bande nach Co-Infektion und kein Signal für Interferon- $\beta$ nach TRBV-Infektion (s. Abbildung 15).
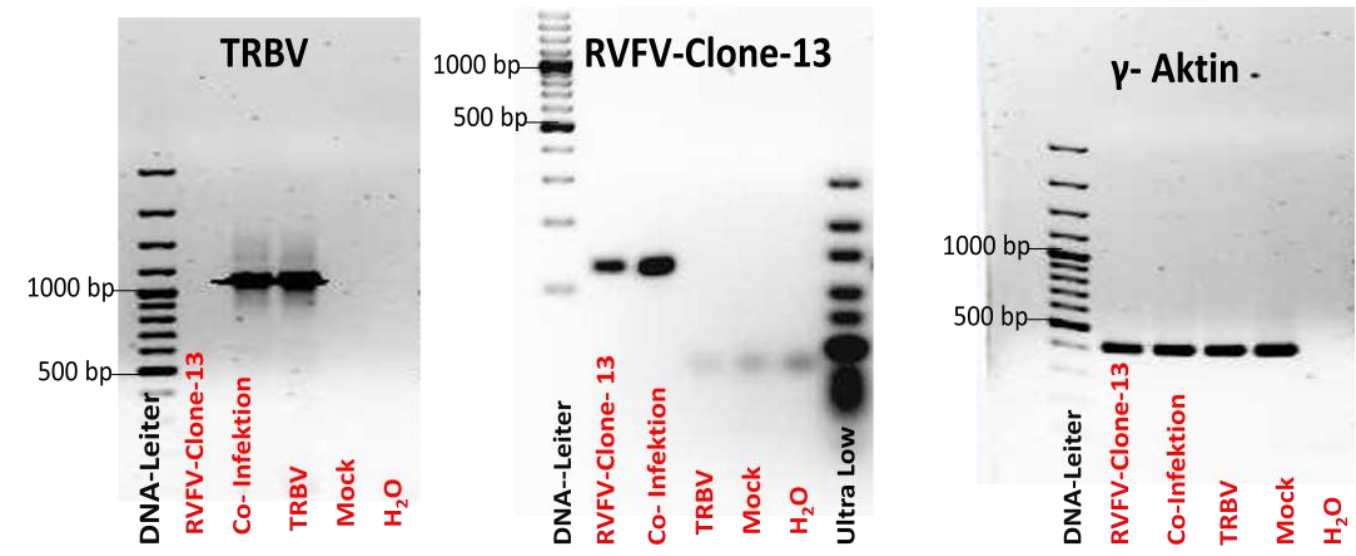

Abbildung 16: Co-Infektion mit RVFV-Clone-13 und TRBV in HEK-293-Zellen, Kontrolle der Virusinfektion mit RVFV-Clone-13 und TRBV, interne Standardkontrolle mit $\gamma$-Aktin.

Zusätzlich wurde virusspezifische RT-PCRs durchgeführt, um auszuschließen, dass die beobachteten Unterschiede bezüglich der Aktivierung der IFN- $\beta$-Expression auf Unterschiede in der Virusreplikation zurückzuführen sind. Die TRBV-spezifischen Banden sind als Nachweis der TRBV-Infektion in den co-infizierten wie auch in den mit TRBV infizierten Zellen deutlich zu sehen (s. Abbildung 16 links). Die RVFVspezifische Bande fällt nach Co-Infektion sogar stärker aus als in der Einzelinfektion mit RVFV-Clone-13 (s. Abbildung 16 Mitte), da das Virus nach Co-Infektion offensichtlich besser replizieren konnte. Die $\gamma$-Aktin-spezifische PCR (s. Abbildung 16 rechts) ergibt in der Gelelektrophorese in allen Proben vergleichbar starke Banden, damit ist auszuschließen, dass die beobachteten Unterschiede auf unterschiedliche Probenmengen zurückzuführen sind. Diese Ergebnisse lassen den Rückschluss auf eine aktive Inhibition der IFN- $\beta$-Expression in mit TRBV infizierten Zellen zu, da TRBV die durch RVFV-Clone-13 induzierte IFN- $\beta$ Expression weitgehend unterdrückt. 


\subsection{Dual-Luciferase-Reporter-Assays}

\subsubsection{IFN- $\beta$-Promotoraktivität nach Infektion und Stimulation mit RNA VSV-infizierter Vero-E6-Zellen}

Die im vorangegangenen Abschnitt beschriebenen Experimente ergaben, dass es nach Infektion mit TRBV nicht zu einer effizienten Aktivierung der IFN- $\beta$ Expression kommt. Um Aufschluss darüber zu erhalten, ob TRBV tatsächlich die Aktivierung des IFN- $\beta$-Promotors hemmen kann, wurde ein Dual-LuciferaseReporter-Assay mit HEK-293-Zellen durchgeführt. Als Positivkontrolle wurde die IFN- $\beta$-Promotoraktivität nach Infektion mit dem Interferon stimulierenden RVFVClone-13 gemessen. Zusätzlich wurde das Interferonsystem der Zellen 26 Stunden nach der Infektion durch Transfektion mit RNA VSV-infizierter Vero-E6-Zellen stimuliert, bzw. zum Vergleich mit RNA nicht infizierter Vero-E6-Zellen transfiziert. Das Experiment wurde fünffach durchgeführt und die Einzelwerte für die FireflyLuciferase-Aktivität mit den Einzelwerten der normalisierten Renilla-LuciferaseAktivität korrigiert. Im Balkendiagramm (s. Abbildung 17) ist der Mittelwert dieser korrigierten Firefly-Luciferase-Aktivitäten in relativen Einheiten dargestellt. Durch die Kopplung der Firefly-Luciferase an den IFN- $\beta$-Promotor ist deren Aktivität proportional zum Aktivitätsgrad des Promotors.

Um zu überprüfen, ob die Stimulation mit RNA VSV-infizierter Vero-E6-Zellen zu einer signifikanten Aktivierung des IFN- $\beta$-Promotors führt, wurde für die nicht infizierten Zellen der Unterschied zwischen der mit zellulärer RNA transfizierten und der mit RNA VSV-infizierter Vero-E6-Zellen stimulierten Probe mit dem Zweistichproben-t-Test unter der Annahme unterschiedlicher Varianzen berechnet. Mit $\mathrm{p}=0,02$ ist dieser Unterschied signifikant, die Stimulation daher effektiv (s. Abbildung 17, rechts außen). 


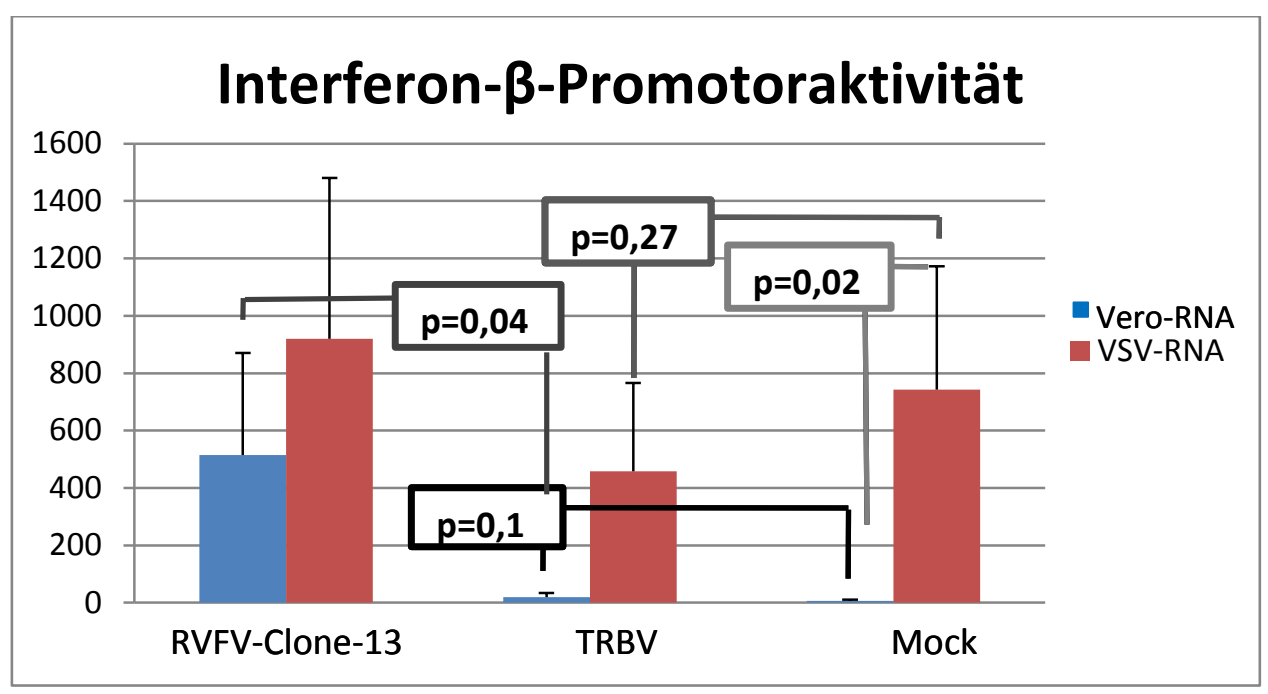

Abbildung 17: Korrigierte Interferon- $\beta$-Promotoraktivität nach Infektion und Stimulation mit RNA VSV-infizierter Vero-E6-Zellen, MW aus fünf Versuchen.

Die mit RVFV-Clone-13 infizierten Zellen zeigen bereits ohne Stimulation eine sehr deutliche Aktivierung des IFN- $\beta$-Promotors (s. Abbildung 17 links blauer Balken), trotzdem steigt die Aktivität nach Stimulation noch einmal um das 1,8fache (s. Abbildung 17 links roter Balken; Abbildung 18 links). Die Aktivierung des IFN- $\beta$ Promotors in den mit TRBV infizierten Zellen (s. Abbildung 17, Mitte, blauer Balken) ist gering. Im Vergleich zur Promotoraktivierung der Mock-infizierten Zellen (s. Abbildung 17 rechts blauer Balken) ist kein signifikanter Unterschied festzustellen $(\mathrm{p}=0,1)$, während der Vergleich zu den mit RVFV-Clone-13 infizierten und mit RNA nicht infizierter Verozellen transfizierten Zellen (blauer Balken links in Abbildung 17) einen signifikanten Unterschied zeigt $(\mathrm{p}=0,04)$. Nach Stimulation mit RNA VSVinfizierter Vero-E6-Zellen ist die Aktivität in den mit TRBV behandelten Proben (s. Abbildung 17 roter Balken, Mitte) niedriger als in den nicht infizierten Zellen (s. Abbildung 17 roter Balken, rechts), ein signifikanter Unterschied ist jedoch aufgrund der hohen Standardabweichungen nicht festzustellen $(p=0,27)$. 


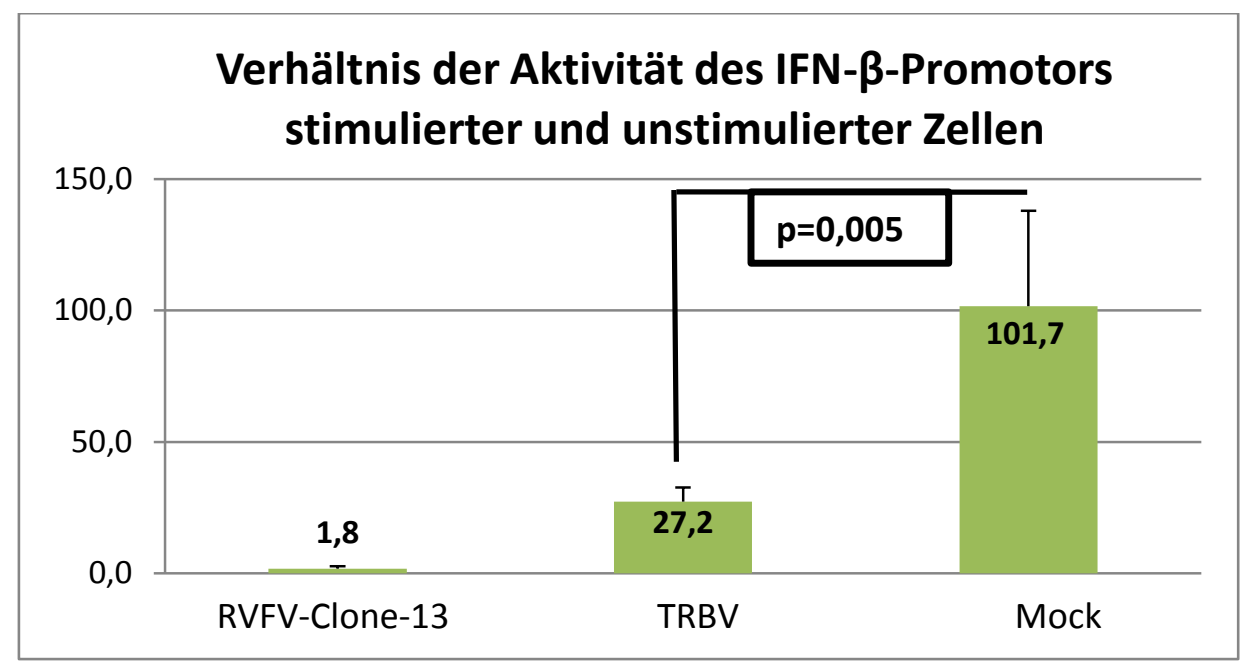

Abbildung 18: Verhältnis der Aktivität des IFN- $\beta$-Promotors stimulierter und unstimulierter Zellen nach Infektion und Stimulation mit RNA VSV-infizierter Vero-E6-Zellen, MW aus fünf Versuchen.

Der Anstieg der Aktivität wurde für jedes Einzelexperiment errechnet, dargestellt ist der Mittelwert aller Anstiegsberechnungen (s. Abbildung 18). Während die Aktivität des IFN- $\beta$-Promotors der nicht infizierten Zellen um mehr als das Hundertfache ansteigt, fällt der Anstieg in den TRBV-infizierten Zellen mit 27,2 wesentlich geringer aus. Dieser Unterschied ist nach Berechnung des Zweistichproben-t-Tests unter der Annahme unterschiedlicher Varianzen mit $\mathrm{p}=0,005 \mathrm{sehr}$ signifikant $(\mathrm{p} \leq 0,01)$.

\subsubsection{IFN- $\beta$-Promotoraktivität nach Infektion und Stimulation mit poly(I:C)}

Wie im vorherigen Experiment wurden Dual-Luciferase-Reporter-Assays mit HEK293-Zellen durchgeführt und die Promotoraktivität des IFN- $\beta$-Gens nach Infektion mit TRBV gemessen. Hier erfolgte die Stimulation mit der synthetischen Substanz Polyinositolcytidinsäure (poly(I:C), entspricht dsRNA). Zum Vergleich wurden Zellen mit RNA nicht infizierter Vero-E6-Zellen transfiziert. Das Experiment wurde $12 \mathrm{Mal}$ durchgeführt. 


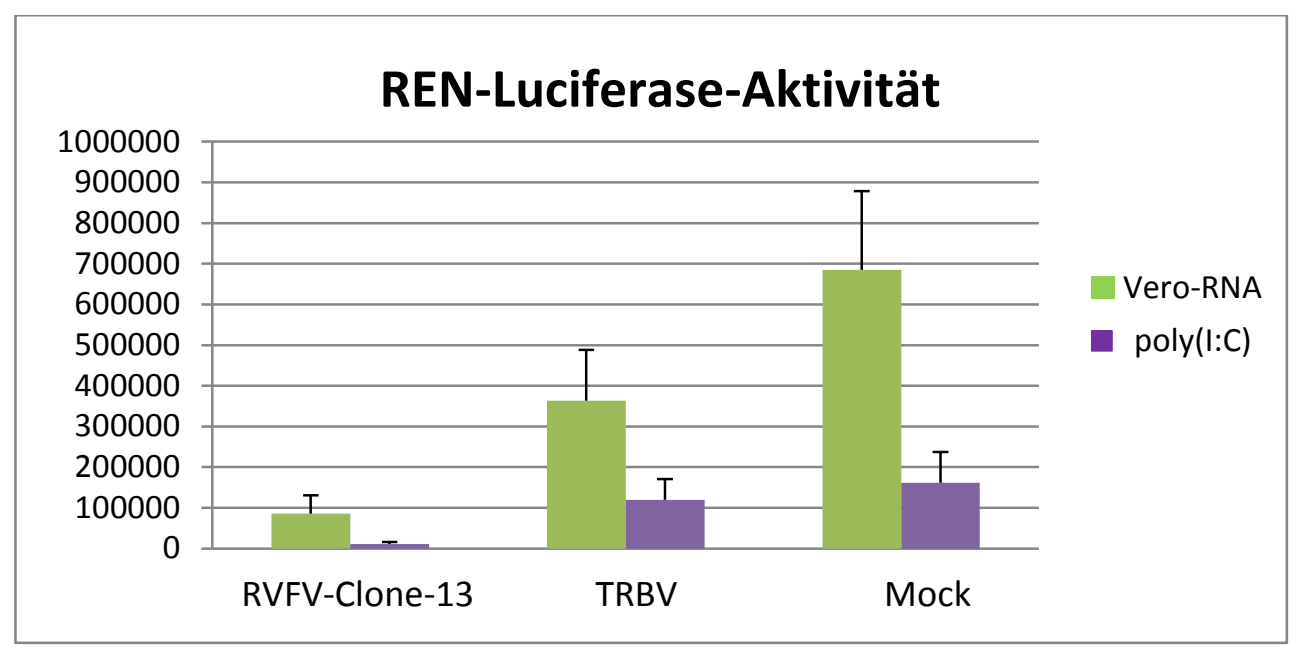

Abbildung 19: Renilla-Luciferase-Aktivität nach Infektion mit TRBV bzw. RVFV-Clone-13 und Stimulation mit poly(I:C), MW aus 12 Versuchen.

Da die Werte der Renilla-Luciferase-Aktivität für die RVFV-Clone-13 behandelten Zellen im Vergleich zu den Werten der anderen Proben extrem gering waren, konnten die Ergebnisse dieser Messung zur Korrektur der Firefly-LuciferaseAktivitäten nicht verwertet werden (s. Abbildung 19). Die Einzelwerte für die FireflyLuciferase-Aktivität wurden daher nicht mit der normalisierten Renilla-LuciferaseAktivität korrigiert. Im Balkendiagramm (Abbildung 20) ist der Mittelwert der Firefly-Luciferase-Aktivitäten in relativen Einheiten dargestellt. Durch die Kopplung der Firefly-Luciferase-cDNA an den IFN- $\beta$-Promotor ist die Aktivität der FireflyLuciferase proportional zum Aktivitätsgrad des Promotors.

Als Kontrolle der Stimulation mit poly(I:C) wurde für die Mock-infizierten Zellen der Unterschied zwischen der mit zellulärer Vero-RNA transfizierten und der mit poly(I:C) stimulierten Probe mit dem Zweistichproben-t-Test unter der Annahme unterschiedlicher Varianzen berechnet. Mit $\mathrm{p}=0,00008$ ist dieser Unterschied hoch signifikant $(p \leq 0,001)$, die Stimulation daher als effektiv zu bewerten (s. Abbildung 20 , rechts außen). 


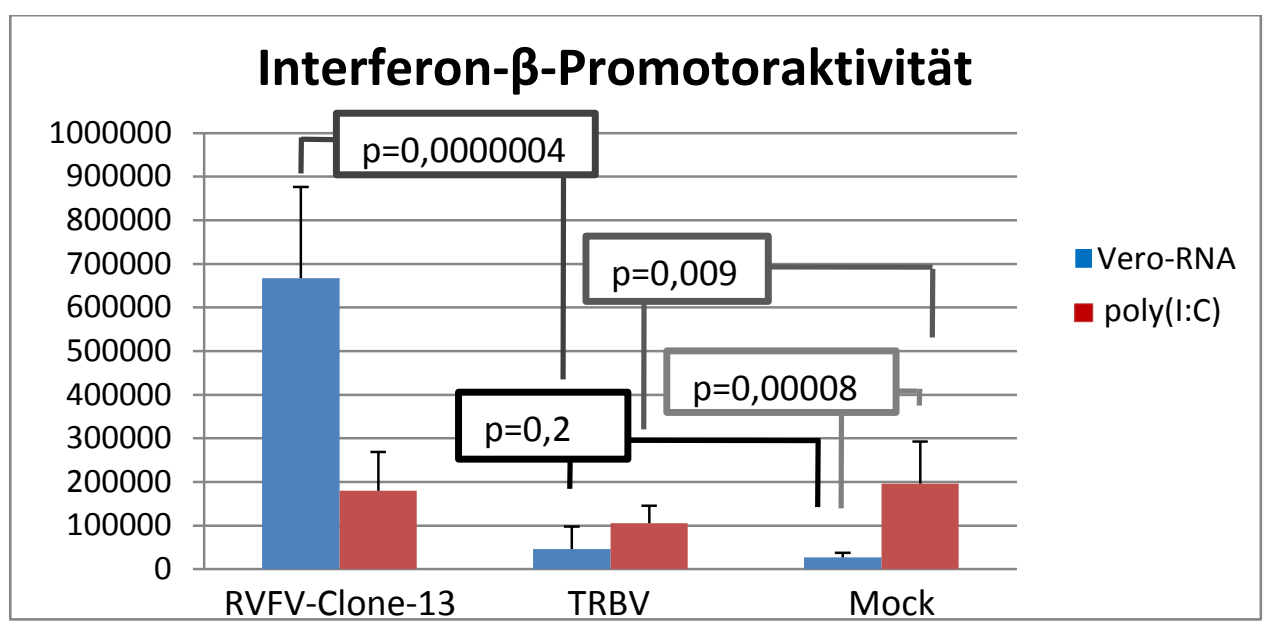

Abbildung 20: IFN- $\beta$-Promotoraktivität nach Infektion und Stimulation mit poly(I:C), MW aus 12 Versuchen.

Wie schon im vorherigen Versuch zeigen die mit RVFV-Clone-13 infizierten Zellen bereits ohne Stimulation eine sehr deutliche Aktivierung des IFN- $\beta$-Promotors (s. Abbildung 20 links, blauer Balken), die Aktivität ist durch die Stimulation nicht weiter zu steigern (s. Abbildung 20 links, roter Balken; Abbildung 21 links). Die Aktivierung des IFN- $\beta$-Promotors in den mit TRBV infizierten Zellen (s. Abbildung 20, Mitte, blauer Balken) ist eher gering, im Vergleich zur Promotoraktivierung der Mock-infizierten Zellen (s. Abbildung 20 rechts blauer Balken) ist kein signifikanter Unterschied festzustellen ( $\mathrm{p}=0,2)$, während der Unterschied zur Promotoraktivierung durch den IFN-induzierenden RVFV-Clone-13 mit $\mathrm{p}=4 \times 10^{-7}$ hoch signifikant ist $(\mathrm{p} \leq 0,001)$. Nach Stimulation mit RNA VSV-infizierter Vero-E6-Zellen ist die Aktivität in den mit TRBV behandelten Proben (s. Abbildung 20 roter Balken, Mitte) mit $p=0,009$ sehr signifikant niedriger $(p \leq 0,01)$ als in den nicht infizierten Zellen (s. Abbildung 20 roter Balken, rechts). 


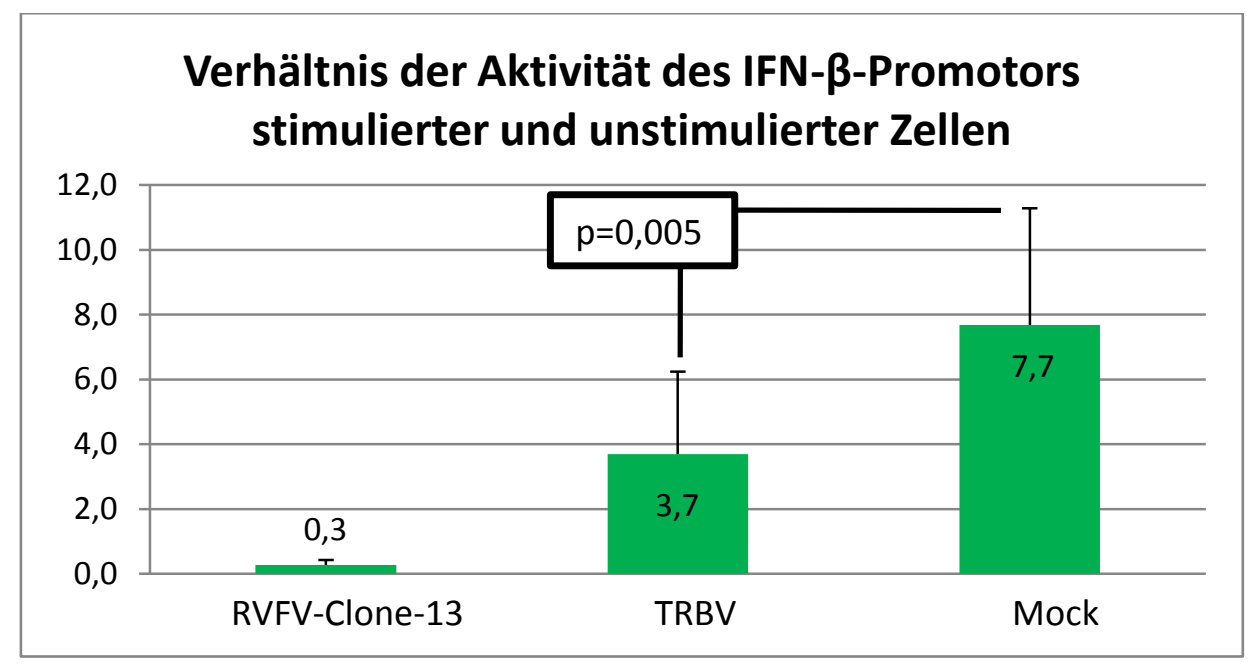

Abbildung 21: Verhältnis der Aktivität des IFN- $\beta$-Promotors stimulierter und unstimulierter Zellen nach Infektion und Stimulation mit poly(I:C), MW aus 12 Versuchen.

Auch hier wurde der Anstieg der Aktivität für jedes Einzelexperiment errechnet, dargestellt ist der Mittelwert aller Anstiegsberechnungen (s. Abbildung 21). Während die Aktivität des Interferon- $\beta$-Promotors der nicht infizierten Zellen um mehr als das Siebenfache ansteigt, fällt der Anstieg in den TRBV-infizierten Zellen mit 3,7 wesentlich geringer aus. Dieser Unterschied ist nach Berechnung des Zweistichproben-t-Tests unter der Annahme unterschiedlicher Varianzen mit $\mathrm{p}=0,005$ sehr signifikant $(\mathrm{p} \leq 0,01)$.

\subsubsection{Einfluss von TRBV-Genprodukten auf die Aktivität des humanen IFN- $\beta$-Promotors}

In einer Reihe weiterer Experimente wurde ein Dual-Luciferase-Reporter-Assay mit HEK-293-Zellen nach Transfektion von Expressionsplasmiden für einzelne TRBVGene durchgeführt. Hierzu wurden die Zellen mit Expressionsplasmiden für das virale Nichtstrukturprotein NS-2 (Segment 7, TRBV-S7) oder die virale Helikase (Segment 9, TRBV-S9, mit ORF-Xa- Region) transfiziert, oder mit beiden Expressionsplasmiden co-transfiziert. Als Kontrolle wurde gleichzeitig die Promotoraktivität nach Transfektion mit pI.18-FDMx gemessen. Es handelt sich hierbei um ein trunkiertes (funktionsloses) Mx-Protein im eukaryontischen 
Expressions-Vektor pI.18, welches keinen Einfluss auf die Aktivierung des IFN- $\beta$ Promotors hat.

Zur Aktivierung des IFN- $\beta$-Promotors wurden die Zellen mit RNA VSV-infizierter Vero-E6-Zellen transfiziert. Zum Vergleich erfolgte eine Transfektion mit RNA nicht infizierter Zellen, hier sollte keine Aktivierung des IFN- $\beta$-Promotors erfolgen. Die Daten der Firefly-Luciferase-Aktivität wurden nicht mit der Renilla-LuciferaseAktivität korrigiert, da die Messung der Renilla-Luciferase-Aktivität nicht zu verwerten war. Offensichtlich haben die exprimierten Gene des Tribec-Virus in ihrer transfizierten Form einen Einfluss auf die SV40-Promotor-vermittelte Expression der Renilla-Luciferase, wodurch die Messung der Renilla-Luciferase-Aktivität nicht mehr proportional zur Zahl der transfizierten Zellen ist. Daher wurde in allen weiteren Transfektionsexperimenten auf eine Korrektur mit der Renilla-LuciferaseAktivität verzichtet und nur die Messung der Firefly-Luciferase verwendet.

\subsubsection{Messung der IFN- $\beta$-Promotoraktivität nach Transfektion von Expressionsplasmiden für TRBV-Gene und Stimulation mit RNA VSV-infizierter Vero-E6-Zellen}

Um die Promotoraktivität des IFN- $\beta$-Gens zu messen wurden die Zellen 24 Stunden nach Transfektion der Expressionsplasmide für TRBV-Gene und der Reporterkonstrukte mit RNA VSV-infizierter Vero-E6-Zellen stimuliert, bzw. mit RNA nicht infizierter Vero-E6-Zellen transfiziert. Nach weiteren 16 Stunden wurden die Zellen lysiert und der Reporter-Assay durchgeführt.

Die Mittelwerte der Firefly-Luciferase-Aktivität aus sieben durchgeführten Experimenten sind in Abbildung 22 in relativen Einheiten dargestellt. Der Anstieg der Aktivität durch die Stimulation wurde für jedes Einzelexperiment errechnet, die Mittelwerte aller Anstiegsberechnungen sind in Abbildung 23 dargestellt.

Als Kontrolle der Stimulation mit RNA VSV-infizierter Verozellen wurde für die pI.18-FDMx-transfizierten Zellen der Unterschied zwischen der nicht stimulierten und der stimulierten Probe mit dem Zweistichproben-t-Test unter der Annahme unterschiedlicher Varianzen berechnet. Mit $\mathrm{p}=0,002$ ist dieser Unterschied sehr signifikant ( $\mathrm{p} \leq 0,01)$, die Stimulation daher effektiv (s. Abbildung 22, rechts außen). 


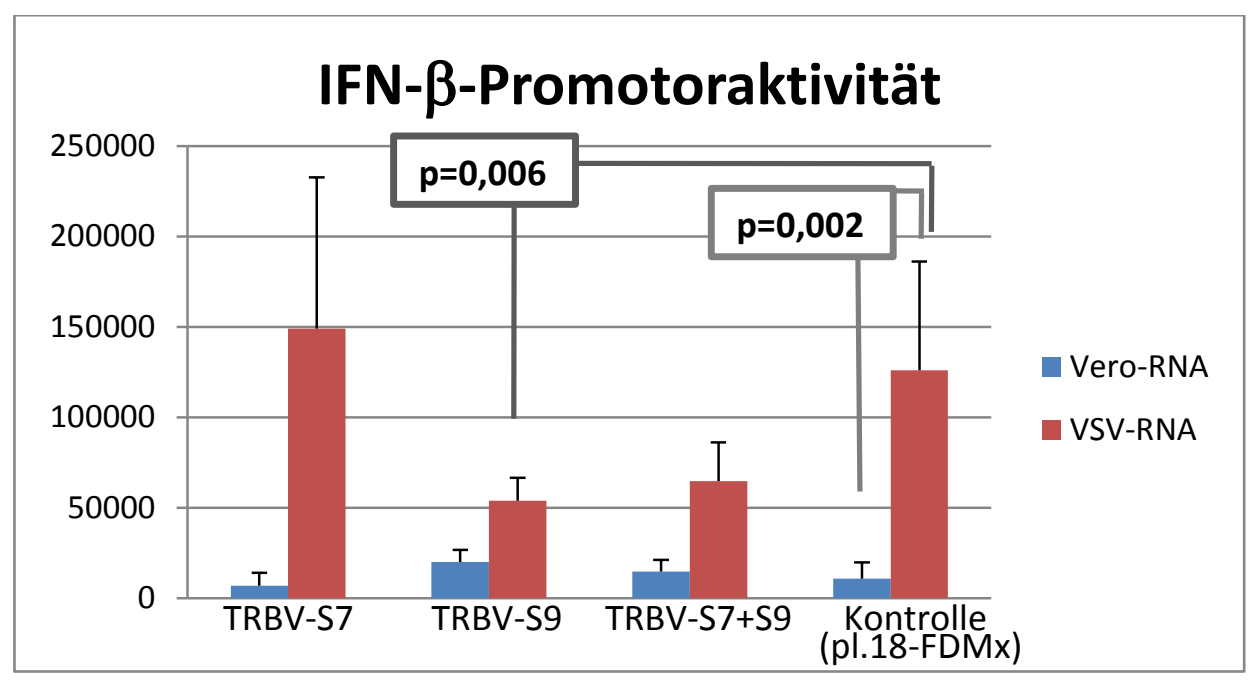

Abbildung 22: Messung der Interferon- $\beta$-Promotoraktivität mittels FF-Luc nach Transfektion mit Expressionsplasmiden für NS-2 (TRBV-S7) und Helikase (TRBV-S9 mit ORF-Xa-Region) bzw. deren Co-Transfektion (TRBV-S7+S9) und Stimulation mit RNA VSV-infizierter Verozellen, MW aus sieben Versuchen.

Ähnlich wie in der Kontrolle mit pI.18-FDMx (s. Abbildung 22, rechts außen) fällt das Ergebnis für die Promotoraktivität nach Transfektion mit TRBV-S7 (Expressionsplasmid für TRBV-NS-2) aus. Die allein mit TRBV-S7 transfizierten Zellen zeigen ohne Stimulation eine geringe Aktivierung des IFN- $\beta$-Promotors (s. Abbildung 22, links außen, blauer Balken), nach Stimulation steigt die Aktivität deutlich an (s. Abbildung 22, links außen, roter Balken; Abbildung 23 links). Die Aktivität des IFN- $\beta$-Promotors nach Transfektion von TRBV-S9 (Expressionsplasmid für TRBV-Helikase/ ORF-Xa, s. Abbildung 22, Mitte links, blauer Balken) ist etwas höher als die Promotoraktivität der Kontrolle (s. Abbildung 22 rechts außen, blauer Balken), ebenso in den mit TRBV-S7 co-transfizierten Zellen (s. Abbildung 22, Mitte rechts, blauer Balken). Nach der Stimulation mit RNA VSVinfizierter Verozellen ist die Aktivität in den mit TRBV-S9 transfizierten Proben (s. Abbildung 22, Mitte links, roter Balken) mit $\mathrm{p}=0,006$ jedoch sehr signifikant niedriger als im Kontrollansatz ( $\mathrm{p} \leq 0,01)$ (s. Abbildung 22 rechts außen, roter Balken). 


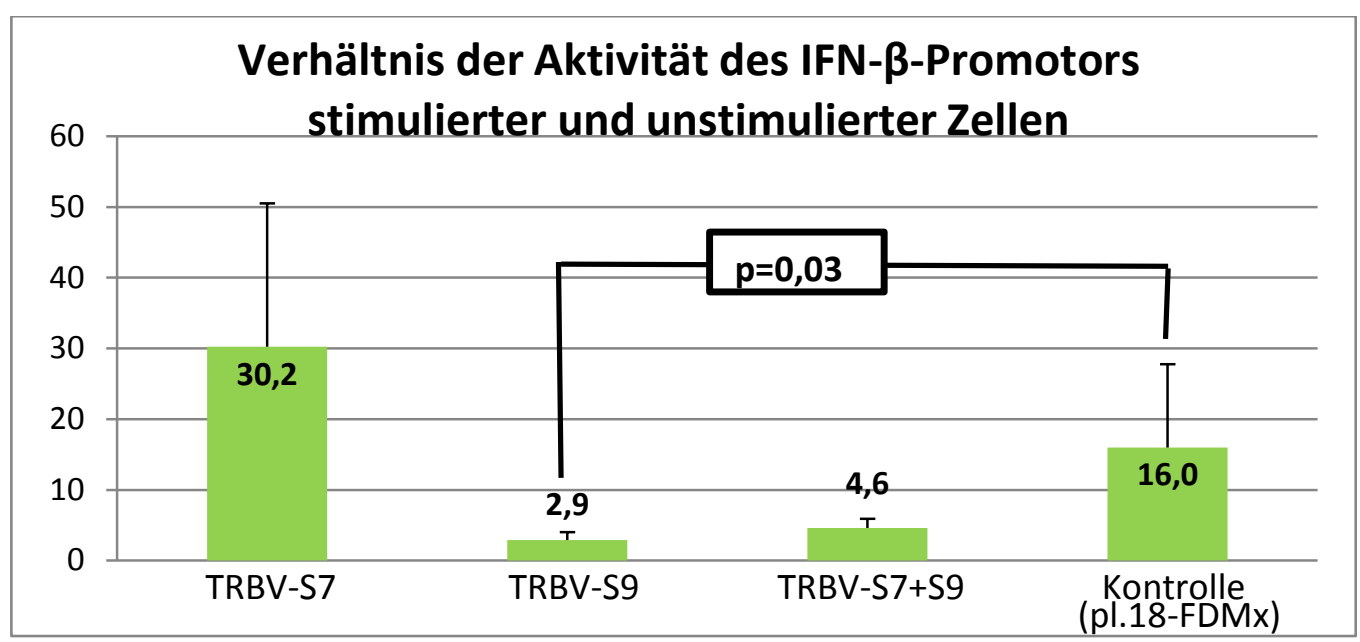

Abbildung 23: Verhältnis der Aktivität des IFN- $\beta$-Promotors stimulierter und unstimulierter Zellen nach Transfektion mit Expressionsplasmiden für NS-2 (TRBV-S7) und Helikase (TRBV-S9 mit ORFXa-Region) bzw. deren Co-Transfektion (TRBV-S7+S9). Die Stimulation erfolgte durch Transfektion von RNA VSV-infizierter Vero-E6-Zellen, unstimulierte Zellen wurden mit zellulärer RNA aus Vero E6 transfiziert, MW aus sieben Versuchen.

Die Promotoraktivität steigt in den mit TRBV-S9 transfizierten Zellen nach der Stimulation auf das 2,9fache der nicht stimulierten Probe. In der stimulierten Kontrolle steigt die Aktivität auf das 16 fache der nicht stimulierten Kontrollprobe. Nach Berechnung des Zweistichproben-t-Test unter der Annahme unterschiedlicher Varianzen fällt der Anstieg der Aktivität in den mit TRBV-S9 transfizierten Zellen mit $\mathrm{p}=0,03$ signifikant geringer aus $(\mathrm{p} \leq 0,05)$ als in der Kontrolle (s. Abbildung 23). Offensichtlich ist die TRBV-Helikase/ ORF-Xa im Gegensatz zu TRBV-NS-2 zumindest teilweise in der Lage, die durch RNA VSV-infizierter Verozellen vermittelte Aktivierung des IFN- $\beta$-Promotors zu unterdrücken.

\subsubsection{Messung der IFN- $\beta$-Promotoraktivität nach Transfektion von Expressionsplasmiden für TRBV-Gene und Stimulation mit poly(I:C)}

In einem zweiten Versuch wurde die Promotoraktivität des IFN- $\beta$-Gens nach Stimulation mit der synthetischen Substanz poly(I:C) gemessen. Hierzu wurden die Zellen 24 Stunden nach Transfektion der Expressionsplasmide für TRBV-Gene und der Reporter-Konstrukte mit poly(I:C) stimuliert, bzw. zum Vergleich mit RNA nicht 
infizierter Vero-E6-Zellen transfiziert. Nach weiteren 16 Stunden wurden die Zellen lysiert und der Reporter-Assay durchgeführt.

Die Mittelwerte der Firefly-Luciferase-Aktivität aus den sechs durchgeführten Experimenten ist in Abbildung 24 in relativen Einheiten dargestellt. Der Anstieg der Aktivität durch die Stimulation wurde für jedes Einzelexperiment errechnet, die Mittelwerte aller Anstiegsberechnungen sind in Abbildung 25 dargestellt.

Als Kontrolle der Stimulation wurde für die pI.18-FDMx-transfizierten Zellen der Unterschied zwischen der mit zellulärer RNA transfizierten und der mit poly(I:C) transfizierten Proben mit dem Zweistichproben-t-Test unter der Annahme unterschiedlicher Varianzen berechnet. Mit $\mathrm{p}=0,009$ ist dieser Unterschied sehr signifikant ( $\mathrm{p} \leq 0,01)$, die Stimulation daher effektiv (s. Abbildung 24, rechts außen).

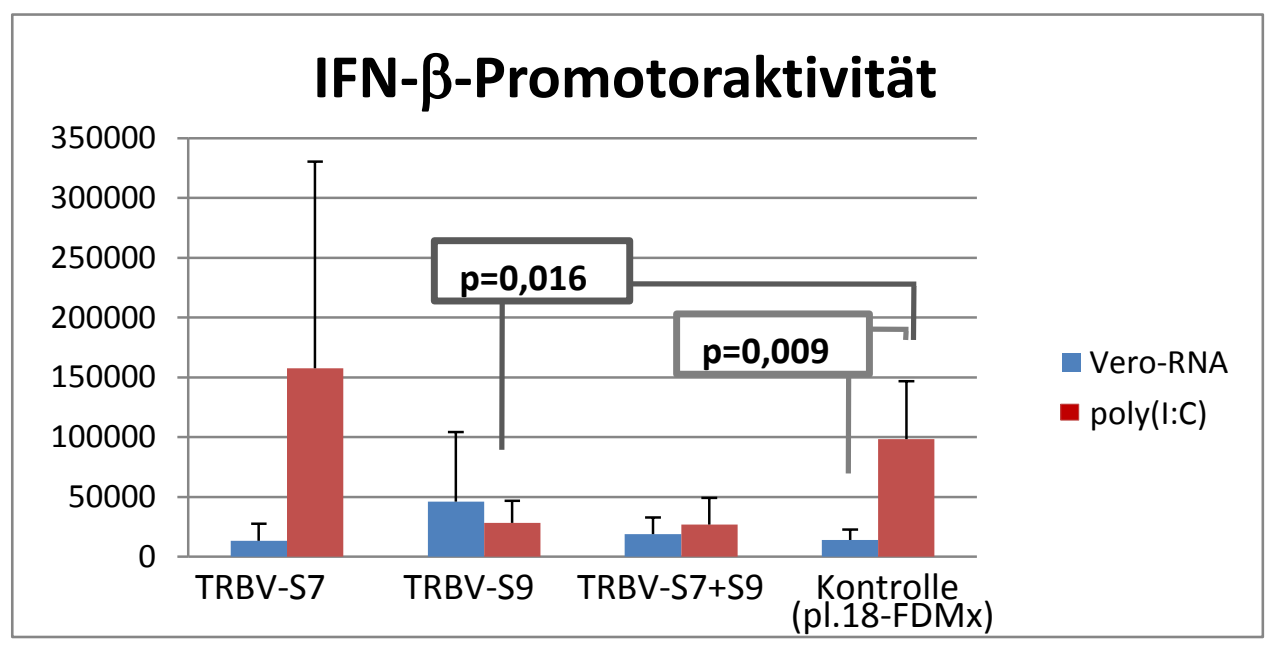

Abbildung 24: Messung der IFN-ß-Promotoraktivität mittels FF-Luc nach Transfektion mit Expressionsplasmiden für NS-2 (TRBV-S7) und Helikase (TRBV-S9 mit ORF-Xa-Region) bzw. deren Co-Transfektion (TRBV-S7+S9) und Stimulation mit poly(I:C), MW aus sechs Versuchen.

Wie nach der Stimulation mit RNA VSV-infizierter Vero-E6-Zellen steigt auch hier die ohne Stimulation geringe IFN-ß-Promotoraktivität der allein mit TRBV-S7 transfizierten Zellen (s. Abbildung 24, links außen, blauer Balken) nach der Stimulation mit poly(I:C) deutlich an (s. Abbildung 24, links außen, roter Balken; Abbildung 25 links). Die Aktivität des IFN- $\beta$-Promotors nach Transfektion von TRBV-S9 ist sowohl in den einzeln transfizierten als auch in den mit TRBV-S7+S9 
co-transfizierten Zellen höher als die Promotoraktivierung der Kontrolle (s. Abbildung 24, blaue Balken), der Unterschied ist jedoch nicht signifikant. Nach der Stimulation mit poly(I:C) ist die IFN- $\beta$-Promotoraktivität in den mit TRBV-S9 transfizierten Proben (s. Abbildung 24, Mitte links, roter Balken) mit $p=0,016$ signifikant niedriger $(\mathrm{p} \leq 0,05)$ als in $\mathrm{pI} .18$-FDMx transfizierten Zellen des Kontrollansatzes (s. Abbildung 24 rechts außen, roter Balken).

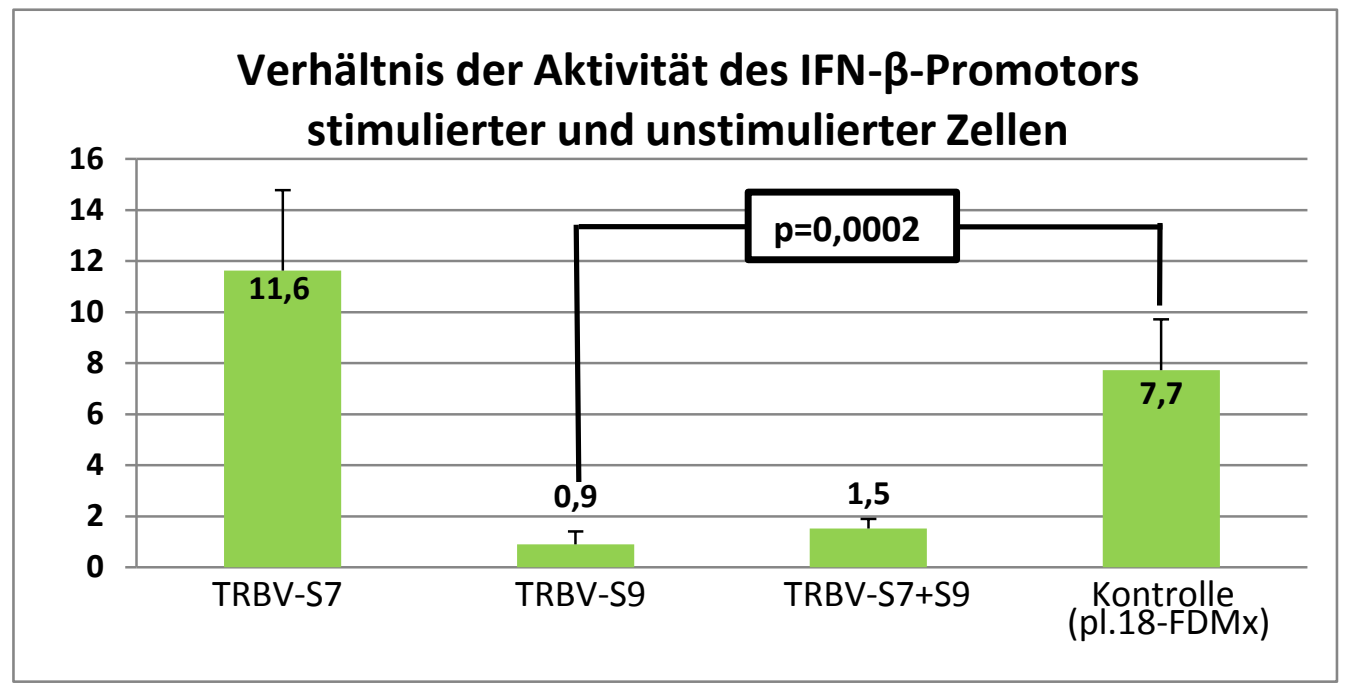

Abbildung 25: Verhältnis der Aktivität des IFN- $\beta$-Promotors stimulierter und unstimulierter Zellen nach Transfektion mit Expressionsplasmiden für NS-2 (TRBV-S7) und Helikase (TRBV-S9 mit ORFXa-Region) bzw. deren Co-Transfektion (TRBV-S7+S9). Die Stimulation erfolgte durch Transfektion mit poly(I:C), unstimulierte Zellen wurden mit zellulärer RNA aus Vero E6 transfiziert, MW aus sechs Versuchen.

Der Anstieg der Promotoraktivität beträgt in den mit TRBV-S9 transfizierten Zellen nach der Stimulation das 0,9fache der nicht stimulierten Probe. In der stimulierten Kontrolle steigt die Aktivität auf das 7,7fache der nicht stimulierten Kontrollprobe. Nach Berechnung des Zweistichproben-t-Test unter der Annahme unterschiedlicher Varianzen fällt der Anstieg der Promotoraktivität in den mit TRBV-S9 transfizierten Zellen geringer aus als in der Kontrolle (s. Abbildung 25). Der Unterschied ist mit $\mathrm{p}=0,0002$ hoch signifikant $(\mathrm{p} \leq 0,001)$. Offensichtlich ist ein durch TRBV-S9 kodiertes Protein im Gegensatz zu TRBV-NS-2 in der Lage, die durch poly(I:C) vermittelte Aktivierung des IFN- $\beta$-Promotors zu unterdrücken. 


\subsubsection{Messung der Aktivität eines AP-1-responsiven Promotors nach Transfektion von Expressionsplasmiden für TRBV-Gene und Stimulation mit MEKK}

Das Aktivierende Protein (AP)-1 ist einer der Transkriptionsfaktoren, welche nach Stimulation im sogenannten Enhanceosom an den IFN- $\beta$-Promotor im Zellkern binden und so die Synthese des IFN- $\beta$ initiieren (s.o.). Um die Aktivität eines AP-1responsiven Promotors zu messen, wurden die Zellen zum Zeitpunkt der Transfektion der Expressionsplasmide für TRBV-Gene und der Reporter-Konstrukte (s. 2.4.6, S. 40) mit pFC-MEKK co-transfiziert, bzw. die nicht stimulierten Proben mit pUC-19 (ein rein bakterielles Plasmid ohne eukaryontischen Promotor, als KontrollDNA verwendet) transfiziert. Nach 12 Stunden wurden die Zellen lysiert und der Reporter-Assay durchgeführt.

Die Mittelwerte der Firefly-Luciferase-Aktivität aus vier durchgeführten Experimenten ist in Abbildung 26 in relativen Einheiten dargestellt. Der Anstieg der Aktivität durch die Stimulation wurde für jedes Einzelexperiment errechnet, die Mittelwerte aller Anstiegsberechnungen sind in Abbildung 27 dargestellt.

Als Kontrolle der Stimulation mit MEKK wurde für die pI.18-FDMx-transfizierten Zellen der Unterschied zwischen der nicht stimulierten und der stimulierten Probe mit dem Zweistichproben-t-Test unter der Annahme unterschiedlicher Varianzen berechnet. Mit $\mathrm{p}=0,05$ ist dieser Unterschied noch signifikant $(\mathrm{p} \leq 0,05)$, die Stimulation daher als effektiv zu bewerten (s. Abbildung 26, rechts außen). 


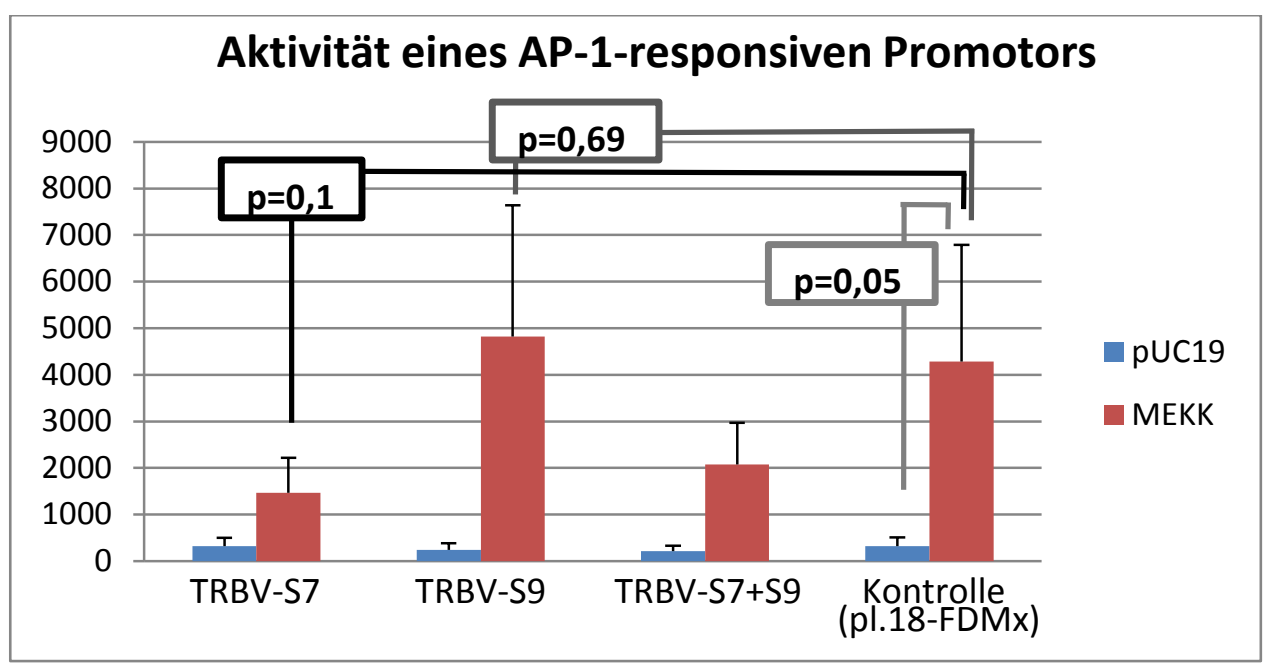

Abbildung 26: Messung der Aktivität eines AP-1-responsiven Promotors mittels FF-Luc nach Transfektion mit Expressionsplasmiden für NS-2 (TRBV-S7) und Helikase (TRBV-S9 mit ORF-XaRegion) bzw. deren Co-Transfektion (TRBV-S7+S9) und Stimulation mit MEKK, MW aus vier Versuchen.

Die AP-1-Promotoraktivität ist in den unstimulierten Zellen aller Proben ähnlich gering, in den mit TRBV-S9 transfizierten Zellen bzw. in den mit TRBV-S7 und -S9 co-transfizierten Zellen ist sie geringfügig niedriger als in der Kontrolle. Die Promotoraktivität nach der Stimulation mit MEKK fällt in den mit dem TRBV-S7 transfizierten bzw. TRBV-S7 und -S9 co-transfizierten Zellen niedriger aus als in der Kontrolle, ein signifikanter Unterschied zwischen der Aktivierung in der TRBV-S7Probe und der Kontrolle ist mit $\mathrm{p}=0,1$ jedoch nicht festzustellen (s. Abbildung 26). Auch ein Unterschied in der Promotoraktivierung der stimulierten Zellen zwischen der mit TRBV-S9 transfizierten Proben und der Kontrolle ist mit $\mathrm{p}=0,69$ nicht auszumachen (s. Abbildung 26). 


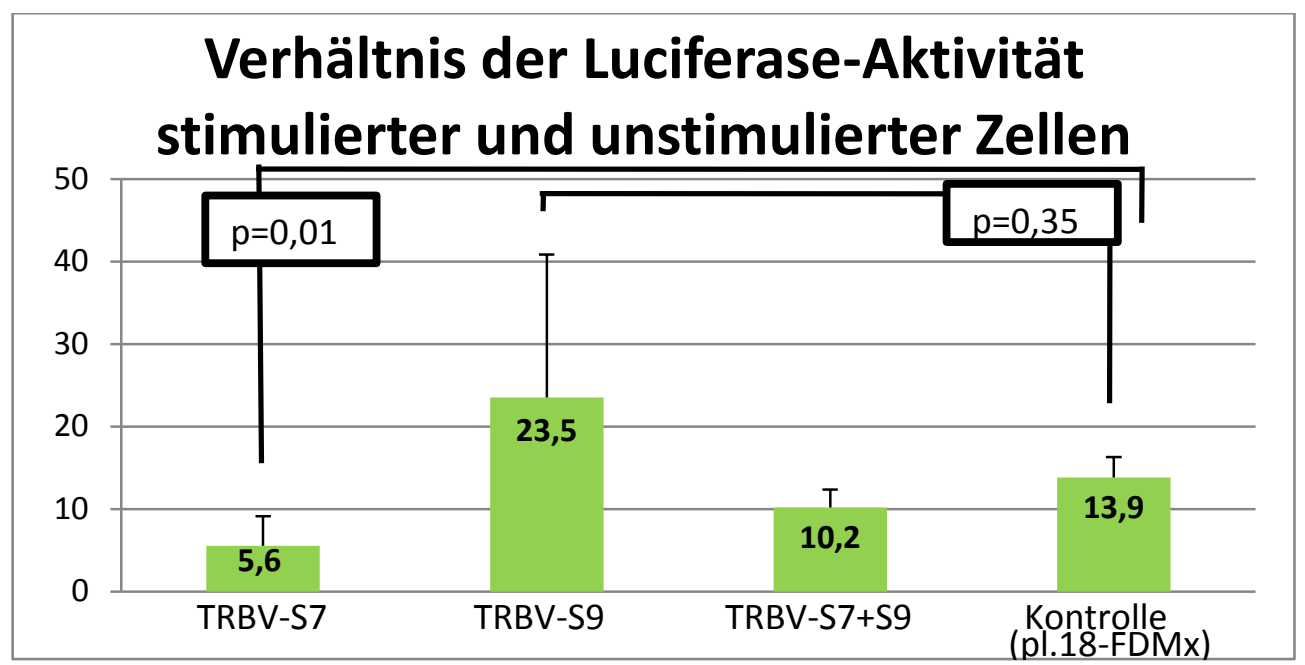

Abbildung 27: Verhältnis der Aktivität des AP-1-responsiven Promotors stimulierter und unstimulierter Zellen nach Transfektion mit Expressionsplasmiden für NS-2 (TRBV-S7) und Helikase (TRBV-S9 mit ORF-Xa-Region) bzw. deren Co-Transfektion (TRBV-S7+S9) und Stimulation mit MEKK, MW aus vier Versuchen.

Der Anstieg der AP-1-Promotoraktivität nach Stimulation (d.h. MEKK-Expression) ist bei den TRBV-S7 transfizierten Zellen wesentlich geringer als in der Kontrolle, mit $\mathrm{p}=0,01$ ist dieser Unterschied sehr signifikant. Der Anstieg der Aktivität in den mit TRBV-S9 transfizierten Zellen fällt höher aus als in der Kontrolle, mit $\mathrm{p}=0,35$ ist der Unterschied aber nicht signifikant. Hierbei ist jedoch die hohe Standardabweichung in der Berechnung der TRBV-S9-Proben $\mathrm{zu}$ beachten (s. Abbildung 27). Offensichtlich hat das TRBV-NS-2 im Gegensatz zur TRBVHelikase/ ORF-Xa einen hemmenden Einfluss auf die AP-1-Aktivierung.

\subsubsection{Messung der Aktivität eines NF- $\varkappa$ B-responsiven Promotors nach Transfektion von Expressionsplasmiden für TRBV-Gene und Stimulation mit poly(I:C)}

Der Transkriptionsfaktor NF-xB (nuclear factor „kappa-light-chain-enhancer of activated B-cells") wird durch zahlreiche Zytokine (z.B. TNF- $\alpha$ ) und Antigene (z.B. virale dsRNA) aktiviert und bewirkt im Zellkern unter anderem zusammen mit anderen Faktoren die Expression von Interferon (Hoffmann et al. 2006). 
Um die Aktivität eines NF- $\varkappa$ B-responsiven Promotors nach Transfektion von Expressionsplasmiden für virale Gene zu untersuchen wurde wie in den oben beschriebenen Experimenten ein Dual-Luciferase-Reporter-Assay mit HEK-293Zellen durchgeführt. Die Transfektion der Reporterkonstrukte (s. 2.4.6, S. 40) sowie der Expressionsplasmide für TRBV-NS-2 und TRBV-Helikase/ ORF-Xa wurde nach 24 Stunden Zellwachstum vorgenommen. Für die Stimulation wurden die Zellen weitere 24 Stunden später mit der synthetischen Substanz Polyinositolcytidinsäure (poly (I:C)) bzw. die nicht stimulierten Proben mit Vero-E6-Zell-RNA behandelt. Die Aktivität der Firefly-Luciferase wurde nach nochmals 16 Stunden Inkubationszeit gemessen. Die Mittelwerte dieser Aktivität aus fünf durchgeführten Experimenten sind in Abbildung 28 in relativen Einheiten dargestellt. Der Anstieg der Aktivität durch die Stimulation wurde auch hier für jedes Einzelexperiment errechnet, die Mittelwerte aller Anstiegsberechnungen sind in Abbildung 29 dargestellt.

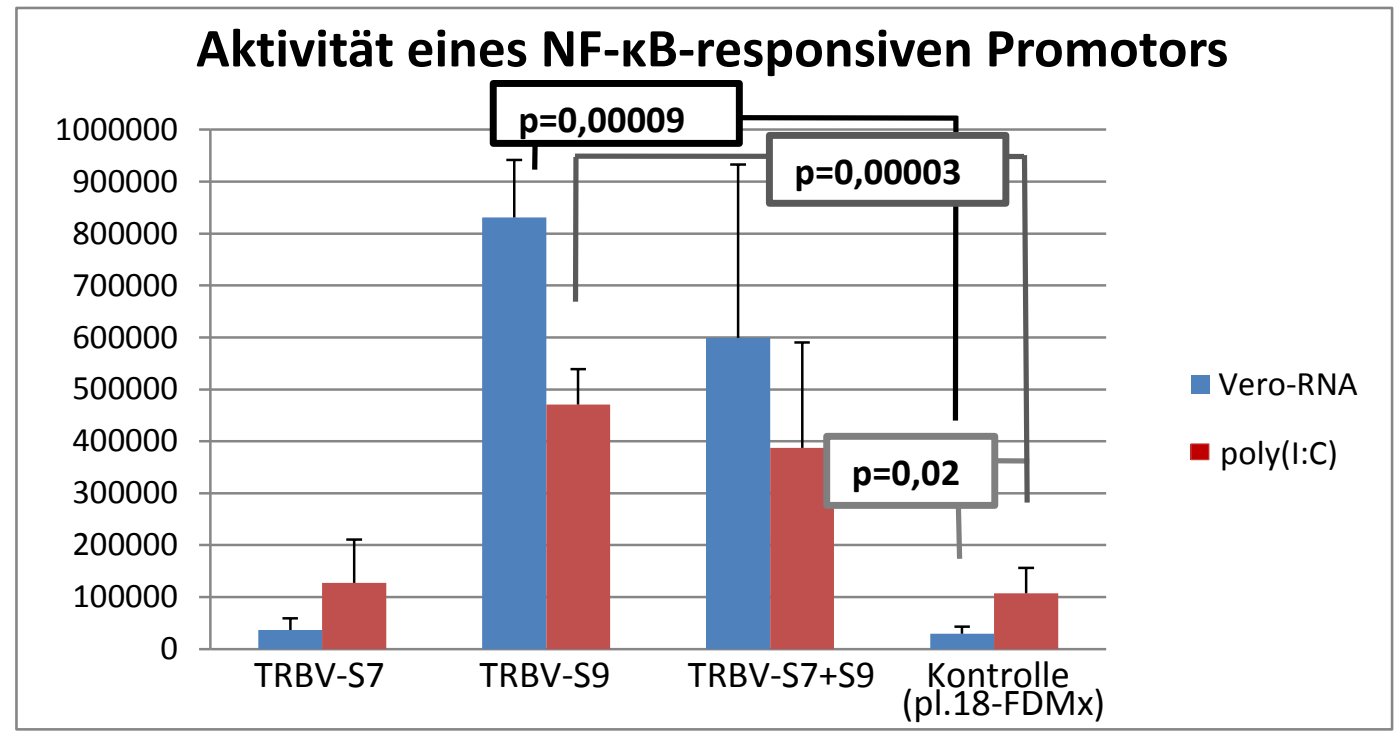

Abbildung 28: Aktivität eines NF-xB-responsiven Promotors nach Transfektion mit Expressionsplasmiden für NS-2 (TRBV-S7) und Helikase (TRBV-S9 mit ORF-Xa-Region) bzw. deren Co-Transfektion (TRBV-S7+S9) und Stimulation mit poly(I:C), MW aus fünf Versuchen.

Der Unterschied zwischen stimulierten und nicht stimulierten Zellen der Kontrollprobe ist mit $\mathrm{p}=0,02$ signifikant, die Stimulation mit poly(I:C) daher als effektiv anzusehen (s. Abbildung 28, rechts außen). 
Während die Messung der NF-xB-Promotoraktivität sowohl in den stimulierten als auch in den nicht stimulierten Proben der mit TRBV-S7 transfizierten Zellen (s. Abbildung 28, links) den Ergebnissen der Kontrollprobe (s. Abbildung 28, rechts) gleicht, ist bei der Aktivität des Promotors in den mit TRBV-S9 transfizierten Zellen ein deutlicher Unterschied zu den mit pI.18-FDMx-transfizierten Zellen zu sehen. Dies gilt sowohl für die nur mit TRBV-S9 transfizierten Zellen (s. Abbildung 28, Mitte links), als auch für die mit TRBV-S7 und -S9 co-transfizierten Zellen (s. Abbildung 28, Mitte rechts). Bereits ohne Stimulation ist die Promotoraktivität in diesen Proben sehr hoch (s. Abbildung 28, Mitte, blaue Balken), eine weitere Aktivierung durch poly(I:C) ist nicht möglich, stattdessen kam es sogar zu einem Abfall der Reporteraktivität (s. Abbildung 28, Mitte, rote Balken). Der Unterschied zwischen der Promotoraktivität der mit TRBV-S9 transfizierten Zellen und der Kontrollprobe ist sowohl ohne Stimulation durch poly(I:C) mit $\mathrm{p}=0,00009$, als auch nach Stimulation mit $\mathrm{p}=0,00003$ hoch signifikant.

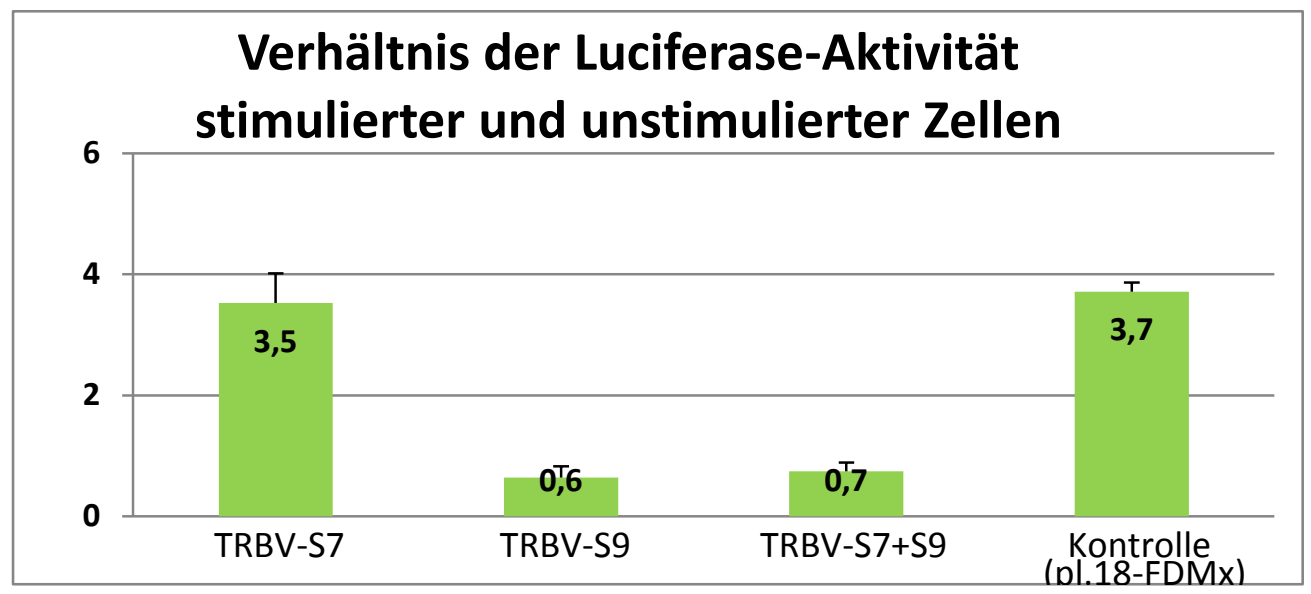

\begin{abstract}
Abbildung 29: Verhältnis der Aktivität des NF- $x$ B-responsiven Promotors stimulierter und unstimulierter Zellen nach Transfektion mit Expressionsplasmiden für NS-2 (TRBV-S7) und Helikase (TRBV-S9 mit ORF-Xa-Region) bzw. deren Co-Transfektion (TRBV-S7+S9) und Stimulation mit poly(I:C), MW aus fünf Versuchen.
\end{abstract}

Der Anstieg der Promotoraktivität von der unstimulierten zur stimulierten Probe ist in den mit TRBV-S7 transfizierten Zellen mit 3,5 (s. Abbildung 29 links außen) vergleichbar hoch wie in den zur Kontrolle mit pI.18-FDMx transfizierten Zellen (3,7fach, s. Abbildung 29 rechts außen). Der Anstieg in den mit TRBV-S9 
transfizierten Zellen (s. Abbildung 29 Mitte) fällt sowohl in den Proben der Einzeltransfektion als auch in den Proben der Co-Transfektion signifikant geringer aus (Ergebnis des Zweistichproben-t-Tests unter der Annahme unterschiedlicher Varianzen für den Unterschied zwischen TRBV-S9 und Kontrolle: $\mathrm{p}=1,4 \times 10^{-9}$ ). Jedoch ist hier zu beachten, dass die Promotoraktivität bereits ohne die Stimulation durch poly(I:C) sehr hoch ist.

\subsubsection{Messung der Aktivität eines NF- $\varkappa$ B-responsiven Promotors nach Transfektion von Expressionsplasmiden für TRBV-Gene mit RNA VSV-infizierter Vero-E6-Zellen}

Wie im oben beschriebenen Experiment wurde in einem weiteren Versuch die Aktivität eines NF- $\varkappa$ B-responsiven Promotors nach Transfektion der Expressionsplasmide für NS-2 (TRBV-S7) und Helikase (TRBV-S9 mit ORF-XaRegion) mittels Firefly-Luciferase-Reporter-Assay auf HEK-293-Zellen untersucht. Die Transfektion der Reporterkonstrukte sowie der Expressionsplasmide wurde nach 24 Stunden Zellwachstum vorgenommen. Für die Stimulation wurden die Zellen jedoch hier 24 Stunden später mit RNA VSV-infizierter Vero-E6-Zellen bzw. die nicht stimulierten Proben mit RNA nicht infizierter Vero-E6-Zellen behandelt. Die Aktivität der Firefly-Luciferase wurde nach weiteren 16 Stunden gemessen. Die Mittelwerte dieser Aktivität aus fünf durchgeführten Experimenten sind in Abbildung 30 in relativen Einheiten dargestellt. Der Anstieg der Aktivität durch die Stimulation wurde auch hier für jedes Einzelexperiment errechnet, die Mittelwerte aller Anstiegsberechnungen sind in Abbildung 31 dargestellt. 


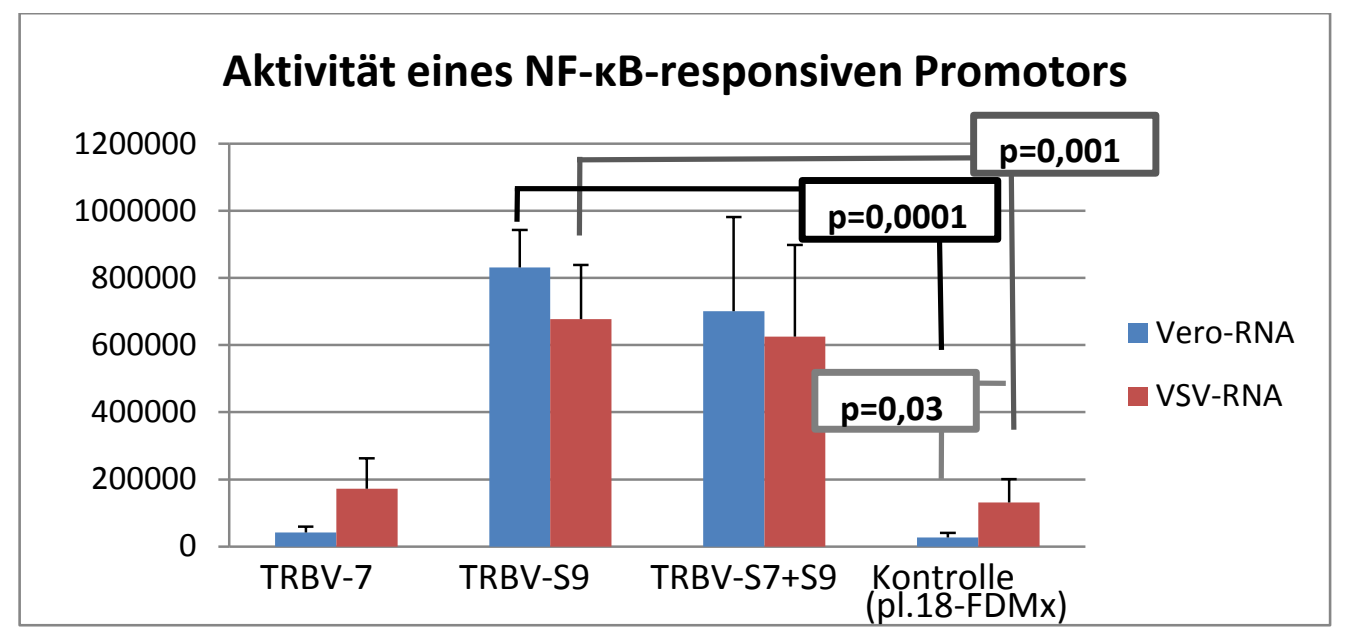

Abbildung 30: Messung der Aktivität eines NF- $x$ B-responsiven Promotors nach Transfektion mit Expressionsplasmiden für NS-2 (TRBV-S7) und Helikase (TRBV-S9 mit ORF-Xa-Region) bzw. deren Co-Transfektion (TRBV-S7+S9) und Stimulation mit RNA VSV-infizierter Vero-E6-Zellen, MW aus fünf Versuchen.

Auch hier ist der Unterschied zwischen stimulierten und nicht stimulierten Zellen der Kontrollprobe mit $\mathrm{p}=0,03$ signifikant, auch die Stimulation mit RNA VSV-infizierter Verozellen ist daher als effektiv anzusehen (s. Abbildung 30, rechts außen).

Die mit TRBV-S7 transfizierten Proben gleichen in ihrer NF- $x$ B-responsiven Promotoraktivität der Kontrolle, während die Aktivität in den mit TRBV-S9 transfizierten bzw. mit TRBV-S7 und -S9 co-transfizierten Zellen bereits ohne zusätzliche Stimulation mit RNA VSV-infizierter Verozellen deutlich höher ist. Der Unterschied zwischen der TRBV-S9-transfizierten Probe und der Kontrolle nach der Stimulation mit RNA VSV-infizierter Verozellen ist mit $\mathrm{p}=0,001$ hoch signifikant. Der Unterschied zwischen der TRBV-S9-transfizierten Probe und der Kontrolle ist ohne Stimulation sogar noch höher ( $p=0,0001$, s. Abbildung 30). 


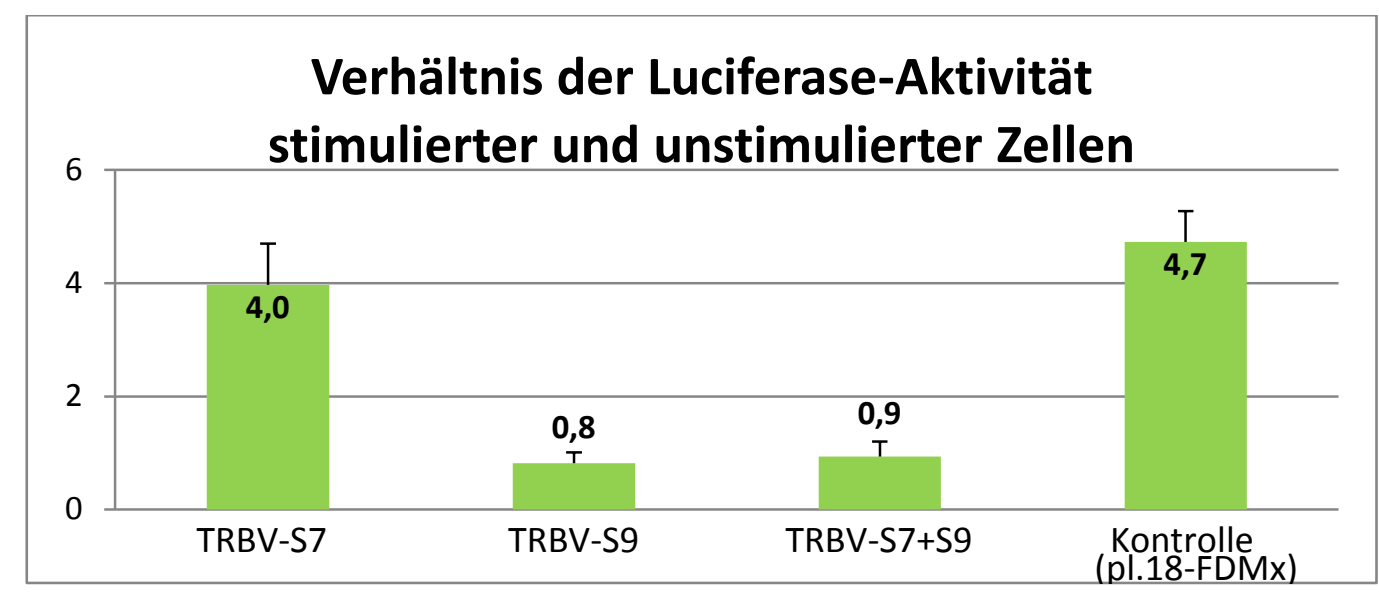

Abbildung 31: Verhältnis der Aktivität des NF-xB-responsiven Promotors stimulierter und unstimulierter Zellen nach Transfektion mit Expressionsplasmiden für NS-2 (TRBV-S7) und Helikase (TRBV-S9 mit ORF-Xa-Region) bzw. deren Co-Transfektion (TRBV-S7+S9). und Stimulation mit RNA VSV-infizierter Verozellen, MW aus fünf Versuchen.

Der Anstieg der Promotoraktivität durch die Stimulation ist in den mit TRBV-S7 transfizierten Zellen (4,0fach s. Abbildung 31 links außen) vergleichbar hoch wie in den zur Kontrolle mit pI.18-FDMx transfizierten Zellen (4,7fach, s. Abbildung 31 rechts außen). Der Anstieg in den mit TRBV-S9 transfizierten Zellen (s. Abbildung 31 Mitte) fällt geringer aus als in der Kontrolle, wobei jedoch die hohe Ausgangsaktivität dieser Proben zu beachten ist.

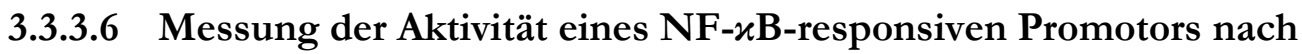 Transfektion von Expressionsplasmiden für TRBV-Gene und Stimulation mit TNF- $\alpha$}

In einem weiteren Versuch wurde wie in den oben beschriebenen Experimenten ein Dual-Luciferase-Reporter-Assay mit HEK-293-Zellen nach Transfektion der Expressionsplasmide für NS-2 (TRBV-S7) und Helikase (TRBV-S9 mit ORF-XaRegion) durchgeführt, um die Aktivität eines NF- $x$ B-responsiven Promotors zu messen. In diesem Versuch wurde jedoch mit TNF- $\alpha$ stimuliert. Der Tumornekrosefaktor (TNF) $-\alpha$ aktiviert NF- $\varkappa$ B sehr effizient (Hoffmann et al. 2006), daher wurde er hier als PAMP-unabhängiger Stimulus benutzt. Die Zellen wurden nach 24stündigem Zellwachstum transfiziert und nach nochmals 12 Stunden 
stimuliert. Die Lyse der Zellen und die Messung der Firefly-Luciferase fanden nach weiteren 12 Stunden statt.

Die Mittelwerte der Firefly-Luciferase-Aktivität aus drei durchgeführten Experimenten ist in Abbildung 32 in relativen Einheiten dargestellt. Der Anstieg der Aktivität durch die Stimulation wurde auch hier für jedes Einzelexperiment errechnet, die Mittelwerte aller Anstiegsberechnungen sind in Abbildung 33 dargestellt.

Der Unterschied zwischen stimulierten und nicht stimulierten Zellen der Kontrollprobe ist mit $\mathrm{p}=0,02$ signifikant, die Stimulation mit TNF- $\alpha$ ist daher als effektiv anzusehen (s. Abbildung 32).

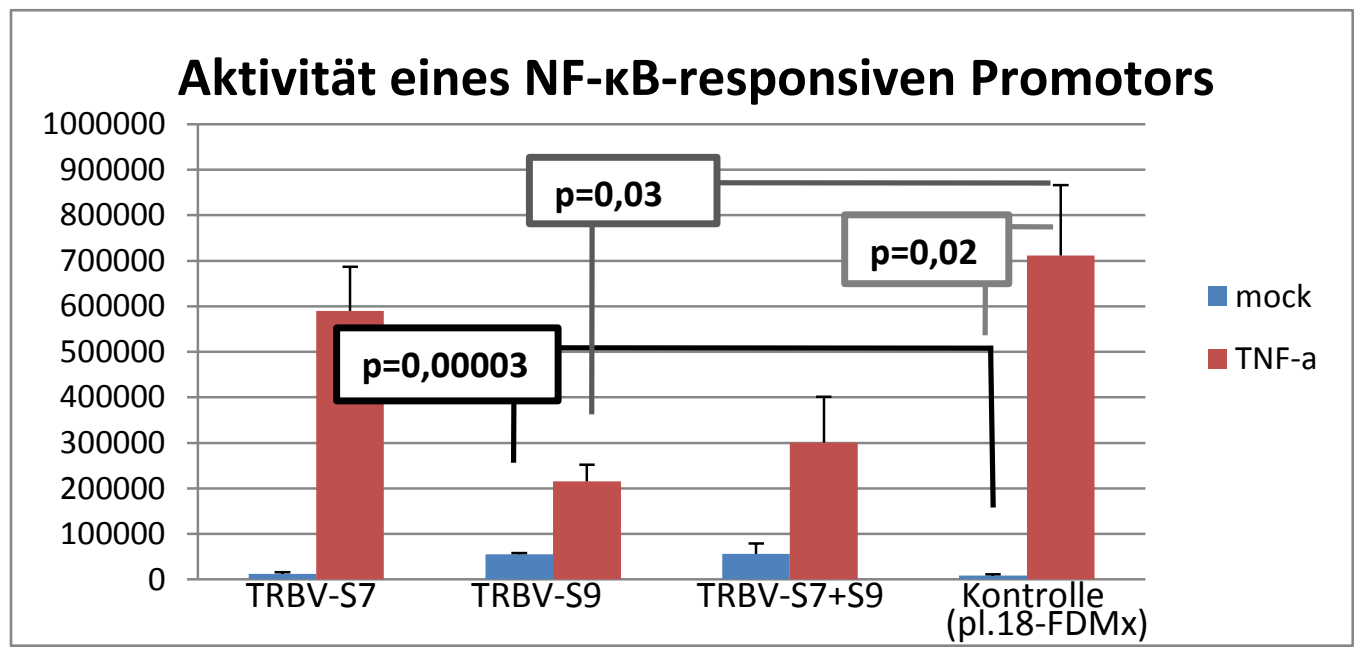

Abbildung 32: Messung der Aktivität eines NF-xB-responsiven Promotors nach Transfektion mit Expressionsplasmiden für NS-2 (TRBV-S7) und Helikase (TRBV-S9 mit ORF-Xa-Region) bzw. deren Co-Transfektion (TRBV-S7+S9) und Stimulation mit TNF- $\alpha$, MW aus drei Versuchen.

Auch hier ist die Aktivität des NF- $x$ B-responsiven Promotors in den mit TRBV-S9 transfizierten Zellen ohne die Stimulation mit TNF- $\alpha$ signifikant höher als in der Kontrolle. Die Promotoraktivität nach Stimulation mit TNF- $\alpha$ ist in diesen Zellen jedoch mit $\mathrm{p}=0,03$ signifikant geringer als im mit $\mathrm{TNF}-\alpha$ stimulierten Kontrollansatz (s. Abbildung 32). 


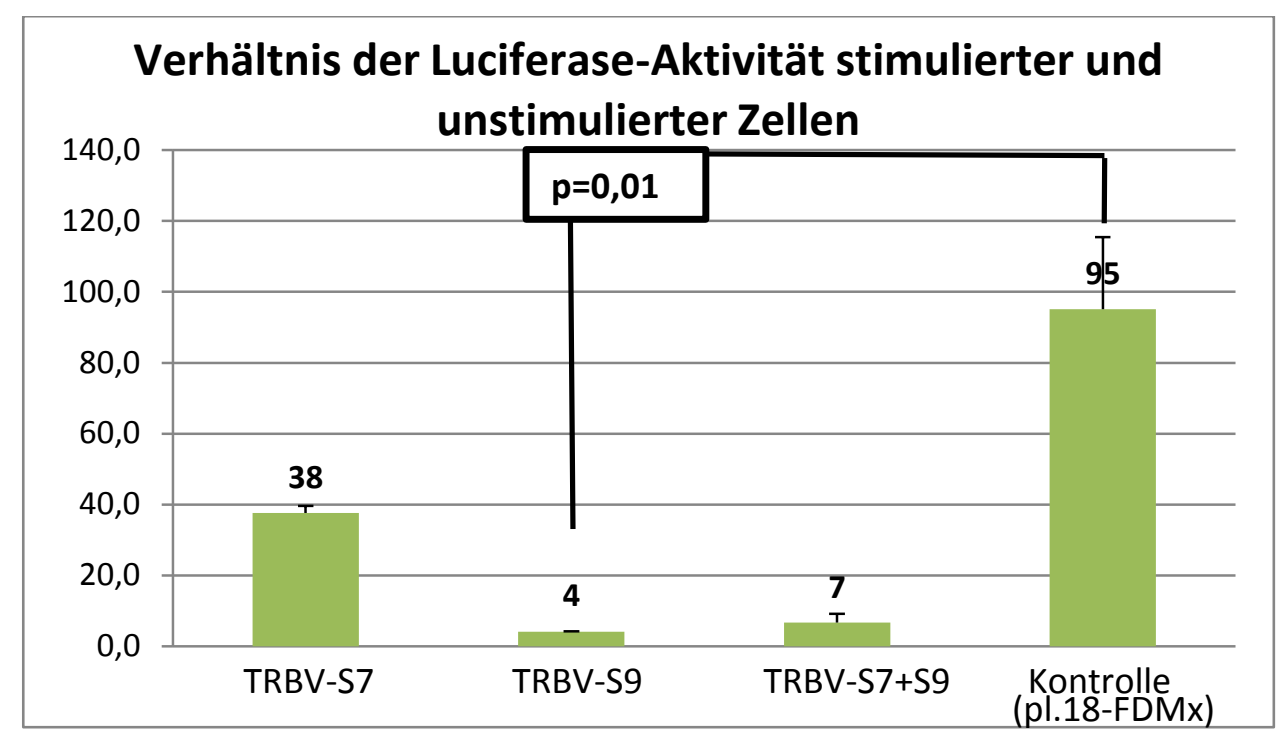

Abbildung 33: Verhältnis der Aktivität des NF-xB-responsiven Promotors stimulierter und unstimulierter Zellen nach Transfektion mit Expressionsplasmiden für NS-2 (TRBV-S7) und Helikase (TRBV-S9 mit ORF-Xa-Region) bzw. deren Co-Transfektion (TRBV-S7+S9) und Stimulation mit TNF- $\alpha$, MW aus drei Versuchen.

Auch der Anstieg zu der Aktivität nach Stimulation mit TNF- $\alpha$ ist in den TRBV-S9 transfizierten Zellen (4fach, s. Abbildung 33 Mitte links) mit $\mathrm{p}=0,01$ signifikant niedriger als in der Kontrolle (95fach, s. Abbildung 33 rechts).

\subsubsection{Messung der Aktivität eines IRF-3-responsiven Promotors nach Transfektion von Expressionsplasmiden für TRBV-Gene und Stimulation mit RNA VSV-infizierter Vero-E6-Zellen}

Der Interferon regulierende Faktor 3 (IRF-3) ist zusammen mit Co-Faktoren für die Steigerung der IFN- $\beta$-Synthese im Zellkern verantwortlich (s.o.), stellt für die Aktivierung des IFN- $\beta$-Promotors jedoch den wichtigsten Transkriptionsfaktor dar (Sato et al. 2000). Um die Aktivität eines IRF-3-responsiven Promotors (s. 2.4.6, S. 40) $\mathrm{zu}$ messen wurde eine Reihe weiterer Dual-Luciferase-Reporter-Assays nach Transfektion mit Expressionsplasmiden für NS-2 (TRBV-S7) und Helikase (TRBVS9 mit ORF-Xa-Region) durchgeführt. Zur Aktivierung des IFN- $\beta$-Promotors wurden die Zellen 24 Stunden nach der Transfektion mit RNA VSV-infizierter VeroE6-Zellen stimuliert, bzw. die nicht stimulierten Proben mit RNA nicht infizierter 
Vero-E6-Zellen transfiziert. Die Lyse erfolgte nach weiteren 16 Stunden. Für die Auswertung wurden die Daten der Firefly-Luciferase-Aktivität verwendet (s.o.).

Die Mittelwerte der Firefly-Luciferase-Aktivität aus sieben durchgeführten Experimenten ist in Abbildung 34 in relativen Einheiten dargestellt. Der Anstieg der Aktivität durch die Stimulation wurde für jedes Einzelexperiment errechnet, die Mittelwerte aller Anstiegsberechnungen sind in Abbildung 35 dargestellt.

Als Kontrolle der Stimulation mit RNA VSV-infizierter Vero-E6-Zellen wurde für die pI.18-FDMx-transfizierten Zellen der Unterschied zwischen der nicht stimulierten und der stimulierten Probe mit dem Zweistichproben-t-Test unter der Annahme unterschiedlicher Varianzen berechnet. Mit $\mathrm{p}=0,003$ ist dieser Unterschied sehr signifikant $(\mathrm{p} \leq 0,01)$, die Stimulation daher effektiv (s. Abbildung 34, rechts außen).

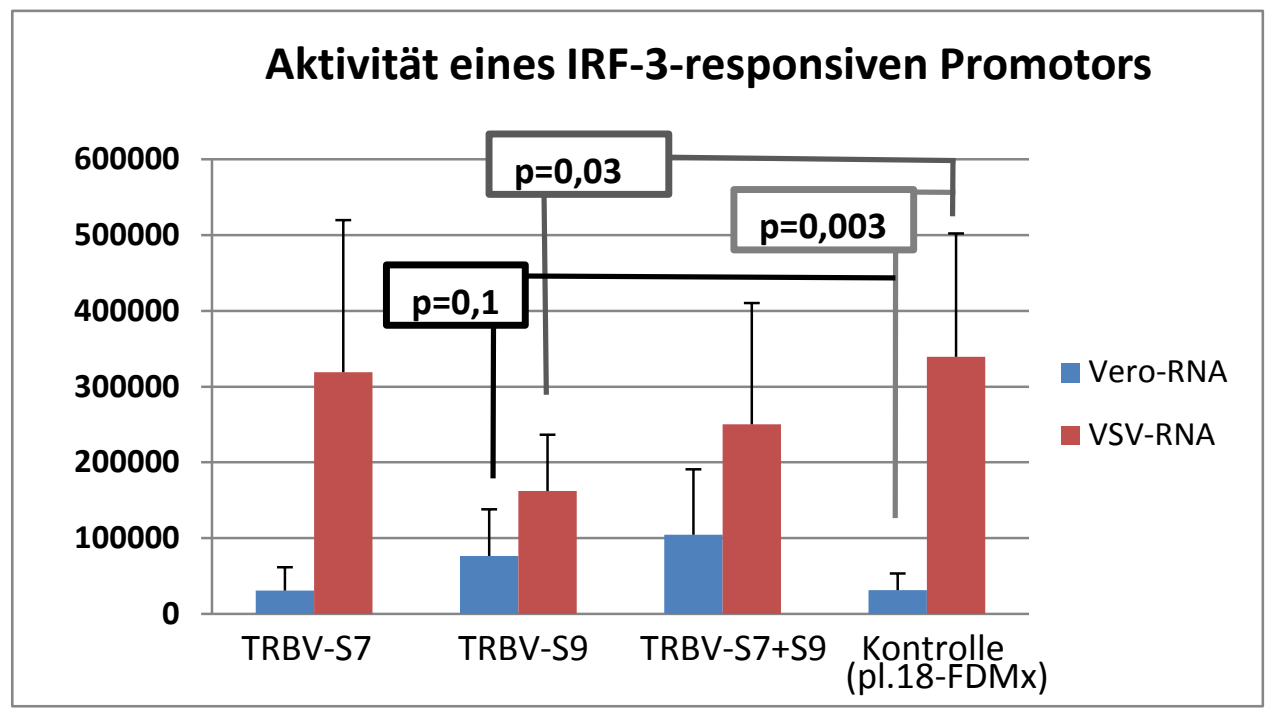

Abbildung 34: Messung der Aktivität eines IRF-3-responsiven Promotors nach Transfektion mit Expressionsplasmiden für NS-2 (TRBV-S7) und Helikase (TRBV-S9 mit ORF-Xa-Region) bzw. deren Co-Transfektion (TRBV-S7+S9) und Stimulation mit RNA VSV-infizierter Verozellen, MW aus sieben Versuchen.

Die IRF-3-Aktivierung in der Kontrolle mit pI.18-FDMx (s. Abbildung 34, rechts außen) ähnelt dem Ergebnis für die Promotoraktivität nach Transfektion mit TRBVS7. Die allein mit TRBV-S7 transfizierten Zellen zeigen ohne Stimulation eine 
geringe Aktivität des IRF-3-responsiven Promotors (s. Abbildung 34, links außen, blauer Balken), welche mit der Aktivität in der Kontrolle vergleichbar ist (s. Abbildung 34, rechts außen, blauer Balken). Nach der Stimulation steigt die Promotoraktivität beider Proben deutlich an (s. Abbildung 34, links und rechts außen, roter Balken; Abbildung 35 links und rechts außen). Die Aktivität des IRF-3responsiven Promotors nach Transfektion von TRBV-S9 ist in den mit TRBV-S7 cotransfizierten Zellen (s. Abbildung 34, Mitte rechts, blauer Balken) ebenso wie in den nur mit TRBV-S9 transfizierten Zellen (s. Abbildung 34, Mitte links, blauer Balken) höher als die Promotoraktivität der Kontrolle (s. Abbildung 34 rechts außen, blauer Balken). Doch der Unterschied der Promotoraktivität zwischen TRBV-S9transfizierten Zellen und der Kontrolle ist mit $\mathrm{p}=0,1$ nicht signifikant. Nach der Stimulation mit RNA VSV-infizierter Vero-E6-Zellen ist die Aktivität in den mit TRBV-S9 transfizierten Proben (s. Abbildung 34, Mitte links, roter Balken) mit $\mathrm{p}=0,03$ jedoch signifikant niedriger als in den Zellen der Kontrollprobe (s. Abbildung 34 rechts außen, roter Balken).

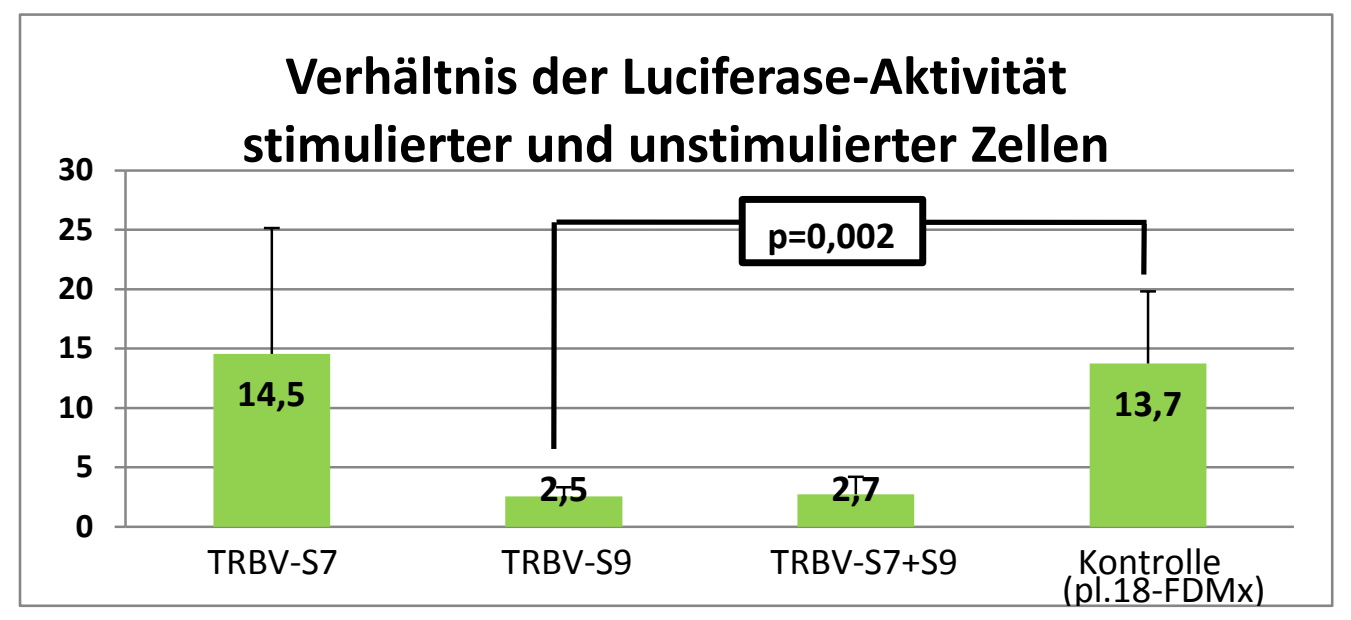

Abbildung 35: Verhältnis der Aktivität des IRF-3-responsiven Promotors stimulierter und unstimulierter Zellen nach Transfektion mit Expressionsplasmiden für NS-2 (TRBV-S7) und Helikase (TRBV-S9 mit ORF-Xa-Region) bzw. deren Co-Transfektion (TRBV-S7+S9) und Stimulation mit RNA VSV-infizierter Verozellen, MW aus sieben Versuchen.

Der Anstieg der Aktivität des IRF3-responsiven Promotors nach Stimulation ist in den mit TRBV-S9 infizierten Zellen (2,5fach) wesentlich geringer als in der Kontrolle (13,7fach). Dieser Unterschied ist mit $p=0,002$ sehr signifikant ( $\mathrm{x} \leq 0,01$, 
s. Abbildung 35). Während der Anstieg der Promotoraktivität in den mit TRBV-S7 transfizierten Zellen (s. Abbildung 35 links) mit der Kontrolle vergleichbar ist, ähnelt der Aktivitätsanstieg der co-transfizierten Probe (s. Abbildung 35 Mitte rechts) dem Ergebnis der nur mit TRBV-S9 transfizierten Zellen. Offensichtlich ist die TRBVHelikase/ ORF-Xa im Gegensatz zu TRBV-NS-2 zumindest teilweise in der Lage die durch RNA VSV-infizierter Verozellen vermittelte Aktivierung des IRF3-responsiven Promotors zu unterdrücken.

\subsubsection{Messung der Aktivität eines IRF-3-responsiven Promotors nach Transfektion von Expressionsplasmiden für TRBV-Gene und Stimulation mit poly(I:C)}

Äquivalent zum oben beschriebenen Experiment wurde ein Dual-LuciferaseReporter-Assay mit HEK-293-Zellen nach Transfektion mit Expressionsplasmiden für NS-2 (TRBV-S7) und Helikase (TRBV-S9 mit ORF-Xa-Region) durchgeführt. In diesem Versuch wurde jedoch mit der synthetischen Substanz poly(I:C) stimuliert. Zum Vergleich erfolgte die Transfektion mit Vero-E6-Zell-RNA.

Die Mittelwerte der Firefly-Luciferase-Aktivität aus sieben durchgeführten Experimenten ist in Abbildung 36 in relativen Einheiten dargestellt. Der Anstieg der Aktivität durch die Stimulation wurde auch hier für jedes Einzelexperiment errechnet, die Mittelwerte aller Anstiegsberechnungen sind in Abbildung 37 dargestellt. 


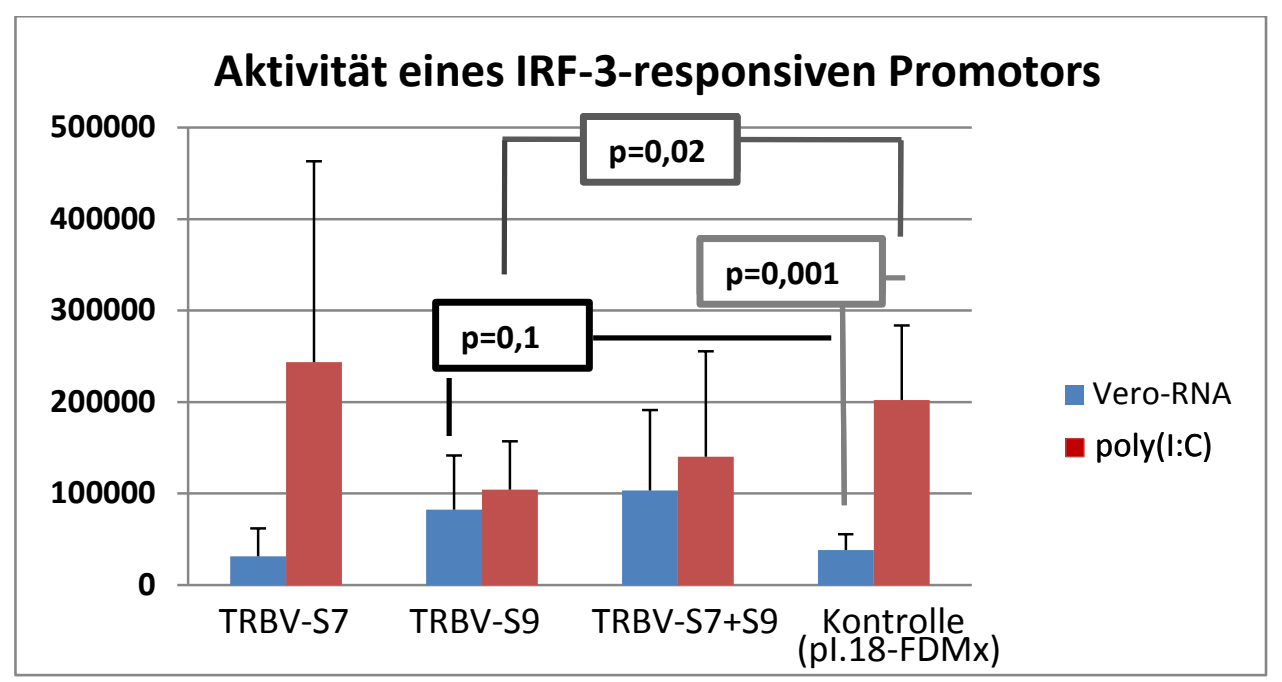

Abbildung 36: Messung der Aktivität eines IRF-3-responsiven Promotors nach Transfektion mit Expressionsplasmiden für NS-2 (TRBV-S7) und Helikase (TRBV-S9 mit ORF-Xa-Region) bzw. deren Co-Transfektion (TRBV-S7+S9) und Stimulation mit poly(I:C), MW aus sieben Versuchen.

Mit $\mathrm{p}=0,001$ ist der Unterschied zwischen stimulierten und nicht stimulierten Zellen der Kontrollprobe hoch signifikant, die Stimulation mit poly(I:C) daher als effektiv anzusehen (s. Abbildung 36, rechts außen).

Wie schon nach der Stimulation mit RNA VSV-infizierter Verozellen fällt die IRF-3responsive Promotoraktivierung in der Kontrolle mit pI.18-FDMx (s. Abbildung 36, rechts außen) ähnlich dem Ergebnis für die Promotoraktivität nach Transfektion mit TRBV-S7 aus. Auch hier zeigen die mit TRBV-S7 transfizierten Zellen ohne Stimulation eine geringe Aktivität des IRF-3-responsiven Promotors (s. Abbildung 36, links außen, blauer Balken), nach Stimulation ist die Aktivität deutlich höher (s. Abbildung 36, links außen, roter Balken). Die Aktivität des IRF-3responsiven Promotors nach Transfektion von TRBV-S9 (s. Abbildung 36, Mitte links, blauer Balken) ist höher als die Promotoraktivität in der Kontrolle (s. Abbildung 36 rechts außen, blauer Balken), mit $\mathrm{p}=0,1$ ist dieser Unterschied jedoch nicht signifikant. Die Promotoraktivitäten in den mit TRBV-S7 und TRBV-S9 co-transfizierten Zellen ähneln dem Ergebnis für die Proben der TRBV-S9Transfektion (s. Abbildung 36, Mitte rechts, blauer Balken). Nach der Stimulation mit poly(I:C) ist die Aktivität in der mit TRBV-S9 transfizierten Proben (s. Abbildung 36, 
Mitte links, roter Balken) mit $\mathrm{p}=0,02$ jedoch signifikant niedriger als in den Zellen der Kontrollprobe (s. Abbildung 36 rechts außen, roter Balken).

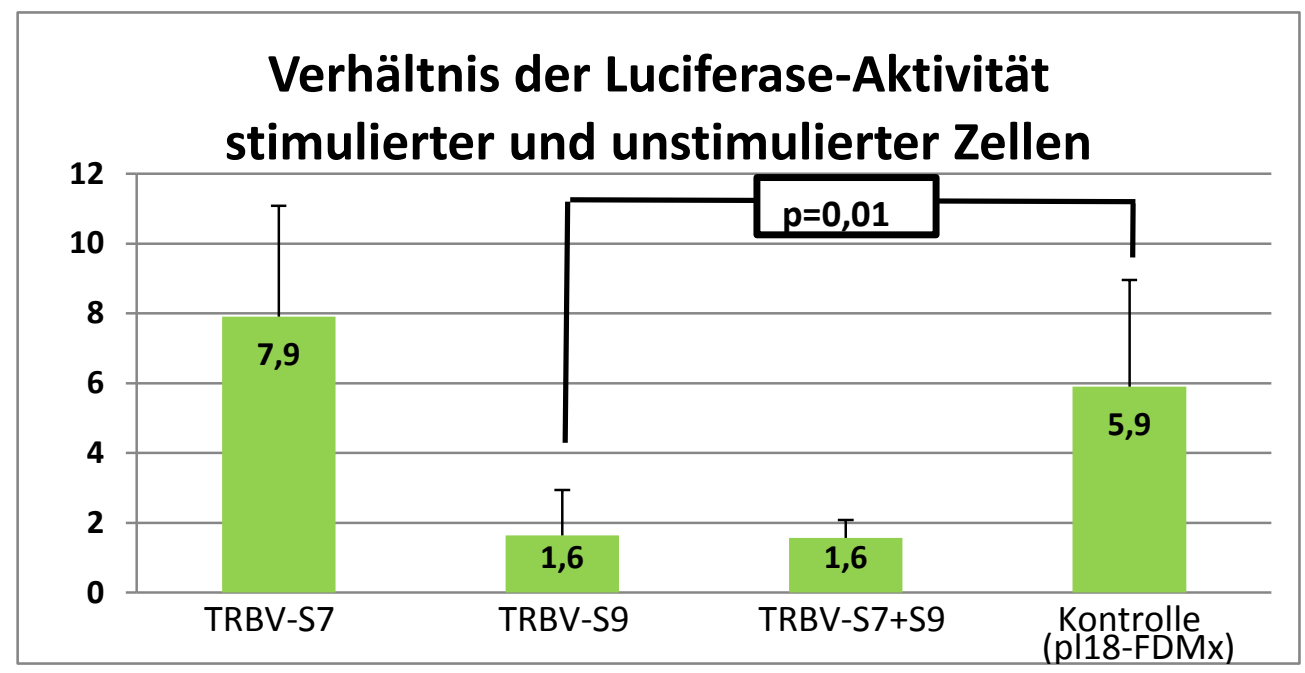

Abbildung 37: Verhältnis der Aktivität des IRF-3-responsiven Promotors stimulierter und unstimulierter Zellen nach Transfektion mit Expressionsplasmiden für NS-2 (TRBV-S7) und Helikase (TRBV-S9 mit ORF-Xa-Region) bzw. deren Co-Transfektion (TRBV-S7+S9) und Stimulation mit poly(I:C), MW aus sieben Versuchen.

Der Anstieg der IRF-3-responsiven Promotoraktivität durch die Stimulation ist in den mit TRBV-S9 infizierten Zellen (nach Stimulation 160\% der Aktivität ohne Stimulation) wesentlich geringer als in der Kontrolle (nach Stimulation 590\% der Aktivität ohne Stimulation). Dieser Unterschied ist mit $\mathrm{p}=0,01$ sehr signifikant ( $\mathrm{p} \leq 0,01)$ (s. Abbildung 37). Damit ist die TRBV-Helikase/ ORF-Xa im Gegensatz zu TRBV-NS-2 zumindest teilweise in der Lage, die dsRNA vermittelte Aktivierung des IRF3-responsiven Promotors zu unterdrücken.

\subsubsection{Messung der Aktivität eines IRF-3-responsiven Promotors nach Transfektion von Expressionsplasmiden für TRBV-Gene und Stimulation mit IRF-3(5D)}

Wie im oben beschriebenen Experiment wurde eine Reihe weiterer Dual-LuciferaseReporter-Assays mit HEK-293-Zellen nach Transfektion der Expressionsplasmide für virale Gene durchgeführt. In diesem Versuch wurde jedoch mittels Transfektion eines Expressionsplasmides für IRF-3(5D) im Vergleich zur Mock-Behandlung mit 
pUC-19 stimuliert. Bei IRF-3(5D) handelt es sich um ein künstliches IRF-3-Protein, bei dem alle Serin-Phosphorylierungsstellen durch Aspartat ersetzt wurden. Dadurch ist dieses IRF3-Protein konstitutiv aktiv, d.h. eine Phosphorylierung zur Aktivierung ist nicht mehr notwendig (Lin et al. 1998).

Die Mittelwerte der Firefly-Luciferase-Aktivität aus vier durchgeführten Experimenten ist in Abbildung 38 in relativen Einheiten dargestellt. Der Anstieg der Aktivität durch die Stimulation wurde auch hier für jedes Einzelexperiment errechnet, die Mittelwerte aller Anstiegsberechnungen sind in Abbildung 39 dargestellt.

Mit $\mathrm{p}=0,002$ ist der Unterschied zwischen stimulierten und nicht stimulierten Zellen der Kontrollprobe sehr signifikant, die Stimulation durch IRF-3(5D)-Expression daher als effektiv anzusehen (s. Abbildung 38, rechts außen).

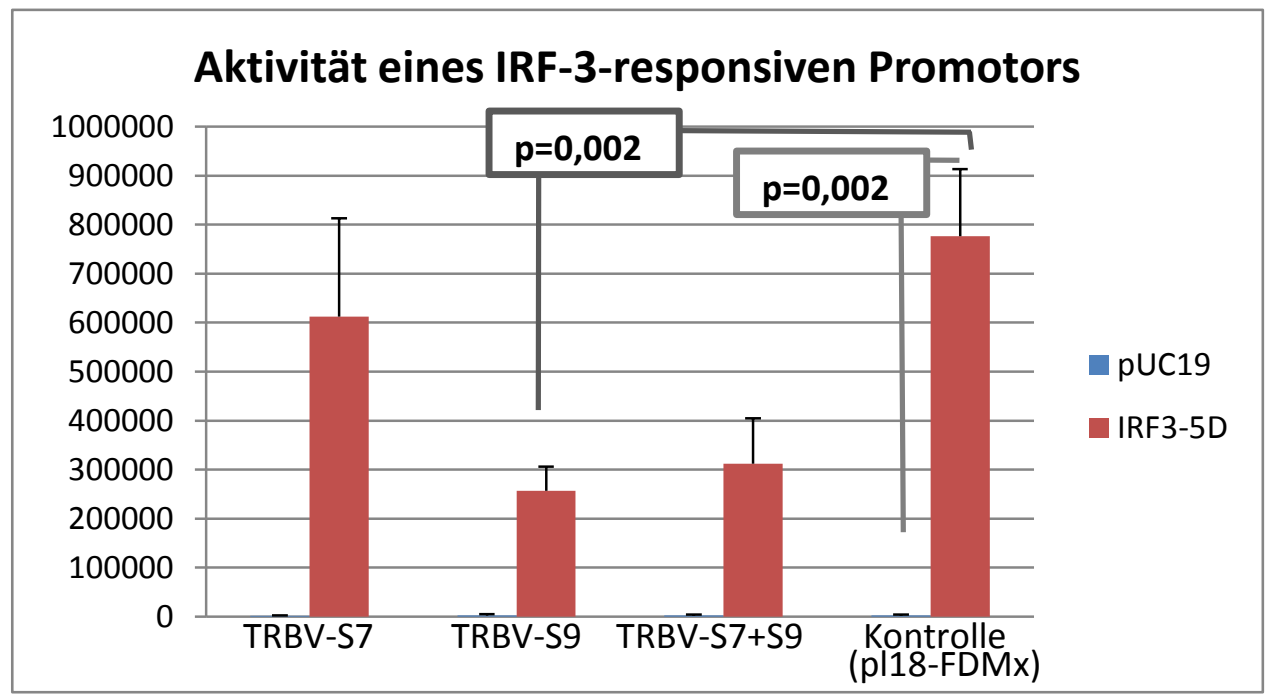

Abbildung 38: Messung der Aktivität eines IRF-3-responsiven Promotors nach Transfektion mit Expressionsplasmiden für NS-2 (TRBV-S7) und Helikase (TRBV-S9 mit ORF-Xa-Region) bzw. deren Co-Transfektion (TRBV-S7+S9) und Stimulation mit IRF-3(5D), MW aus vier Versuchen.

Die Aktivität des IRF-3-responsiven Promotors der mit pUC-19 transfizierten Zellen ist in allen Proben vergleichbar niedrig. In den mit IRF-3(5D) stimulierten Proben fällt die Promotoraktivität für die mit TRBV-S9 transfizierten Zellen wesentlich 
geringer aus als für die Kontrolle. Dieser Unterschied ist mit $\mathrm{p}=0,002$ sehr signifikant (s. Abbildung 38, rote Balken).

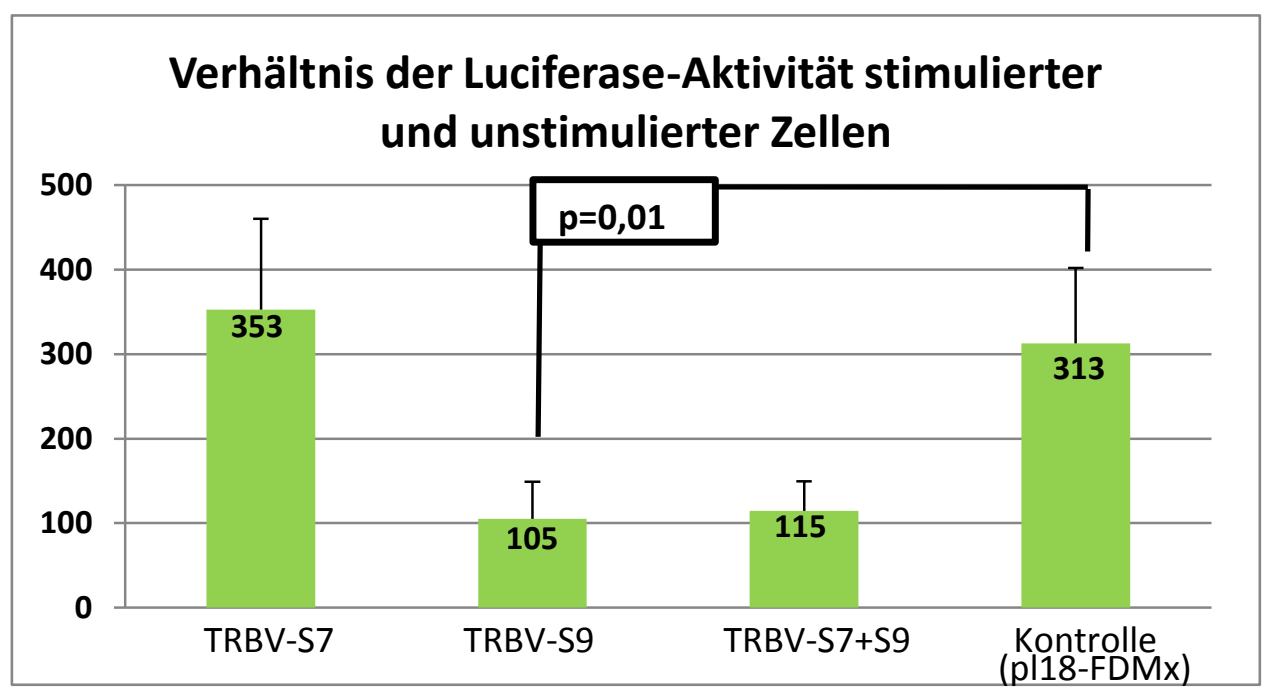

Abbildung 39: Verhältnis der Aktivität des IRF-3-responsiven Promotors stimulierter und unstimulierter Zellen nach Transfektion mit Expressionsplasmiden für NS-2 (TRBV-S7) und Helikase (TRBV-S9 mit ORF-Xa-Region) bzw. deren Co-Transfektion (TRBV-S7+S9) und Stimulation mit IRF-3(5D), MW aus vier Versuchen.

Dieser gezeigte Unterschied spiegelt sich auch in dem Anstieg der Promotoraktivität von den nicht stimulierten Zellen zu den stimulierten Proben wieder. Auch hier ist der Unterschied zwischen den mit TRBV-S9 transfizierten Zellen zu der Kontrollprobe mit $\mathrm{p}=0,01 \mathrm{sehr}$ signifikant $(\mathrm{p} \leq 0,01)$ (s. Abbildung 39). Somit konnte auch hier gezeigt werden, dass die TRBV-Helikase/ ORF-Xa im Gegensatz zu TRBV-NS-2 zumindest teilweise in der Lage ist, die durch IRF-3(5D) vermittelte Aktivierung des IRF-3-responsiven IFN- $\beta$-Promotors zu unterdrücken. 


\section{$4 \quad$ Diskussion}

Das Tribec-Virus ist ein in Europa weit verbreitetes Virus (Dobler 1996; Suss und Schrader 2004; Dobler et al. 2006), welches möglicherweise beim Menschen eine unspezifische, fieberhafte Erkrankung mit neurologischen Symptomen verursacht und bei der Entstehung aseptischer Meningitiden, Meningoenzephalitiden und Enzephalitiden eine Rolle spielt (Gresikova et al. 1966; Suss und Schrader 2004). Bei viralen Infektionen reagiert der infizierte Organismus mit der Aktivierung seines Immunsystems, um die Erreger abzuwehren. Als primäre Immunantwort bei Virusinfektionen wird das Interferonsystem aktiviert. Dieses wird zum angeborenen, unspezifischen Immunsystem gerechnet (Kayser et al. 2005). Um diese erste Abwehr zu umgehen haben viele Viren wirkungsvolle Gegenstrategien entwickelt, wie die Unterdrückung der Interferonsynthese, die Ausschaltung des IFN-Signalweges oder die Blockierung von antiviralen Effektorproteinen (Weber et al. 2004; Randall und Goodbourn 2008). Mögliche Angriffspunkte zur Blockierung der Interferonsynthese sind die Transkriptionsfaktoren AP-1, IRF-3 und NF- $x$ B (Weber et al. 2003).

Das Ziel der vorliegenden Arbeit war die Untersuchung der Pathogenitätsfaktoren des TRBV und deren Wirkung auf das Interferonsystem von infizierten Zellen. Hierzu sollte die Aktivierung des Interferonsystems beziehungsweise dessen Hemmung durch das Virus in verschiedenen Zelllinien untersucht werden. Weiterhin sollten die viralen Genprodukte identifiziert werden, welche einen Einfluss auf das Interferonsystem ausüben.

Ein Einfluss auf die Aktivierung des Interferonsystems der infizierten Zellen wurde für die Nicht-Strukturproteine wie das NS-2 auf TRBV-S7 oder ein durch die alternativ gelesene Sequenz ORF-Xa auf TRBV-S9 kodiertes Protein vermutet, da Proteine, die nicht Bestandteil der viralen Partikel sind, in aller Regel akzessorische Funktionen besitzen. 


\subsection{Interferonkompetente Zellen sind nicht vor einer Infektion durch das TRBV geschützt}

Mittels Impedanzmessung wurde die Wachstumskurve verschiedener Zelllinien nach Infektion mit dem zu untersuchenden TRBV im Vergleich zum IFN stimulierenden RVFV-Clone-13 gemessen.

In den interferonkompetenten murinen Wildtypzellen PKR+/+ konnte nach TRBVInfektion mit einer MOI von 1 ein $\mathrm{CPE}$ nachgewiesen werden, während sich die RVFV-Clone-13-Infektion bei gleicher MOI praktisch nicht auf die Viabilität der Zellen auswirkte (s. Abbildung 8, S. 52). Das TRBV scheint also über einen Pathogenitätsfaktor zu verfügen, welcher es ihm ermöglicht, IFN-kompetente Zellen im Vergleich zum RVFV-Clone-13 effizienter zu infizieren.

Auf den nicht interferonkompetenten Zellen IFNAR-/- konnte wie erwartet nach Infektion mit beiden Viren ein CPE nachgewiesen werden. Es zeigt sich im Absinken des Zellindex kein Unterschied zwischen den mit hoher und mit niedriger MOI TRBV-infizierten Zellen (s Abbildung 9, S. 53), während es bei der RVFV-Clone-13Infektion einen Einfluss der MOI auf die Geschwindigkeit des Zellsterbens zu geben scheint (s. Abbildung 10, S. 54). Dieser Unterschied in der RVFV-Clone-13-Infektion kann auf die noch vorhandene Induktion der übrigen antiviralen Mechanismen in den IFNAR-/- Zellen zurückgeführt werden. Da diesen Zellen der Interferonrezeptor IFNAR fehlt, kommt es nicht zur Aktivierung der InterferonSignalkaskade, wohl aber zu einer Virus-vermittelten Aktivierung antiviral wirksamer Gene wie z.B. ISG-56 über IRF-3 (Collins et al. 2004), welche für die leichte Verzögerung der Infektion bei geringer MOI des IFN-induzierenden RVFV-Clone13 verantwortlich sein könnte.

In den interferonkompetenten HEK-293-Zellen ist ein deutlicher Unterschied zwischen den mit TRBV und den mit RVFV-Clone-13 infizierten Proben zu sehen (s. Abbildung 11, S. 56). Während sich die mit RVFV-Clone-13 infizierten Zellen ebenso wie die Mock-infizierten Zellen einige Stunden nach der Manipulation wieder erholen, kommt es in den mit TRBV behandelten Kavitäten zu einem klaren Abfall des Zellindex, welcher in den mit einer hohen MOI infizierten Proben noch 
deutlicher zu sehen ist. Das TRBV ist also in der Lage, in Zellen, welche nach Infektion mit dem das Interferon-induzierenden RVFV-Clone-13 eine praktisch unveränderte Viabilität im Vergleich zu Mock-infizierten Zellen aufweisen, einen CPE auszulösen. Dies spricht für eine Umgehung der Interferonabwehr durch das TRBV.

In einem weiterem Experiment wurden HEK-293-Zellen im Vergleich zur Einzelinfektion mit RVFV-Clone-13 und TRBV co-infiziert (s. Abbildung 12, S. 57). Hierbei wurde sowohl für die Einzelinfektionen als auch für die Co-Infektion eine sehr hohe MOI gewählt, um sicherzustellen, dass alle Zellen infiziert werden. Im Gegensatz zu den vorangegangenen Experimenten kam es hierbei auch nach RVFVClone-13-Infektion zu einem Absinken des Zellindex. Hierfür könnten folgende Faktoren verantwortlich sein: Zum einen ist anzunehmen, dass es zu einer initialen Virusreplikation kommt, die einen gewissen CPE auslöst. Zum anderen kommt es sicherlich zu einer starken Aktivierung des IFN-Systems und damit zur Synthese antiviral-aktiver Proteine wie z.B. PKR. Viele dieser Proteine besitzen wachstumshemmende Eigenschaften (Stark et al. 1998; de Veer et al. 2001). Offensichtlich führt dies aber auch zu einer effizienten Hemmung der RVFV-Clone13- Replikation, da es nicht zu einem weiteren Absinken des Zellindex kommt. Im Gegensatz zu den mit RVFV-Clone-13-behandelten Proben sinkt der Index in den mit TRBV behandelten Kavitäten zunächst nicht ab, was auf ein Ausbleiben des durch IFN induzierten Wachstumsarrests zurückzuführen sein könnte. Die Effektivität der Infektion mit TRBV wird in dem rapiden Abfall des Zellindex sowohl in der Einzelinfektion mit TRBV als auch in der Co-Infektion zu einem späteren Zeitpunkt deutlich. Vor diesem Hintergrund spricht der Kurvenverlauf des Zellindex der co-infizierten Proben für die ausbleibende Aktivierung des IFNSystems durch das interferoninduzierende RVFV-Clone-13 in Anwesenheit von TRBV und somit für eine aktive Hemmung dieser Immunabwehr durch TRBV.

\subsection{Das TRBV hemmt die Induktion des Typ-I-Interferons IFN- $\beta$}

Anschließend wurde die Induktion des Typ-I-Interferons IFN- $\beta$ durch TRBV untersucht. Hierzu wurde mittels RT-PCR die IFN- $\beta$-Transkription in HEK-293- 
Zellen nach Infektion mit dem TRBV sowie nach Infektion mit dem das Interferonsystem induzierenden RVFV-Clone-13 analysiert. Die Gelelektrophorese (s. Abbildung 13, S. 59) zeigt, dass die Induktion des $\beta$-Interferons nach Infektion mit TRBV wesentlich schwächer ausfällt als in den mit RVFV-Clone-13 infizierten Zellen, obwohl eine Virusreplikation in beiden Proben nachgewiesen werden konnte (s. Abbildung 14, S. 59). Eine TRBV-Infektion führt zu keiner effektiven Aktivierung des IFN-Systems, während RVFV-Clone-13 ein effizienter IFN- $\beta$-Induktor ist.

Um Aufschluss darüber zu erhalten, ob es sich hierbei um eine fehlende Detektion der TRBV-spezifischen PAMPs (z.B. durch unterschiedliche intrazelluläre Lokalisation von viraler RNA und Sensor) oder um eine aktive Inhibition des IFNSystems durch TRBV handelt, wurden Co-Infektionsexperimente durchgeführt. Hierbei ergab sich, dass bei der Co-Infektion von TRBV und dem IFNinduzierenden RVFV-Clone-13 keine effiziente Aktivierung der IFN- $\beta$ Transkription erfolgt (s. Abbildung 15, S. 60). Da ausgeschlossen werden konnte, dass eine verminderte RVFV-Clone-13 spezifische Transkription für die fehlende IFN- $\beta$ Induktion verantwortlich ist (s. Abbildung 16, S. 61), spricht dieses Ergebnis für eine aktive Inhibition des IFN-Systems durch TRBV.

\subsubsection{Der Einfluss von TRBV-Infektionen auf die Aktivierung des IFN- $\beta$ - Promotors}

Um die Aktivität des IFN- $\beta$-Promotors nach Infektion mit TRBV zu messen wurden Dual-Luciferase-Reporter-Assays mit HEK-293-Zellen durchgeführt. Als positive Kontrolle wurde gleichzeitig die IFN- $\beta$-Promotoraktivität nach Infektion mit dem Interferon stimulierenden RVFV-Clone-13 gemessen. Zusätzlich wurden die infizierten Zellen mit RNA VSV-infizierter Vero-E6-Zellen bzw. mit poly(I:C) stimuliert, um Aufschluss darüber zu erhalten, ob eine TRBV-Infektion die Aktivierung des IFN- $\beta$-Promotors durch bekannte PAMPs (5'-Triphosphat-RNA über RIG-I bzw. poly(I:C) über MDA5) (Brennan und Bowie 2010) inhibieren kann.

Nach Infektion mit TRBV ohne Stimulation ist die IFN- $\beta$-Promotoraktivität nur geringfügig erhöht, ein signifikanter Unterschied zur Kontrolle ist nicht festzustellen. Der Unterschied zu der durch RVFV-Clone-13 induzierten IFN- $\beta$-Promotoraktivität 
ist jedoch signifikant (vgl. Abbildung 17, S. 63 und Abbildung 20, S. 66). Im Gegensatz zu einer Infektion mit RVFV-Clone-13 wird der IFN- $\beta$-Promotor durch TRBV also nur sehr geringfügig aktiviert.

Nach der Stimulation mit RNA VSV-infizierter Vero-E6-Zellen ist die Promotoraktivität in den mit TRBV behandelten Proben niedriger als in der Kontrolle, ein signifikanter Unterschied ist jedoch durch die hohen Standardabweichungen nicht festzustellen (s. Abbildung 17, S. 63). Die Stimulation mit poly(I:C) zeigt eine signifikant geringere Aktivierung des IFN- $\beta$-Promotors in der mit TRBV infizierten Probe im Vergleich zur Kontrolle (Abbildung 20, S. 66). Durch eine höhere Anzahl der Versuche zur Stimulation mit RNA VSV-infizierter Vero-E6-Zellen hätte man sicherlich ein ähnliches Signifikanzniveau wie in den häufiger durchgeführten Versuchen zur Stimulation durch poly(I:C) erreichen können. Für die Stimulation mit beiden untersuchten PAMPs bleibt festzuhalten, dass die Aktivierung des IFN- $\beta$ Promotors durch TRBV nicht komplett, sondern nur teilweise gehemmt wird.

Der Anstieg der Promotoraktivität nach Stimulation fällt in beiden Versuchen in den TRBV-infizierten Zellen signifikant geringer aus als in der Kontrolle (s. Abbildung 18, S. 64 und Abbildung 21, S. 67). Dies liegt jedoch auch daran, dass die Aktivität des IFN- $\beta$-Promotors nach Infektion mit TRBV leicht, wenn auch nicht signifikant erhöht ist. Daher kommt es auch zusammen mit der ebenfalls nicht signifikant geringeren Promotoraktivierung durch Stimulation mit RNA VSV-infizierter Verozellen in mit TRBV infizierten Zellen zu einem sehr signifikant geringeren Anstieg der Promotoraktivierung.

Da RVFV-Clone-13 ein sehr effizienter IFN- $\beta$-Induktor ist, ist der IFN- $\beta$-Promotor durch die Infektion bereits maximal aktiviert, so dass eine weitere Aktivierung durch Stimulation mit PAMPs nicht mehr möglich ist. Dies ist jedoch nicht mit einer Hemmung der Promotoraktivierung durch RVFV-Clone-13 zu verwechseln, wie sie für TRBV gezeigt werden konnte (s. Abbildung 17, S. 63, und Abbildung 20, S. 66). Während bei den RVFV-Clone-13 infizierten Zellen eine weitere Aktivierung des IFN- $\beta$-Promotors durch Stimulation mit RNA VSV-infizierter Verozellen bzw. poly(I:C) nicht möglich ist, ist der Unterschied im Anstieg der Promotoraktivität 
zwischen TRBV-infizierten Zellen und der Kontrolle als real zu bewerten, da es hier ohne Stimulation keinen signifikanten Unterschied in der Promotoraktivität zu den nicht infizierten Zellen gibt.

Diese Ergebnisse zeigen eine geringfügige, latente Aktivierung des IFN- $\beta$-Promotors nach TRBV-Infektion. Die zusätzliche Aktivierung des IFN- $\beta$-Promotors durch RNA-PAMPs wird durch TRBV nicht komplett, sondern nur teilweise gehemmt. Dies ist durch die vorherige latente Aktivierung zu erklären, welche $\mathrm{zu}$ einer effizienteren Stimulation des Typ-I-IFN-Systems führt und eine vollständige Unterdrückung der Aktivierung durch virale Erreger verhindern kann (Kuri et al. 2009).

\subsubsection{Einfluss verschiedener TRBV-Proteine auf die Aktivierung des IFN- $\beta$ - Promotors}

In einer Reihe weiterer Experimente wurden Dual-Luciferase Assays mit HEK-293Zellen nach Transfektion von Expressionsplasmiden für verschiedene TRBV-Gene durchgeführt. Hierzu wurden die Zellen mit den Expressionskonstrukten TRBV-S7 (zur Expression des NS-2) oder TRBV-S9 (zur Expression der Helikase bzw. des ORF-Xa) transfiziert, oder beide Konstrukte co-transfiziert. Innerhalb des Leserahmens der Helikase befindet sich der alternative Leserahmen ORF-Xa, dessen Protein bislang noch keine Funktion zugeordnet werden konnte. Als Kontrolle wurde gleichzeitig die Promotoraktivität nach Transfektion mit pI.18-FDMx gemessen.

Die Daten der Firefly-Luciferase-Aktivität wurden nicht mit der Renilla-LuciferaseAktivität korrigiert, da die Messung der Renilla-Luciferase-Aktivität nicht zu verwerten war. Offensichtlich haben die Gensegmente des TRBV in ihrer transfizierten Form einen Einfluss auf die SV40-Promotor getriebene Expression der Renilla-Luciferase (nach Co-Transfektion des Kontrollplasmids pRLSV40), wodurch die Renilla-Luciferase-Aktivität nicht mehr als Maß für die Transfektionseffizienz verwendet werden kann. Daher wurde in allen weiteren Transfektionsexperimenten auf eine Korrektur mit der Renilla-Luciferase-Aktivität verzichtet und nur die Messung der Firefly-Luciferase verwendet. 


\subsubsection{TRBV-Segment 9 codiert für ein oder mehrere Proteine, die die IFN- $\beta$-Synthese hemmen}

Zunächst wurde die IFN- $\beta$-Promotoraktivität nach Transfektion von Expressionsplasmiden für TRBV-Gene und Stimulation mit RNA VSV-infizierter Verozellen gemessen.

Die Expression des auf Segment 7 codierten NS-2-Proteins zeigt im Vergleich zur Kontrolle (Expression des FLAG-deltaMx Proteins) keinen Einfluss des auf die IFN- $\beta$-Promotoraktivität (s. Abbildung 22, S. 69). Zwar wurde die Expression des NS-2 nicht auf Proteinebene überprüft; da mittels Sequenzierung der korrekte Einbau der NS-2-cDNA in die Expressionskassette gezeigt wurde und bisher alle hergestellten pI.18-Expressionskonstrukte funktionell sind, ist jedoch davon auszugehen, dass eine Proteinsynthese stattgefunden hat.

Nach Transfektion des Expressionsplasmides für die auf Segment 9 in überlappenden Leserahmen codierten Proteine Helikase und ORF-Xa ist die Aktivität des IFN- $\beta$-Promotors etwas höher als in der Kontrolle (Expression des FLAG-deltaMx Proteins), ebenso in den mit TRBV-S7 (Expressionsplasmid für TRBV-NS-2) und TRBV-S9 co-transfizierten Zellen. Hier scheint ein nach TRBV-S9 Transfektion exprimiertes Protein zu der bereits in den Infektionsexperimenten beobachteten latenten Aktivierung des IFN-Systems zu führen.

Nach der Stimulation mit RNA VSV-infizierter Verozellen ist die Aktivität in den mit TRBV-S9 transfizierten Proben jedoch hoch signifikant niedriger als in den Zellen der Kontrollprobe (s. Abbildung 22, S. 69). Auch der Anstieg der Aktivität durch die Stimulation fällt in den mit TRBV-S9 transfizierten Zellen signifikant geringer aus als in der Kontrolle (s. Abbildung 23, S. 70). Dies lässt auf eine aktive Inhibition der Aktivität des IFN- $\beta$-Promotors durch ein auf TRBV-S9 codiertes Protein schließen.

In einer zweiten Versuchsreihe wurde die IFN- $\beta$-Promotoraktivität nach Stimulation mit der synthetischen Substanz poly(I:C) gemessen.

Die Ergebnisse der Promotoraktivierung der TRBV-S7-transfizierten Zellen ähneln wie auch im vorherigen Versuch (Stimulation mit RNA VSV-infizierter Verozellen) denen der Kontrolle. Auch nach der Stimulation mit poly(I:C) kann kein Einfluss des 
auf TRBV-S7 kodierten NS-2 auf die Interferon- $\beta$-Promotoraktivität nachgewiesen werden.

Wie bereits im vorherigen Versuch ist die Grundaktivität des IFN- $\beta$-Promotors nach Transfektion von TRBV-S9 sowohl in den einzeln transfizierten als auch in den mit TRBV-S7 co-transfizierten Zellen etwas höher als die Promotoraktivierung der Kontrolle (s. Abbildung 24, S. 71), was auf eine latente Aktivierung des IFN-Systems durch Helikase/ORF-Xa schließen lässt.

Nach der Stimulation mit poly(I:C) ist die Aktivität in den mit TRBV-S9 transfizierten Proben jedoch auch hier signifikant niedriger als in den mit pI.18FDMx transfizierten Zellen der Kontrolle (s. Abbildung 24, S. 71). Der Unterschied bezüglich der IFN- $\beta$-Promotor-Aktivierung zwischen den TRBV-S9-transfizierten Proben und der Kontrolle fällt hier sogar noch deutlicher aus als nach der Stimulation mit RNA VSV-infizierter Verozellen (s. Abbildung 25, S. 72). Diese hoch signifikante Hemmung der Aktivierung des Interferon-Promotors in den mit TRBVS9 transfizierten Zellen im Vergleich zur Kontrolle zeigt eine effektive und aktive Hemmung der poly(I:C)-induzierten Aktivierung des Interferon- $\beta$-Promotors durch ein auf TRBV-S9 kodiertes Protein.

\subsubsection{TRBV-Helikase/ORF-Xa haben keinen Einfluss auf die AP-1- abhängige Promotoraktivität}

Das Aktivierende Protein (AP)-1 ist einer der Transkriptionsfaktoren, welche nach Stimulation im sogenannten Enhanceosom an den IFN- $\beta$-Promotor im Zellkern binden und so die Synthese des IFN- $\beta$ initiieren (s.o.). Um die Aktivität eines AP-1 responsiven Promotors (s. 2.4.6, S. 40) zu messen wurden die Zellen mit den Expressionsplasmiden für Helikase und ORF-Xa (TRBV-S9) bzw. TRBV-NS-2 (TRBV-S7), dem Reporter-Konstrukt pAP1-Luc sowie pFC MEKK co-transfiziert, bzw. die nicht stimulierten Proben mit pUC-19 (ein rein bakterielles Plasmid ohne eukaryontischen Promotor, als Kontroll-DNA verwendet) transfiziert.

Als Kontrolle der Stimulation mit MEKK wurde für die pI18-FDMx-transfizierten Zellen der Unterschied zwischen der nicht stimulierten und der stimulierten Probe mit dem zweiseitigen Zweistichproben-t-Test unter der Annahme unterschiedlicher Varianzen berechnet. Aufgrund der hohen Standardabweichung in den 
Messergebnissen der stimulierten Proben ist dieser Unterschied mit $\mathrm{p}=0,05$ gerade noch signifikant $(\mathrm{p} \leq 0,05)$, die Stimulation wurde daher als effektiv bewertet (s. Abbildung 26, S. 74).

Der Unterschied in der Promotoraktivierung zwischen den TRBV-S9-transfizierten Zellen und der Kontrolle ist mit p=0,69 so weit von einer Signifikanz entfernt, dass von einem Einfluss des TRBV-S9 auf die AP-1-Promotoraktivität nicht auszugehen ist (s. Abbildung 26, S. 74). Hierfür spricht auch der berechnete Anstieg der Promotoraktivität nach Stimulation mit MEKK. Der Anstieg der Aktivität in den mit TRBV-S9 transfizierten Zellen fällt sogar höher aus als in der Kontrolle, mit p=0,35 ist der Unterschied aber nicht signifikant (s. Abbildung 27, S. 75).

In den mit dem TRBV-S7 transfizierten Zellen fällt die Promotoraktivität nach der Stimulation mit MEKK niedriger aus als in der Kontrolle, ein signifikanter Unterschied zwischen der Aktivierung in der TRBV-S7-Probe und der Kontrolle ist bei dem vorgegebenen Signifikanzniveau mit $\mathrm{p}=0,1$ jedoch nicht festzustellen (s. Abbildung 26, S. 74). Der Anstieg der AP-1-responsiven Promotoraktivität von der unstimulierten zur stimulierten Probe ist bei den TRBV-S7 transfizierten Zellen wesentlich geringer als in der Kontrolle, mit $\mathrm{p}=0,01$ ist dieser Unterschied signifikant (s. Abbildung 27, S. 75).

Das TRBV-NS-2 scheint eine hemmende Wirkung auf die Aktivierung des AP-1Promotors zu besitzen, die TRBV-Helikase bzw. das ORF-Xa jedoch nicht. Damit kann ausgeschlossen werden, dass die Helikase/ORF-Xa-vermittelte Hemmung der Aktivierung des IFN- $\beta$-Promotors auf eine Hemmung der AP-1-Aktivierung zurückzuführen ist. Die Hemmung der AP-1-Aktivierung durch TRBV-NS-2 scheint keinen Einfluss auf die Aktivierung des IFN- $\beta$-Promotors zu haben, da diese durch NS-2 nicht gehemmt wird (s. Abbildung 22, S. 69 und Abbildung 24, S. 71). Dies ist wahrscheinlich auf die Tatsache zurückzuführen, dass AP-1 im Vergleich zu NF- $x$ B und IRF-3 den geringsten Beitrag zur Aktivierung des IFN- $\beta$-Promotors leistet (Panne 2008). 


\subsubsection{TRBV-Helikase/ORF-Xa induzieren eine NF- $x \mathrm{~B}$-abhängige Promotoraktivität nach Transfektion verschiedener RNA-Spezies}

Der Transkriptionsfaktor NF- $x \mathrm{~B}$ (nuclear factor 'kappa-light-chain-enhancer' of activated B-cells) wird durch zahlreiche Zytokine (z.B. TNF- $\alpha$ ) und PAMPs (z.B. virale dsRNA) aktiviert und bewirkt im Zellkern unter anderem zusammen mit anderen Faktoren die Expression von Interferon.

Um die NF- $x \mathrm{~B}$ responsive Promotoraktivität in Anwesenheit des Nichtstrukturproteins NS-2 (TRBV-S7) bzw. Helikase/ORF-Xa (TRBV-S9) zu untersuchen, wurden - wie oben beschriebenen - Dual-Luciferase-Reporter-Assays mit HEK-293-Zellen durchgeführt. Die Stimulation erfolgte mit poly(I:C), die nicht stimulierten Proben wurden mit Vero-E6-Zell-RNA behandelt. Insgesamt dauerte die Inkubation von der Transfektion bis zur Zelllyse hier 40 Stunden, von der Stimulation bis zur Lyse 16 Stunden.

Die Ergebnisse der TRBV-S7-transfizierten Proben ähneln der Kontrolle und zeigen keinen Einfluss des TRBV-NS-2 auf die Aktivität des NF- $\varkappa$ B-responsiven Promotors (s. Abbildung 28, S. 76). Auch der Anstieg der Promotoraktivität nach Stimulation mit poly(I:C) ist in den mit TRBV-S7 transfizierten Zellen vergleichbar zur Kontrolle (mit pI18-FDMx transfizierte Zellen, s. Abbildung 29, S. 77) und lässt damit keinen Einfluss von TRBV-NS-2 auf die Aktivierung des Promotors erkennen.

Bei der Aktivität des Promotors in den mit TRBV-S9 transfizierten Zellen ist ein deutlicher Unterschied zu der Kontrolle zu sehen. Dies gilt sowohl für die nur mit TRBV-S9 transfizierten, als auch für die mit TRBV-S7 und -S9 co-transfizierten Zellen (s. Abbildung 28, S. 76). Bereits ohne poly(I:C)-Stimulation ist die Promotoraktivität in diesen Proben sehr hoch, eine weitere Aktivierung durch poly(I:C) ist nicht möglich (vgl. Abbildung 29, S. 77). Der beobachtete Abfall der Reporteraktivität nach Stimulation mit poly(I:C) ist unter Umständen darauf zurückzuführen, dass poly(I:C) auch eine PKR-vermittelte Hemmung der Translation induziert (Meurs et al. 1992; de Veer et al. 2001). Der Unterschied zwischen der Promotoraktivität der mit TRBV-S9 transfizierten Zellen und der Kontrolle nach Stimulation ist hoch signifikant, die Expression der TRBV-Helikase bzw. des ORF- 
$\mathrm{Xa}$ führt unter diesen Versuchsbedingungen also zur Aktivierung des NF- $x \mathrm{~B}-$ responsiven Promotors.

Wie im oben beschriebenen Experiment wurde in einem weiteren Versuch die NFxB-Promotoraktivität untersucht, die Stimulation erfolgte hier mit RNA VSVinfizierter Verozellen bzw. wurden die nicht stimulierten Proben mit RNA nicht infizierter Verozellen behandelt.

Auch die Ergebnisse aus diesem Experiment zeigen keinen Unterschied der TRBVS7-transfizierten Zellen zur Kontrolle und damit keinen Einfluss von NS-2 auf die NF- $x$ B responsive Promotoraktivität (s. Abbildung 30, S. 79).

Die NF- $x$ B-Promotoraktivität in den mit TRBV-S9 transfizierten bzw. mit TRBV-S7 und-S9 co-transfizierten Zellen ist auch hier bereits ohne zusätzliche Stimulation mit RNA VSV-infizierter Verozellen deutlich höher als in der Kontrolle und sogar höher als in den mit RNA VSV-infizierter Verozellen stimulierten Zellen der gleichen Proben, weshalb auch die Berechnung des Anstiegs der Promotoraktivität für diese Proben keine realen Ergebnisse liefert.

Der Unterschied bezüglich der Aktivität des NF- $\varkappa$ B-responsiven Promotors zwischen den TRBV-S9-transfizierten Zellen und der Kontrolle ist hoch signifikant (s. Abbildung 30, S. 79). Aus den Ergebnissen ergibt sich eine NF- $x$ B-induzierende Eigenschaft der TRBV-Helikase/TRBV-ORF-Xa. Damit kann die beobachtete Hemmung der Aktivierung des IFN- $\beta$-Promotors durch die TRBV-Helikase/TRBVORF-Xa nicht auf eine Hemmung der Aktivierung von NF- $x \mathrm{~B}$ zurückgeführt werden.

\subsubsection{TRBV-Helikase/ORF-Xa hemmen die TNF- $\alpha$-induzierte Aktivierung eines NF- $\varkappa$ B-responsiven Promotors}

In einem weiteren Versuch wurde wie in den oben beschriebenen Experimenten ein Dual-Luciferase-Reporter-Assay mit HEK-293-Zellen nach Transfektion der Expressionsplasmide TRBV-S7 und TRBV-S9 durchgeführt, um die Aktivität des NF-xB-responsiven Promotors (s. 2.4.6, S. 40) zu messen. In diesem Versuch wurde jedoch mit dem NF- $x$ B-aktivierendem TNF- $\alpha$ im Vergleich zur Mock-Behandlung stimuliert. Die Transfektion dauerte hier insgesamt 24 Stunden, die Stimulation nur 
12 Stunden, da die I $x$ B-Inhibitorprotein-Kinase (IKK)-vermittelte Stimulation durch TNF- $\alpha$ ihren Höhepunkt zu einem sehr frühen Zeitpunkt erreicht (Werner et al. 2005). In der Kontrolle ist die Stimulation mit TNF- $\alpha$ sehr effektiv.

Auch in diesem Versuch ist die Aktivität des NF- $x$ B-responsiven Promotors in den mit TRBV-S9 transfizierten Zellen ohne die Stimulation mit TNF- $\alpha$ signifikant höher als in der Kontrolle (s. Abbildung 32, S. 81), so dass auch nach der kürzeren Inkubationszeit bereits die Induktion des NF- $x$ B-responsiven Promotors durch TRBV-S9 gezeigt werden konnte. Hier fällt die NF-xB-Induktion jedoch wesentlich geringer aus, als in den mit RNA aus nicht infizierten Vero-Zellen behandelten Proben (vgl. mit Abbildung 28, S. 76 und Abbildung 30, S. 79), so dass hier nach der Stimulation mit TNF- $\alpha$ die hemmenden Eigenschaften zu überwiegen scheinen.

Nach Stimulation mit TNF- $\alpha$ ist in den mit TRBV-S9 transfizierten Zellen die Promotoraktivität signifikant geringer als in stimulierten Kontrollzellen (s. Abbildung 32, S. 81). Auch die Berechnung des Anstiegs der Promotoraktivität durch die Stimulation zeigt die signifikant geringere Promotoraktivierung in den TRBV-S9transfizierten Zellen im Vergleich zur Kontrolle (s. Abbildung 33, S. 82). Nach Stimulation mit TNF- $\alpha$ kommt es im Gegensatz zur Stimulation mit RNA VSVinfizierter Verozellen und poly(I:C) zu einer Hemmung der Aktivierung des NF- $x$ Bresponsiven Promotors durch ein TRBV-S9 kodiertes Protein.

Diese Ergebnisse zur Aktivierung des NF- $x$ B-responsiven Promotors lassen sich dahingehend interpretieren, dass bei Transfektion von RNA (Vero-RNA, RNA VSVinfizierter Verozellen, poly(I:C)) die Helikase-Aktivität des auf Segment 9 kodierten VP6 die transfizierte RNA bindet und eventuell auch modifiziert, so dass diese eine starke Aktivierung von NF-xB induziert. Für mehrere zelluläre RNA-Helikasen konnte gezeigt werden, dass sie NF- $x$ B aktivieren können (Ishaq et al. 2009; Zhang et al. 2011). Unter Umständen stellt TRBV-VP6 ein virales Homolog einer zellulären Helikase dar, das für die Aktivierung von $\mathrm{NF}-\varkappa \mathrm{B}$ im Rahmen des viralen Replikationszyklus gebraucht wird. Für das mit TRBV verwandte BTV ist die Aktivierung von NF-xB beschrieben, allerdings sind bei BTV hierfür VP2 und VP5 verantwortlich (Mortola et al. 2004). Erfolgt dagegen die Aktivierung von NF-xB mit 
TNF- $\alpha$ kommt es zu einer Hemmung der Promotoraktivierung entweder durch eine zweite Funktion des VP6 oder durch das auf dem alternativen Leserahmen kodierten ORF-Xa Protein.

\subsubsection{TRBV-Helikase/ORF-Xa hemmen die Aktivierung eines IRF-3- responsiven Promotors}

Der Interferon regulierende Faktor 3 (IRF-3) ist zusammen mit Co-Faktoren für die Steigerung der Interferon- $\beta$-Synthese im Zellkern verantwortlich (s. 1.2.2.1, S. 18). Um die Aktivität des IRF-3-responsiven Promotors (s. Abschnitt 2.4.6, S. 40) zu messen, wurde eine Reihe weiterer Dual-Luciferase-Reporter-Assays nach Transfektion der Expressionsplasmide TRBV-S7 und TRBV-S9 durchgeführt. Als Kontrolle wurde gleichzeitig die Aktivität des IRF-3-responsiven Promotors nach Transfektion von pI.18-FDMx gemessen. Die Stimulation erfolgte mit RNA VSVinfizierter Verozellen, als Negativkontrolle wurde mit RNA nicht infizierter Verozellen transfiziert.

Ein Unterschied in der IRF-3-responsiven Promotoraktivität durch die Transfektion von TRBV-S7 war im Vergleich zur Kontrolle mit pI.18-FDMx nicht festzustellen (s. Abbildung 34, S. 83). Das Nichtstrukturprotein NS-2 hat also keinen Einfluss auf den untersuchten Promotor.

Die Aktivität des IRF-3-responsiven Promotors nach Transfektion von TRBV-S9 ist in den mit TRBV-S7 co-transfizierten Zellen ebenso wie in den nur mit TRBV-S9 transfizierten Zellen höher als die Aktivität des Promotors in der Kontrolle. Dieser Unterschied ist aber nicht signifikant, die TRBV-Helikase/ORF-Xa sind daher nicht als IRF-3-Aktivatoren zu bewerten.

Nach der Stimulation mit RNA VSV-infizierter Verozellen ist die Aktivität in den mit TRBV-S9 transfizierten Proben jedoch signifikant niedriger als in den Zellen der Kontrolle (s. Abbildung 34, S. 83). Dieser Unterschied bestätigt sich auch bei der Berechnung des durch RNA VSV-infizierter Verozellen stimulierten Anstieges der Promotoraktivität. Dieser Anstieg fällt in Gegenwart von TRBV-S9 hoch signifikant geringer aus als in der Kontrolle. Ein vergleichbares Ergebnis liefert die 
Aktivitätssteigerung in den co-transfizierten Zellen. Dieses Ergebnis zeigt die Inhibition der Aktivierung des IRF-3-responsiven Promotors durch TRBVHelikase/ORF-Xa. Damit ergibt sich, das TRBV-Helikase/ORF-Xa mit der Aktivierung von IRF-3 interferiert.

Äquivalent zum oben beschriebenen Experiment wurde ein Dual-LuciferaseReporter-Assay mit HEK-293-Zellen nach Transfektion der Expressionsplasmide TRBV-S7 und TRBV-S9 durchgeführt. In diesem Versuch wurde jedoch mit poly(I:C) im Vergleich zur Mock-Behandlung mit RNA aus nicht infizierten VeroZellen stimuliert.

Auch hier war kein Unterschied in der Aktivität des IRF-3-responsiven Promotors durch die Transfektion von TRBV-S7 im Vergleich zur Kontrolle mit pI.18-FDMx und damit kein Einfluss des TRBV-NS-2 auf die IRF-3 vermittelte IFN- $\beta$ Expression festzustellen (s. Abbildung 36, S. 86).

Nach Transfektion von TRBV-S9 ist auch hier die IRF-3-responsive Promotoraktivität höher als in der Kontrolle, mit $\mathrm{p}=0,1$ ist dieser Unterschied jedoch nicht signifikant. Die Promotoraktivitäten in den mit TRBV-S7 und TRBV-S9 cotransfizierten Zellen ähneln dem Ergebnis für die Probe der TRBV-S9-Transfektion (s. Abbildung 36, S. 86). Nach der Stimulation mit poly(I:C) ist die Aktivität in der mit TRBV-S9 transfizierten Zellen wiederum signifikant niedriger als in den Zellen der Kontrollprobe (s. Abbildung 36, S. 86). Auch der Aktivitätsanstieg durch die Stimulation fällt in der TRBV-S9-transfizierten Probe signifikant geringer aus als in der Kontrolle (s. Abbildung 37, S. 87). Dieses Ergebnis deutet auf eine Funktion der mit Hilfe von TRBV-S9 exprimierten Proteine als IRF-3-Inhibitor hin.

Da mit der Stimulation durch RNA VSV-infizierter Verozellen (5'-Triphosphat-RNA) und poly(I:C) die Signalwege über die zwei verschiedenen intrazellulären PAMPRezeptoren der IFN- $\beta$-Induktion RIG-I und MDA5 (Brennan und Bowie 2010) untersucht wurden, deutet die gezeigte Inhibition der Aktivierung des IRF-3responsiven IFN-Promotors durch TRBV-S9 exprimierte Proteine auf eine Hemmung der bereits konvergierten Signalkaskade dieser intrazellulären PAMPRezeptoren hin. 
In einem weiteren Versuch zur Messung der IRF-3-responsiven Promotoraktivität wurde mit IRF-3(5D) im Vergleich zur Mock-Behandlung mit pUC-19 stimuliert. Bei IRF-3(5D) handelt es sich um ein künstliches, konstitutiv aktives IRF-3-Protein (Lin et al. 1998).

Die Aktivität des IRF-3-responsiven Promotors der mit pUC19 transfizierten Zellen ist in allen Proben vergleichbar niedrig. In den mit IRF-3(5D) transfizierten Proben fällt die Aktivierung des Promotors für die mit TRBV-S9 transfizierten Zellen wesentlich geringer aus als für die Kontrolle. Dieser Unterschied ist hoch signifikant (s. Abbildung 38, S. 88) und spiegelt sich auch in dem Anstieg der Promotoraktivität durch die Stimulation wieder. Auch hier ist der Unterschied zwischen den mit TRBVS9 transfizierten Zellen und der Kontrolle signifikant (s. Abbildung 39, S. 89), während für TRBV-S7 kein Unterschied gezeigt werden konnte.

Obwohl das IRF-3(5D) konstitutiv aktiv ist, wird die Aktivierung des IRF-3responsiven IFN-Promotors also durch TRBV-Helikase/ORF-Xa unterdrückt. Dies deutet auf eine Hemmung der Translokation oder der Interaktion mit CBP, bzw. der Bindung an den Promotor von IRF-3 durch die TRBV-Helikase/ORF-Xa hin (vgl. Abschnitt 1.2.2.1 und Abbildung 4, S. 18). 


\subsection{Fazit}

Die Ergebnisse zeigen die inhibitorischen Eigenschaften des TRBV auf die Interferon-Induktion, speziell die aktive Hemmung der IRF-3-Aktivierung.

Damit wurde mit TRBV zum ersten Mal für ein Orbivirus gezeigt, dass es wie viele andere Viren das Interferonsystem blockiert, indem es aktiv die Synthese von Interferon- $\beta$ durch den wichtigen Transkriptionsfaktor IRF-3 hemmt. Diese Inhibition findet wahrscheinlich während der Translokation oder der Interaktion mit CBP, bzw. der Bindung an den Promotor von IRF-3 statt. Interessanterweise ist das Gen für den viralen IFN-Antagonisten auf Segment 9 des TRBV-Genoms lokalisiert, welches neben VP6 für das ORF-Xa-Protein mit bisher unbekannter Funktion kodiert. Da es sich bei VP6 um eine Helikase handelt, die vermutlich für die Virusreplikation notwendig ist, liegt ein Zusammenhang mit dem alternativen Leserahmen ORF-X nahe. Diese ORF-X-Sequenz ist bislang bei sechs weiteren Orbiviren nachgewiesen worden (Dilcher et al. 2012) und lässt ähnliche Eigenschaften auch bei diesen Viren vermuten. 


\section{$5 \quad$ Zusammenfassung}

\subsection{Zusammenfassung deutsch}

Das Tribec-Virus (TRBV) ist ein in Europa weit verbreitetes, durch Zecken übertragenes Orbivirus (Familie Reoviridae), welches möglicherweise beim Menschen eine unspezifische, fieberhafte Erkrankung mit neurologischen Symptomen verursacht (aseptische Meningoenzephalitis). Bei viralen Infektionen reagiert der infizierte Organismus primär mit der Aktivierung seines Interferonsystems als Bestandteil des angeborenen, unspezifischen Immunsystems, um die Erreger abzuwehren. Eine mögliche Hemmung dieses antiviralen Interferonsystems ist ein wichtiger Faktor für die Effektivität einer Infektion und damit wichtig für das Verständnis der Pathogenität des Virus.

In der vorliegenden Arbeit konnte eine Inhibition der Interferon- $\beta$-Induktion durch TRBV gezeigt werden, welche durch Hemmung der IRF-3-Aktivierung durch ein auf Segment 9 des viralen Genoms kodiertes Protein verursacht wird.

Damit wurde zum ersten Mal für ein Orbivirus gezeigt, dass das TRBV, wie viele andere Viren, das Interferonsystem blockiert, indem es aktiv die Synthese von Interferon- $\beta$ durch den wichtigen Transkriptionsfaktor IRF-3 hemmt. Da auf Segment 9 des viralen Genoms neben VP6 (eine virale RNA-Helikase) mit ORF-Xa ein weiteres Protein mit bisher unbekannter Funktion in einem alternativen Leserahmen codiert wird, liegt die Vermutung nahe, dass es sich hierbei um ein akzessorisches Protein handelt, welches für die Inhibition der Interferon-Induktion verantwortlich ist. ORF-X-Sequenzen konnten bislang bei noch sechs weiteren Orbiviren nachgewiesen werden.

Schlagwörter:

Tribec-Virus (TRBV), Interferon (IFN), IRF-3, Orbivirus, ORF-X 


\subsection{Zusammenfassung englisch}

The Tribec virus (TRBV) is a tick-transmitted Orbivirus (family Reoviridae) which is suspected to cause neurologic aseptic encephalitis in humans. The activation of the interferon system is the first immune response in case of any viral infection. The inhibition of this extremely powerful antiviral interferon (IFN) system is an important factor for the efficiency of any viral infection. To know the means by which viruses possibly inhibit the antiviral response is crucial in understanding viral pathogenicity.

This work shows the existence of such an inhibition of the interferon- $\beta$-induction by TRBV, mediated by a viral protein encoded on segment 9 of the TRBV genome which causes inhibition of IRF-3 activation.

Concerning orbiviruses it could be demonstrated for the first time that TRBV circumvent the antiviral IFN system by active inhibition of IFN- $\beta$ synthesis via inhibition of IRF-3 activation. Segment 9 of the TRBV genome encodes two proteins in overlapping open reading frames: VP6 (a viral RNA-Helicase) and ORF$\mathrm{Xa}$, a protein of yet unknown function. It is tempting to speculate that ORF-Xa is an accessory protein which acts as a viral inhibitor of interferon induction. ORF-X sequences are present in the genomes of at least six other orbiviruses.

Keywords:

Tribec virus (TRBV), interferon (IFN), IRF-3, Orbivirus, ORF-X 


\section{Abbildungsverzeichnis}

Abbildung 1: BTV als Vertreter der Orbiviren (Swiss Institute of Bioinformatics 2011).

Abbildung 2: Genom der Orbiviren (hier BTV) (Swiss Institute of Bioinformatics 2011).

Abbildung 3: Genomsegmente des TRBV (Dilcher et al. 2010)......

Abbildung 4: Induktion der Interferon- $\beta$-Gen-Expression durch Viren. 18

Abbildung 5: Interferon- $\beta$ Signalkaskade.

Abbildung 6: Inhibition des Interferonsystems durch verschiedene Viren, Abbildung modifiziert nach (Weber et al. 2003, S. 210).

Abbildung 7: Schema der miteinander verbundenen Mikroelektroden, die in den Boden jeder Kavität der E-Plates eingearbeitet sind. Die Interaktion adhärenter Säugerzellen mit den Mikroelektroden führt zu einer Zell-Substrat-ImpedanzAntwort, die proportional zur Zahl der ausgesäten Zellen in den Wells, der Zellmorphologie und der Art der Zelladhäsion ist (Abassi 2008).

Abbildung 8: PKR+/+ (10 000 Zellen/Kavität), Infektion mit TRBV und RVFVClone-13, MOI=1 $\mathrm{TCID}_{50}$-Einheiten.

Abbildung 9: IFNAR-/- (10 000/Kavität) mit Tribec-Virus MOI 10 und 1 TCID $_{50^{-}}$ Einheiten.

Abbildung 10: IFNAR-/- (10 000/Kavität) mit RVFV-Clone-13, MOI 10 und 1 $\mathrm{TCID}_{50}$-Einheiten.

Abbildung 11: HEK-293-Zellen, 10000/Kavität, Infektion mit TRBV und RVFVClone-13, MOI $=10$ und MOI $=1 \mathrm{TCID}_{50}$-Einheiten

Abbildung 12: HEK-293-Zellen, 2.500/Kavität, Co-Infektion mit TRBV und RVFVClone-13, MOI=20 TCID $_{50}$-Einheiten.

Abbildung 13: IFN- $\beta$-Induktion von RVFV-Clone-13 und TRBV in HEK-293Zellen.

Abbildung 14: IFN- $\beta$-Induktion von RVFV-Clone-13 und TRBV in HEK-293Zellen, Kontrolle der Virusinfektion mit TRBV und RVFV-Clone-13, interne Standardkontrolle mit $\gamma$-Aktin.

Abbildung 15: IFN-Induktion durch Co-Infektion mit RVFV-Clone-13 und TRBV in HEK-293-Zellen. 
Abbildung 16: Co-Infektion mit RVFV-Clone-13 und TRBV in HEK-293-Zellen, Kontrolle der Virusinfektion mit RVFV-Clone-13 und TRBV, interne Standardkontrolle mit $\gamma$-Aktin.

Abbildung 17: Korrigierte Interferon- $\beta$-Promotoraktivität nach Infektion und Stimulation mit RNA VSV-infizierter Vero-E6-Zellen, MW aus fünf Versuchen..

Abbildung 18: Verhältnis der Aktivität des IFN- $\beta$-Promotors stimulierter und unstimulierter Zellen nach Infektion und Stimulation mit RNA VSV-infizierter VeroE6-Zellen, MW aus fünf Versuchen.

Abbildung 19: Renilla-Luciferase-Aktivität nach Infektion mit TRBV bzw. RVFVClone-13 und Stimulation mit poly(I:C), MW aus 12 Versuchen.

Abbildung 20: IFN- $\beta$-Promotoraktivität nach Infektion und Stimulation mit poly(I:C), MW aus 12 Versuchen.

Abbildung 21: Verhältnis der Aktivität des IFN- $\beta$-Promotors stimulierter und unstimulierter Zellen nach Infektion und Stimulation mit poly(I:C), MW aus 12 Versuchen.

Abbildung 22: Messung der Interferon- $\beta$-Promotoraktivität mittels FF-Luc nach Transfektion mit Expressionsplasmiden für NS-2 (TRBV-S7) und Helikase (TRBVS9 mit ORF-Xa-Region) bzw. deren Co-Transfektion (TRBV-S7+S9) und Stimulation mit RNA VSV-infizierter Verozellen, MW aus sieben Versuchen.

Abbildung 23: Verhältnis der Aktivität des IFN- $\beta$-Promotors stimulierter und unstimulierter Zellen nach Transfektion mit Expressionsplasmiden für NS-2 (TRBVS7) und Helikase (TRBV-S9 mit ORF-Xa-Region) bzw. deren Co-Transfektion (TRBV-S7+S9). Die Stimulation erfolgte durch Transfektion von RNA VSVinfizierter Vero-E6-Zellen, unstimulierte Zellen wurden mit zellulärer RNA aus Vero E6 transfiziert, MW aus sieben Versuchen.

Abbildung 24: Messung der IFN- $\beta$-Promotoraktivität mittels FF-Luc nach Transfektion mit Expressionsplasmiden für NS-2 (TRBV-S7) und Helikase (TRBVS9 mit ORF-Xa-Region) bzw. deren Co-Transfektion (TRBV-S7+S9) und Stimulation mit poly(I:C), MW aus sechs Versuchen.

Abbildung 25: Verhältnis der Aktivität des IFN- $\beta$-Promotors stimulierter und unstimulierter Zellen nach Transfektion mit Expressionsplasmiden für NS-2 (TRBVS7) und Helikase (TRBV-S9 mit ORF-Xa-Region) bzw. deren Co-Transfektion (TRBV-S7+S9). Die Stimulation erfolgte durch Transfektion mit poly(I:C), unstimulierte Zellen wurden mit zellulärer RNA aus Vero E6 transfiziert, MW aus sechs Versuchen. 
Abbildung 26: Messung der Aktivität eines AP-1-responsiven Promotors mittels FFLuc nach Transfektion mit Expressionsplasmiden für NS-2 (TRBV-S7) und Helikase (TRBV-S9 mit ORF-Xa-Region) bzw. deren Co-Transfektion (TRBV-S7+S9) und Stimulation mit MEKK, MW aus vier Versuchen.

Abbildung 27: Verhältnis der Aktivität des AP-1-responsiven Promotors stimulierter und unstimulierter Zellen nach Transfektion mit Expressionsplasmiden für NS-2 (TRBV-S7) und Helikase (TRBV-S9 mit ORF-Xa-Region) bzw. deren CoTransfektion (TRBV-S7+S9) und Stimulation mit MEKK, MW aus vier Versuchen.

Abbildung 28: Aktivität eines NF- $\varkappa$ B-responsiven Promotors nach Transfektion mit Expressionsplasmiden für NS-2 (TRBV-S7) und Helikase (TRBV-S9 mit ORF-XaRegion) bzw. deren Co-Transfektion (TRBV-S7+S9) und Stimulation mit poly(I:C), MW aus fünf Versuchen. .76

Abbildung 29: Verhältnis der Aktivität des NF-xB-responsiven Promotors stimulierter und unstimulierter Zellen nach Transfektion mit Expressionsplasmiden für NS-2 (TRBV-S7) und Helikase (TRBV-S9 mit ORF-Xa-Region) bzw. deren CoTransfektion (TRBV-S7+S9) und Stimulation mit poly(I:C), MW aus fünf Versuchen.

Abbildung 30: Messung der Aktivität eines NF-xB-responsiven Promotors nach Transfektion mit Expressionsplasmiden für NS-2 (TRBV-S7) und Helikase (TRBVS9 mit ORF-Xa-Region) bzw. deren Co-Transfektion (TRBV-S7+S9) und Stimulation mit RNA VSV-infizierter Vero-E6-Zellen, MW aus fünf Versuchen.

Abbildung 31: Verhältnis der Aktivität des NF- $x$ B-responsiven Promotors stimulierter und unstimulierter Zellen nach Transfektion mit Expressionsplasmiden für NS-2 (TRBV-S7) und Helikase (TRBV-S9 mit ORF-Xa-Region) bzw. deren CoTransfektion (TRBV-S7+S9).und Stimulation mit RNA VSV-infizierter Verozellen, MW aus fünf Versuchen. . .80

Abbildung 32: Messung der Aktivität eines NF-xB-responsiven Promotors nach Transfektion mit Expressionsplasmiden für NS-2 (TRBV-S7) und Helikase (TRBVS9 mit ORF-Xa-Region) bzw. deren Co-Transfektion (TRBV-S7+S9) und Stimulation mit TNF- $\alpha$, MW aus drei Versuchen.

Abbildung 33: Verhältnis der Aktivität des NF-xB-responsiven Promotors stimulierter und unstimulierter Zellen nach Transfektion mit Expressionsplasmiden für NS-2 (TRBV-S7) und Helikase (TRBV-S9 mit ORF-Xa-Region) bzw. deren CoTransfektion (TRBV-S7+S9) und Stimulation mit TNF- $\alpha$, MW aus drei Versuchen. 82

Abbildung 34: Messung der Aktivität eines IRF-3-responsiven Promotors nach Transfektion mit Expressionsplasmiden für NS-2 (TRBV-S7) und Helikase (TRBVS9 mit ORF-Xa-Region) bzw. deren Co-Transfektion (TRBV-S7+S9) und Stimulation mit RNA VSV-infizierter Verozellen, MW aus sieben Versuchen. 
Abbildung 35: Verhältnis der Aktivität des IRF-3-responsiven Promotors stimulierter und unstimulierter Zellen nach Transfektion mit Expressionsplasmiden für NS-2 (TRBV-S7) und Helikase (TRBV-S9 mit ORF-Xa-Region) bzw. deren CoTransfektion (TRBV-S7+S9) und Stimulation mit RNA VSV-infizierter Verozellen, MW aus sieben Versuchen.

Abbildung 36: Messung der Aktivität eines IRF-3-responsiven Promotors nach Transfektion mit Expressionsplasmiden für NS-2 (TRBV-S7) und Helikase (TRBVS9 mit ORF-Xa-Region) bzw. deren Co-Transfektion (TRBV-S7+S9) und Stimulation mit poly(I:C), MW aus sieben Versuchen.

Abbildung 37: Verhältnis der Aktivität des IRF-3-responsiven Promotors stimulierter und unstimulierter Zellen nach Transfektion mit Expressionsplasmiden für NS-2 (TRBV-S7) und Helikase (TRBV-S9 mit ORF-Xa-Region) bzw. deren CoTransfektion (TRBV-S7+S9) und Stimulation mit poly(I:C), MW aus sieben Versuchen.

Abbildung 38: Messung der Aktivität eines IRF-3-responsiven Promotors nach Transfektion mit Expressionsplasmiden für NS-2 (TRBV-S7) und Helikase (TRBVS9 mit ORF-Xa-Region) bzw. deren Co-Transfektion (TRBV-S7+S9) und Stimulation mit IRF-3(5D), MW aus vier Versuchen. 88

Abbildung 39: Verhältnis der Aktivität des IRF-3-responsiven Promotors stimulierter und unstimulierter Zellen nach Transfektion mit Expressionsplasmiden für NS-2 (TRBV-S7) und Helikase (TRBV-S9 mit ORF-Xa-Region) bzw. deren CoTransfektion (TRBV-S7+S9) und Stimulation mit IRF-3(5D), MW aus vier Versuchen. 
Abassi Y (2008): Label-Free and Dynamic Monitoring of Cell-Based Assays. Biochemica No. 2 8-11

Brennan K und Bowie AG (2010): Activation of host pattern recognition receptors by viruses. Curr Opin Microbiol $\underline{13}$ (4), 503-7

Bundesamt für Verbraucherschutz und Lebensmittelsicherheit. (2009).

"Empfehlung der ZKBS zur Risikobewertung des Tribeč-Virus als Spender- oder Empfängerorganismus für gentechnische Arbeiten gemäß \5 Absatz 1 GenTSV." Az. 6790-05-02-0054. from http://www.bvl.bund.de/SharedDocs/Downloads/06 Gentechnik/ZKBS/01 Allgemeine Stellungnahmen deutsch/09 Viren/Tribec Virus.pdf? blob=publ icationFile\&v $=2$.

Collins SE, Noyce RS und Mossman KL (2004): Innate cellular response to virus particle entry requires IRF3 but not virus replication. J Virol $\underline{78}$ (4), 1706-17

De Clercq E (2006): Interferon and its inducers - a never-ending story: "old" and "new" data in a new perspective. J Infect Dis 194 S19-S26

de Veer MJ, Holko M, Frevel M, Walker E, Der S, Paranjape JM, Silverman RH und Williams BR (2001): Functional classification of interferon-stimulated genes identified using microarrays. J Leukoc Biol $\underline{69}$ (6), 912-20

de Wet JR, Wood KV, DeLuca M, Helinski DR und Subramani S (1987): Firefly luciferase gene: structure and expression in mammalian cells. Mol Cell Biol $\underline{7}$ (2), 725-37

Dilcher M, Goldmann U, Hasib L, Dobler G, Hufert F und Weidmann M: Pyrosequencing of Tribec virus, a tick-transmitted Orbivirus of the Kemerovo serogroup. Symposium on Zoonoses Research, Berlin 2010, 184

Dilcher M, Hasib L, Lechner M, Wieseke N, Middendorf M, Marz M, Koch A, Spiegel M, Dobler G, Hufert FT, et al. (2012): Genetic characterization of Tribec virus and Kemerovo virus, two tick-transmitted human-pathogenic Orbiviruses. Virology $\underline{423}$ (1), 68-76

Dobler G (1996): Arboviruses causing neurological disorders in the central nervous system. Arch Virol Suppl 11 33-40

Dobler G, Wolfel R, Schmuser H, Essbauer S und Pfeffer M (2006):

Seroprevalence of tick-borne and mosquito-borne arboviruses in European brown hares in Northern and Western Germany. Int J Med Microbiol 296 Suppl 40 80-3 
Ernek E, Kozuch O und Gresikova M (1966): Isolation of Tribec virus from the blood of sentinel pastured goats in Tribec region (Slovakia). Acta Virol 10 (4), 367-8

Fitzgerald KA, McWhirter SM, Faia KL, Rowe DC, Latz E, Golenbock DT, Coyle AJ, Liao SM und Maniatis T (2003): IKKepsilon and TBK1 are essential components of the IRF3 signaling pathway. Nat Immunol 4 (5), 491-6

Fujita T, Miyamoto M, Kimura Y, Hammer J und Taniguchi T (1989): Involvement of a cis-element that binds an H2TF-1/NF kappa B like factor(s) in the virus-induced interferon-beta gene expression. Nucleic Acids Res 17 (9), 3335-46

Gresikova M, Rajcani J und Hruzik J (1966): Pathogenicity of Tribec virus for Macaca rhesus monkeys and white mice. Acta Virol $\underline{10}$ (5), 420-4

Gresikova M, Nosek J, Kozuch O, Ernek E und Lichard M (1965): Study on the Ecology of Tribe C Virus. Acta Virol 2 83-8

Hiscott J (2007): Triggering the innate antiviral response through IRF-3 activation. J Biol Chem 282 (21), 15325-9

Hoffmann A, Natoli G und Ghosh G (2006): Transcriptional regulation via the NF-kappaB signaling module. Oncogene 25 (51), 6706-16

Isaacs A und Lindenmann J (1957): Virus interference. I. The interferon. Proc R Soc Lond B Biol Sci 147 (927), 258-67

Ishaq M, Ma L, Wu X, Mu Y, Pan J, Hu J, Hu T, Fu Q und Guo D (2009): The DEAD-box RNA helicase DDX1 interacts with RelA and enhances nuclear factor kappaB-mediated transcription. J Cell Biochem $\underline{106}$ (2), 296-305

Kayser FK, Böttger EC, Haller O, Eckert J, Deplazes P und Zinkernagel RM: Taschenlehrbuch Medizinische Mikrobiologie Georg Thieme Verlag, Stuttgart, 2005

Kuri T, Zhang X, Habjan M, Martinez-Sobrido L, Garcia-Sastre A, Yuan Z und Weber F (2009): Interferon priming enables cells to partially overturn the SARS coronavirus-induced block in innate immune activation. J Gen Virol $\underline{90}(\mathrm{Pt} 11)$, 2686-94

Libikova H, Rehacek J, Gresikova M, Kozuch O, Somogyiova J und Ernek E (1964): Cytopathic Viruses Isolated from Ixodes Ricinus Ticks in Czechoslovakia. Acta Virol $\underline{8} 96$

Lin R, Heylbroeck C, Pitha PM und Hiscott J (1998): Virus-dependent phosphorylation of the IRF-3 transcription factor regulates nuclear translocation, 
transactivation potential, and proteasome-mediated degradation. Mol Cell Biol $\underline{18}$ (5), 2986-96

Meurs EF, Watanabe Y, Kadereit S, Barber GN, Katze MG, Chong K, Williams BR und Hovanessian AG (1992): Constitutive expression of human doublestranded RNA-activated p68 kinase in murine cells mediates phosphorylation of eukaryotic initiation factor 2 and partial resistance to encephalomyocarditis virus growth. J Virol $\underline{66}$ (10), 5805-14

Modrow S, Falke D und Truyen U: Molekulare Virologie. Spektrum Akademischer Verlag GmbH, Heidelberg Berlin, 2003

Mortola E, Noad R und Roy P (2004): Bluetongue virus outer capsid proteins are sufficient to trigger apoptosis in mammalian cells. J Virol $\underline{78}$ (6), 2875-83

Muller R, Saluzzo JF, Lopez N, Dreier T, Turell M, Smith J und Bouloy M (1995): Characterization of clone 13, a naturally attenuated avirulent isolate of Rift Valley fever virus, which is altered in the small segment. Am J Trop Med Hyg $\underline{53}$ (4), 405-11

Muller U, Steinhoff U, Reis LF, Hemmi S, Pavlovic J, Zinkernagel RM und Aguet M (1994): Functional role of type I and type II interferons in antiviral defense. Science 264 (5167), 1918-21

Panne D (2008): The enhanceosome. Curr Opin Struct Biol 18 (2), 236-42

Panne D, Maniatis T und Harrison SC (2007): An atomic model of the interferon-beta enhanceosome. Cell $\underline{129}$ (6), 1111-23

Pichlmair A, Schulz O, Tan CP, Naslund TI, Liljestrom P, Weber F und Reis e Sousa C (2006): RIG-I-mediated antiviral responses to single-stranded RNA bearing 5'-phosphates. Science $\underline{314}$ (5801), 997-1001

Randall RE und Goodbourn S (2008): Interferons and viruses: an interplay between induction, signalling, antiviral responses and virus countermeasures. J Gen Virol $\underline{89}$ (Pt 1), 1-47

Roy P (1996): Orbivirus structure and assembly. Virology 216 (1), 1-11

Sato M, Suemori H, Hata N, Asagiri M, Ogasawara K, Nakao K, Nakaya T, Katsuki M, Noguchi S, Tanaka N, et al. (2000): Distinct and essential roles of transcription factors IRF-3 and IRF-7 in response to viruses for IFN-alpha/beta gene induction. Immunity $\underline{13}$ (4), 539-48

Sherf BA, Navarro SL, Hannah RR und Wood KV (1996): Dual-LuciferaseTM Reporter Assay: An Advanced Co-Reporter Technology Integrating Firefly and Renilla Luciferase Assays. Promega Notes Magazine 57, 2 
Stark GR, Kerr IM, Williams BR, Silverman RH und Schreiber RD (1998): How cells respond to interferons. Annu Rev Biochem $\underline{67}$ 227-64

Suhara W, Yoneyama M, Kitabayashi I und Fujita T (2002): Direct involvement of CREB-binding protein/p300 in sequence-specific DNA binding of virusactivated interferon regulatory factor-3 holocomplex. J Biol Chem $\underline{277}$ (25), 22304-13

Suss J und Schrader C (2004): [Tick-borne human pathogenic microorganisms found in Europe and those considered nonpathogenic. Part I: Ticks and Viruses]. Bundesgesundheitsblatt Gesundheitsforschung Gesundheitsschutz 47 (4), 392404

Swiss Institute of Bioinformatics. (2011). from http://expasy.org/viralzone/complete by species/106.html.

Taniguchi T und Takaoka A (2001): A weak signal for strong responses: interferon-alpha/beta revisited. Nat Rev Mol Cell Biol 2 (5), 378-86

Uze G und Monneron D (2007): IL-28 and IL-29: newcomers to the interferon family. Biochimie $\underline{89}$ (6-7), 729-34

Weber F, Kochs G, Haller O und Staeheli P (2003): Viral evasion of the interferon system: old viruses, new tricks. J Interferon Cytokine Res 23 (4), 20913

Weber F, Kochs G und Haller O (2004): Inverse interference: how viruses fight the interferon system. Viral Immunol 17 (4), 498-515

Werner SL, Barken D und Hoffmann A (2005): Stimulus specificity of gene expression programs determined by temporal control of IKK activity. Science $\underline{309}$ (5742), 1857-61

Yoneyama M, Suhara W, Fukuhara Y, Sato M, Ozato K und Fujita T (1996): Autocrine amplification of type I interferon gene expression mediated by interferon stimulated gene factor 3 (ISGF3). J Biochem $\underline{120}$ (1), 160-9

Yoneyama M, Suhara W, Fukuhara Y, Fukuda M, Nishida E und Fujita T (1998): Direct triggering of the type I interferon system by virus infection: activation of a transcription factor complex containing IRF-3 and CBP/p300. EMBO J 17 (4), 1087-95

Zhang Z, Kim T, Bao M, Facchinetti V, Jung SY, Ghaffari AA, Qin J, Cheng G und Liu YJ (2011): DDX1, DDX21, and DHX36 helicases form a complex with the adaptor molecule TRIF to sense dsRNA in dendritic cells. Immunity $\underline{34}$ (6), 866-78 
Zietara N, Lyszkiewicz M, Gekara N, Puchalka J, Dos Santos VA, Hunt CR, Pandita TK, Lienenklaus S und Weiss S (2009): Absence of IFN-beta impairs antigen presentation capacity of splenic dendritic cells via down-regulation of heat shock protein 70. J Immunol 183 (2), 1099-109 


\section{Danksagung}

An dieser Stelle möchte ich mich ganz herzlich bei all denjenigen bedanken, die mich bei der Erstellung dieser Arbeit unterstützt haben:

Herrn Prof. Dr. Frank Hufert danke ich herzlich für die Überlassung des Themas und die Betreuung der Dissertation sowie die Möglichkeit, diese in der Abteilung Virologie am Zentrum Hygiene und Humangenetik der Medizinischen Fakultät der Universität Göttingen zu durchzuführen.

Ganz besonderer Dank gilt Herrn Dr. Martin Spiegel für die praktische Anleitung und wissenschaftliche Unterstützung sowie für die Korrektur der schriftlichen Arbeit ebenso wie für die Geduld und stete Diskussionsbereitschaft.

Dr. Meik Dilcher danke ich für viele wissenschaftliche Informationen nicht nur zum Tribec-Virus.

Den Mitarbeitern des Labors gilt ein herzliches Dankeschön für ihre stete Hilfsbereitschaft, besonders Andrea Paluschkiwitz und Susanne Böhlken-Fascher für die praktische Anleitung und Unterstützung im Labor.

Und allen anderen, die mich während dieser Zeit unterstützt haben:

Herzlichen Dank. 